UC-NRLF

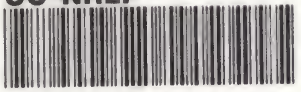

\title{
+B 73 己28
}

\section{CAMINAIONS}

\section{AND PINKS}

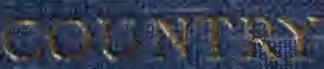

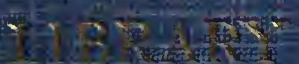




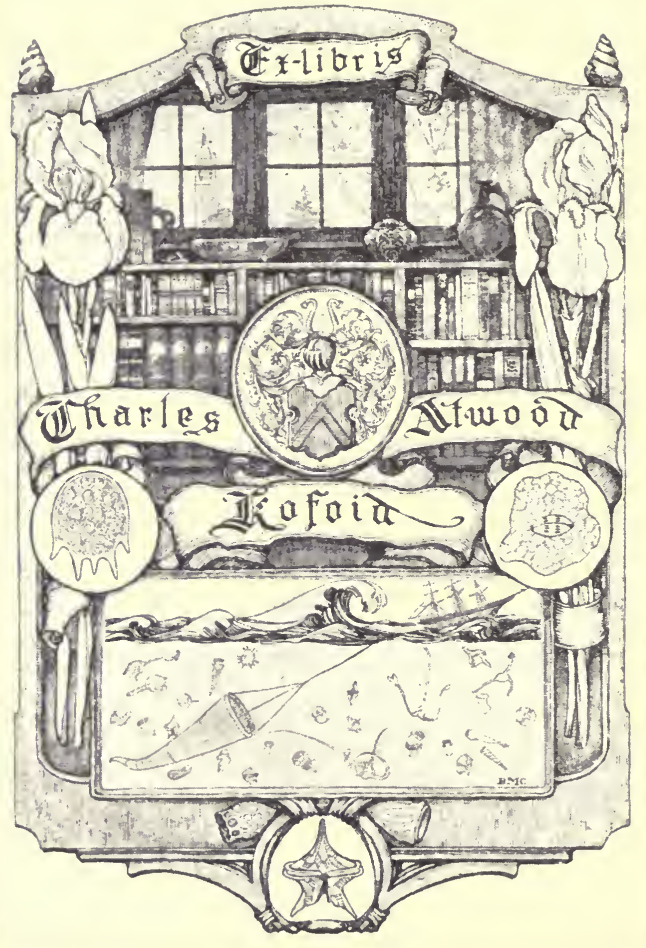




CARNATIONS, PICOTEES

AND THE WILD AND

GARDEN PINKS 


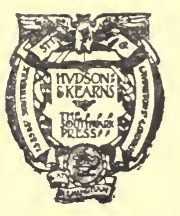





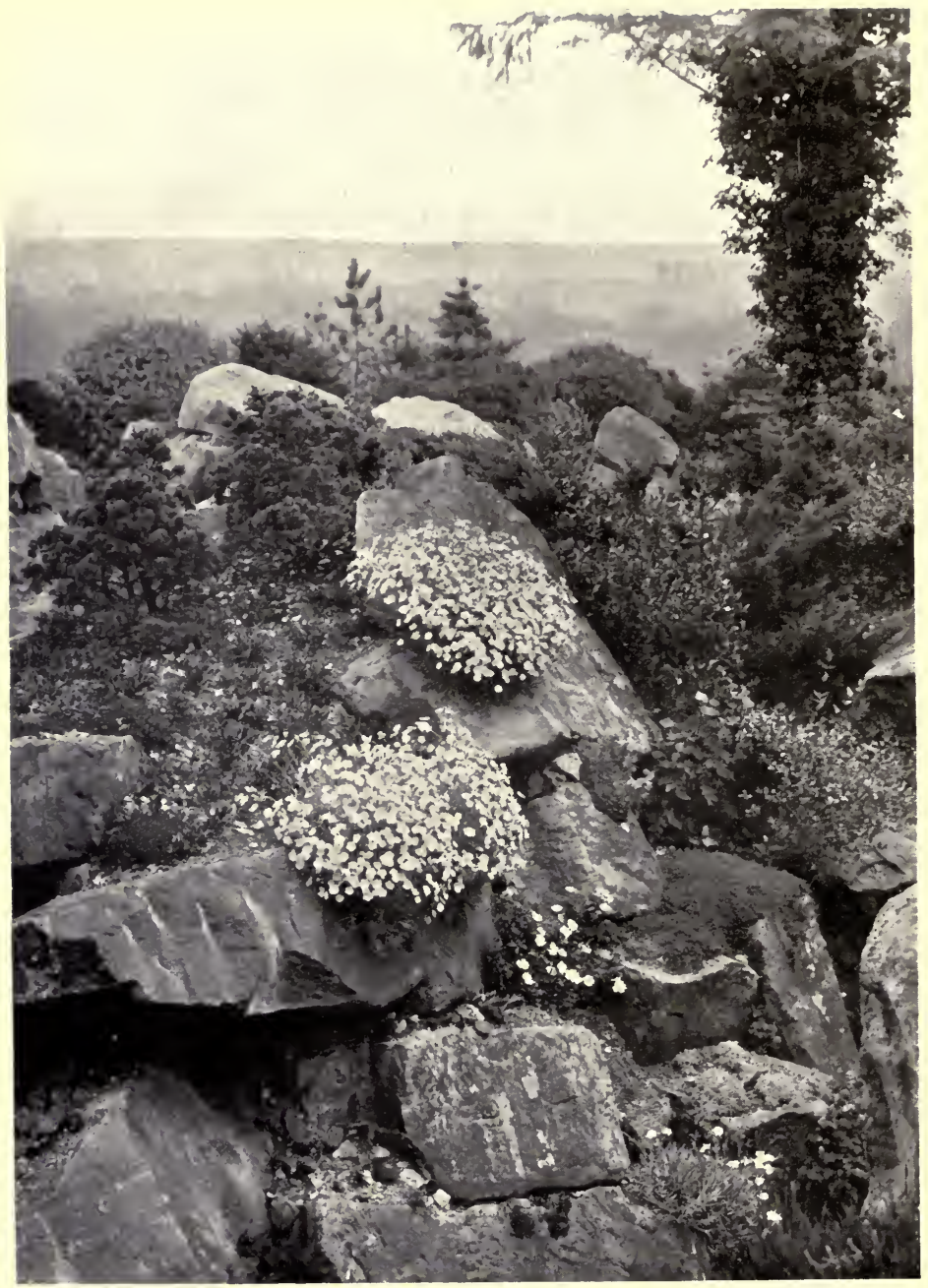

IVILD PINKS ON THE ROCK GARDEN. FRIAR'S PARK, HENLEY-ON-THAMES. 
THE "COUNTRY LIFE"

LIBRARY.

\section{CARNATIONS, PICOTEES,}

\section{AND THE WILD AND GARDEN PINKS.}

WRITTEN BY SEVERAL AUTHORITIES
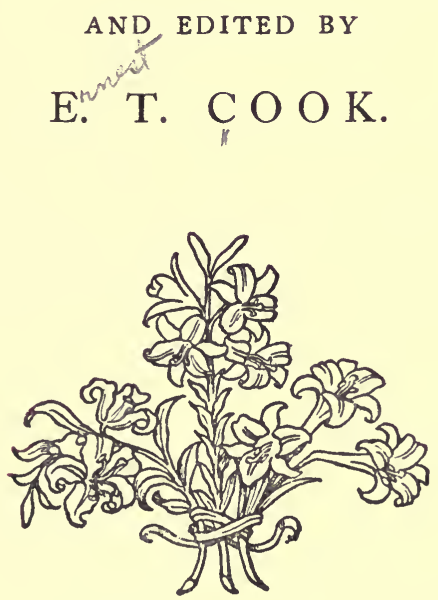

LONDON : PUBLISHED AT THE OFFICES OF “COUNTRY LIFE," LTd. TAVISTOCK STREET, COVENT GARDEN, W.C. छ BY GEORGE NEWNES, LTD. SOUTHAMPTON STREET, STRAND, W.C. NEW YORK : CHARLES SCRIBNER'S SONS MCMV 


\section{P R E F A C E}

THIS little volume is a companion to "Sweet Violets and Pansies," which formed the first of the smaller gardening books in the "Country Life" Library. It has been written at the request of many readers of Country Life and The Garden, and it is to be hoped that the ripe experience of the contributors to its pages, and the simple directions for the growing of the Carnation, Picotee, and the beautiful wild Pinks, will have their value.

The brave masses of old Clove Carnations in the gardens of our forbears, the sweet drifts of white Pinks, and the warm fragrance scenting the summer air, are pleasant reminiscences. With a greater choice of varieties, the Carnation has developed in interest and popularity, and a garden is not a garden that is without the silvery tufts of growth which have a quiet beauty even in winter days, when we are wise enough to group them with grey-leaved shrubs, such as Rosemary and Lavender.

Although Pinks and Carnations are welcome in so many ways of gardening, perhaps their greatest use, other than in wall and rockwork, is as edgings and underplantings to Roses, or something of taller stature than their own. By "edgings" is not meant 
straight or stiff borderings only, though the white Pink and its forms are among the very best plants for this use, but informal fillings of the outer portions of beds and borders. Used like this with Roses, they are admirable, each plant enhancing the beauty of the other.

They are perhaps least suited for filling up whole beds, unless the beds are quite small, and especially narrow, in form.

The deepening love for hardy flowers should have a good effect on floral exhibitions, which have not always directed the would-be gardener into wholesome channels. The showing of Carnation flowers in little paper collars is grotesque and without reason. Surely it is more instructive to show a flower in its natural beauty, and not attempt to cheat the visitor into the belief that the flower there arranged in a paper collar will reveal the same symmetry of form and colouring in the open garden. A Carnation that is fit only for a show box, and is useless in the garden, should have no claim upon our consideration.

Raisers must strive to obtain flowers that keep their petals within bounds. A Carnation that splits has little garden value, and whether it splits or not, if it is without fragrance, we would have none of it. The crimson Clove has the charm of a distinctive and deliciously warm fragrance, but there are varieties as scentless as a Baroness Rothschild Rose. This should not be tolerated. The first act generally of a buyer of Carnations is to smell them, and it is in 
the interests of the trade as well as the gardener to intensify rather than obliterate one of the great charms of the flower.

I thank most heartily the contributors to this little book; and if the reader wishes to consult other writers, the following works may be recommended :-

"Le Jardinage des Oeillets." A. Paris, I647.

"Nouveau Traité des Oeillets." A. Paris, I676.

"A Practical Treatise on the Carnation." By Thomas Hogg, Florist, Paddington Green, 1839.

"The American Carnation-How to Grow it." By Chas. Willis Ward. A. T. De la Mare Printing and Publishing Company, New York.

"Rea's Flora." By John Rea, London. Printed for George Marviott, Fleet Street, I676.

"Dodwell on the Carnation." Derby, W. Bacon, Beckett Hill Works.

"Carnation Manual." Published by the Carnation Society. Messrs. Cassell \& Co.

"The Book of the Carnation." By R. P. Brotherston. John Lane, Bodley Head, London.

E. T. COOK.

May 1905 . 



\section{O N T E N T S}

\section{CHAPTER I}

Early History of the Carnation, Sweet William, AND PINK

CHAPTER II

The Carnation in the Garden . . . . . 8

CHAPTER III

The Border Carnation . . . . . . . 14

CHAPTER IV

The Picotee-White and Yellow Ground . . 3I

CHAPTER V

The Malmaison Carnation . . . . . 39

CHAPTER VI

The Tree or Perpetual-Flowering Carnation . 47

CHAPTER VII

Carnations for Exhibition: A Year's Work $\underset{\text { ix }}{b} 54$ 
CHAPTER VIII

Carnations in Town Gardens . . . . 63

CHAPTER IX

Carnation Growing in America . . . . 75

CHAPTER X

Diseases of the Carnation . . . . . . 8 I

CHAPTER XI

The Pink.

94

CHAPTER XII

The Wild Pinks

CHAPTER XIII

The Pinks of the Alps . . . . . . 130.

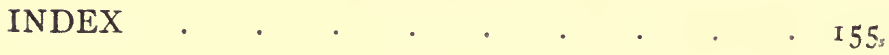




\section{LIST OF ILLUSTRATIONS}

Wild Pinks on an ENGLish Rock-Garden Frontispiece

The Feathered Wild Pink (Dianthus PlUmariUs) . . . . . . . To face page 5

A Margin of Carnations in AN OLd ENGLish GARDEN . . . . . " " "

CARNations ON TOP OF DRY WALL . . " , " 9

A Bed of Mr. W. A. Watts' New Yellow Border Carnation Ceres . . . " " " I4

A Bed of the Pure White Carnation

George Maquay • • • . . " " ,

Old TyPES OF CARnations . . . . " " " 28

Old Types of White Ground Picotees • " " 29

A House of Malmaison Carnation, Prin-

CESS OF WALES . . . . . . . " " " 39

A House of Malmaison Carnations . . " " "4 I

A Flower of Carnation Mrs. T. W. Lawson " " 53

Self Carnation Trojan in a London Garden " , " 63

The Yellow Carnation Miss Audrey

CAMPBELL . . . . . . . . " " 70

The Marguerite Carnation . . . . " " 7 I

The New American Carnation The Bride " ", 76 


\section{xii LIST OF ILLUSTRATIONS}

House of Carnation, The Bride. . . To face page 77

AN Edging of the Old White Fringed

PINK . . . . . . . . $"$.

Bordering of Double Pink to Mixed Border „ " 95

The Old White Fringed Pink . . . " " 97

Old Fringed White and Smooth Petalled

PINK . . . . . . . . , " 100

Tufts of The Wild Pinks . . . . " " IOI

LACED PINKS . . . . . . . " " 102

LACED PINKS . . . . . . . " " " 103

Dianthus Spencer Bickham in Messrs.

R. Veitch's NURSERy at EXeter . . ” „ 108

WILD PINKS . . . . . . . . " " 109

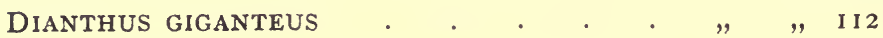

Alpine Pinks on Rock Garden . . . " " il3

Dianthus Callizonus . . . . . " " 134

The Maiden Pink (Dianthus Deltoides) . ” " 135

A Form of Dianthus plumarius . . . " " 140 


\title{
CARNATIONS, PICOTEES
}

\author{
AND THE WILD AND \\ GARDEN PINKS
}

\section{CHAPTER I}

EARLY HISTORY OF THE CARNATION, SWEET WILLIAM, AND PINK

By the Rev. Professor Henslow, M.A.

\section{The Carnation}

$\mathrm{T}$

URNING first to the writers of antiquity, no description of the Carnation (Dianthus Caryophyllus, Linn.) can be recognised in ancient Greek and Roman authors. Theophrastus uses the word dianthe, meaning either "doubleflowering" or "variegated," or, as others think, "hermaphrodite," but as the sexes of ordinary plants (excepting a few such as the Date Palm) were unknown, this last suggestion is impossible. Curiously enough, Shakespeare introduced the idea of crossing in reference to Gillyflowers:

PERdita. The fairest flowers o' the season Are our carnations and streak'd gillòflowers, Which some call nature's bastards : of that kind Our rustic garden's barren, and I care not To get slips of them. -Winter's Tale, Act iv. sc. iii. 
Gilloflowers may here mean variegated Stocks, to which this name became transferred from the Carnation. Gerarde (I597) calls them "Stock Gilloflowers." As the Clove was called Cariophillon, or sometimes Gariophlus, in the fifteenth century, the Carnation was known as Caryophyllus, having a similar scent. The Clove is in French "Clou de Girofle," Giroflée being the Wallflower. Though Cloves are mentioned in various recipes, there does not appear to be any reference to the Carnation before the sixteenth century. Chaucer says, "And many a clove gelofre and note muge to put in ale." This has been thought to refer to the Carnation, but it is clearly the spice he refers to. Gelofere and golofer were other spellings in the fourteenth century.

Girofle seems to have been a French corruption of Caryophyllon, the latter being the Greek karuon, a " nut" or "fruit-stone," and phullon, a "leaf," but the connexion with clove is obscure. Then, by a transposition of $p h$ and $l$ it became gelofer and gillyflower. Lastly, Professor Bradley in 1727 wrote it Jullyflower, and so we arrive at July-flower, the name known to herbalists in the eighteenth century. Another Latin name for the Carnation was Vetonica. This is used as the titles or headings of the plates in his Imagines Stirpium, \&c., by Dodonæus (Dodoens, I 559), but Matthiolus in his Commentary on Dioscorides says he failed to discover who was the author of this name. Dodoens calls the Carnation Vetonica altilis (i.e. fat or juicy). Yet another name was Ocellus, "a little eye," hence the modẹn French name was (Eillet. 


\section{EARLY HISTORY OF CARNATION 3}

Gerarde observes that Ruellius thought that "the Gilloflower was vnknowen to the olde writers, especially bicause this flower is not like to that of Vetonica or Cantabrica" (possibly the Pink). It is "marvell," saith he, "that such a famous flower, so pleasant and sweete, should lie hid, and not be made knowen by the olde writers, which may be thought not inferior to the Rose in beautie, smell and varietie." The word Carnation has been thought by some to be derived from caro carnis, the Latin for flesh, from the colour of some varieties. One, indeed, Gerarde says, was called "Horseflesh." The name, however, was more correctly spelt Coronation, "as the flowers were used in chaplets," as C. Stephanus says, in France, by girls (sixteenth century). It was cultivated in the division of the garden called Area coronalis. It is not known when it was introduced as a garden flower into England, but as it is found semi-wild on old abbey and monastic ruins, it was probably grown early in the gardens of the monks. It would certainly require some time to attain the size figured by Gerarde, if his Caryophyllus maximus multiplex, or "the great double Carnation," be at all true to nature. It is represented as being three inches in diameter. By the end of the sixteenth century the varieties cultivated were innumerable, for Gerarde, writing in 1597, says: "There are at this day, vnder the name of Caryophyllus, comprehended diuers and sundrie sorts of plants, of such variable colours and also severall shapes that a great and large volume would not suffice to write of euery 
one at large in particular, considering how infinite they are."

The name Dianthus was given to the genus by Linnæus, apparently adapting it from Dios anthos, meaning "Jove's flower," recommended by Pliny for coronal purposes. It would appear to have been the species of Agrostemma which Linnæus named Coronaria. It has been grown in England since ${ }^{5} 596$. In France, however, the name was applied in the sixteenth century to the Pasque-flower, or Anemone Pulsatilla, now known as "Coquelourde."

The Carnation was the first plant upon which hybridisation was practically performed. Richard Bradley in his "New Improvements of Planting and Gardening, both Philosophical and Practical" (I7I7), says: "The Carnation and Sweet William are in some respects alike : the farina of one will impregnate the other, and the seed so enlivened will produce a plant differing from either, as may be now seen in the garden of $\mathrm{Mr}$. Thomas Fairchild, resembling both equally, which was raised from the seed of a Carnation that had been impregnated by the farina of the Sweet William." Bradley, who was Professor of Botany in the University of Cambridge, does not appear to have entertained the idea of natural hybrids, but in his work, "Ten Practical Discourses concerning Earth and Water, Fire and Air, as they relate to the Growth of Plants," I727, he writes upon the saving of seed. "If we save it from such Plants as stood among a good collection, we may expect variety enough from it, according to the system of 



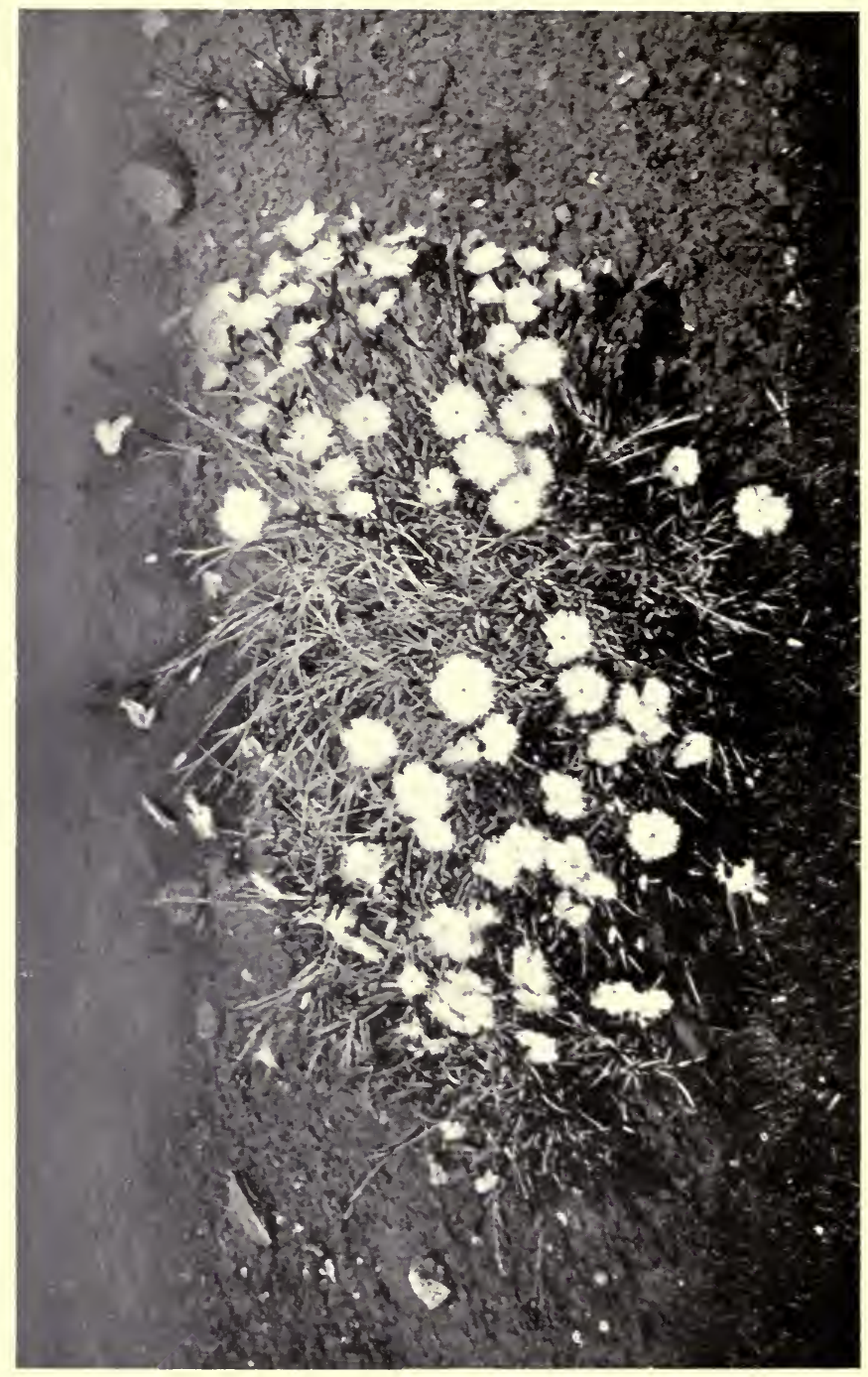

告 


\section{HISTORY OF SWEET WILLIAM 5}

the generation of Plants." In illustration he alludes to the Tulip, "The Triumph of Europe," from which Mr. S. Trawell saved seed. "It has a particular manner of flowering, very different from many other curious Tulips, as the seedlings partake of them all." This is suspiciously suggestive of intercrossing by insects.

\section{The Sweet William}

This species was named Dianthus barbatus by Linnæus, from the bearded character of the petals. It was known in the sixteenth century as Lychnis monachorum hortensis and Caryophyllus Carthusianorum, these names showing that it was probably introduced by the Carthusian monks, who came to England somewhere about the twelfth century. The name "William" appears to have been a corruption from the French " Eillet," from Ocellus, "little eye."

Some varieties with narrow leaves were called "Sweete Iohns." Gerarde describes them under the names Armeria alba and A. rubra. Like the Carnation, the Sweet William soon formed many varieties, so that Tournefort, after describing several special varieties, adds, "There are infinite varieties of this species, which you may find in Parkinson and other authors who have written of flowers" (I730).

\section{The Pink}

This is Linnæus' Dianthus plumarius. Early names were Caryophyllus sylvestris, Vetonica secundum genus (Dodoens); in French, Des Armoiries. In the shops 
of the sixteenth century it was known as Herba Tunica.

There was a plant which Pliny called Cantabrica, thought by Turner in the sixteenth century to be Pink. What Pliny says is : "In Spain is found the Cantabrica, which was first discovered by the natives of the Cantabri. ${ }^{1}$ It has a stem like that of a rush, a foot in height, and bears small oblong flowers like a calathus in shape, and encloses an extremely diminutive seed." The calathus was a lady's work-basket, broad above but tapering below. It might be compared to the flower of a Carnation or Pink, taking the calyx and expanded corolla together; but Pliny uses the same word to indicate the form of the perianth of the White Lily, which he otherwise describes with great accuracy ; so it would seem to be more descriptive of a Convolvulus, which, too, has a small fruit at the bottom of the tube, that of the Pink being large. Linnæus, indeed, named a species of Convolvulus C. cantabricus, which might be the plant in question. It was introduced into England from Southern Europe in 1640 , according to Paxton.

Castore Durante, in his Herbarium ( $16{ }_{3} 6$ ), gives an illustration of Cantabrica, and describes it as creeping, or rather, as we should say, procumbent, for the tips of the shoots rise up again. "The leaves," he says, "are like those of the periwinkle, the flowers being long, purple, scentless, and shaped like a vessel, with a small seed." $\mathrm{He}$ is here copying Pliny. Nothing, however, can be identified from the illustration. The

1 By the Bay of Biscay. 


\section{EARLY HISTORY OF THE PINK 7}

corolla, moreover, is represented as being gamopetalous.

Turner, in his "Names of Herbes," says : "Cantabrica of Plenie, is called the english wylde gelower or gelefloure, in duch, Wylder negleblorum, in frenche, Armoris. Some call the same herbe, Garyophillata siluestre." This last would seem to be the same as Gerarde's name, Caryophyllus sylvestris, and he figures twelve sorts of "Pinkes," though they would not all be the same genus. Now some called it "Superba," in French, Gyrofflees, Oeilletz, and Violettes herbues; in English, Pinkes and small Honesties. "These," he adds, "are not used in phisicke, but esteemed their vse in garlands and nose gaies." As in the case of the Carnation and Sweet William, it is not known when the Pink was first introduced from the Continent. 


\title{
CHAPTER II
}

\section{THE CARNATION IN THE GARDEN}

\author{
By E. H. WOODALL
}

$\mathrm{F}$ the Rose holds the first place in the garden, the
Carnation surely must come next though the Lily may surpass it in grace, and the Carnation has this merit, that in gardens near towns or in smoky districts it will thrive quite as happily as in pure air, while the Rose demands both shelter and the country.

In the country, however, it must be confessed that hares and rabbits work havoc among Carnations, and make it impossible to grow them in many gardens unless carefully wired in from all attacks of their enemies.

For this reason, and for others which I shall specify, I want to suggest that the continental plan of growing Carnations in boxes or pots on balconies, house-tops, or any such place of vantage is worth considering. In Spain Carnations are grown almost entirely in this way, and flowers hang down naturally, so that the guard petals are then able to fulfil their function and shelter the centre of the flower from sun and rain, thereby causing it to fill $\operatorname{up}_{8}$ perfectly. I fancy that 


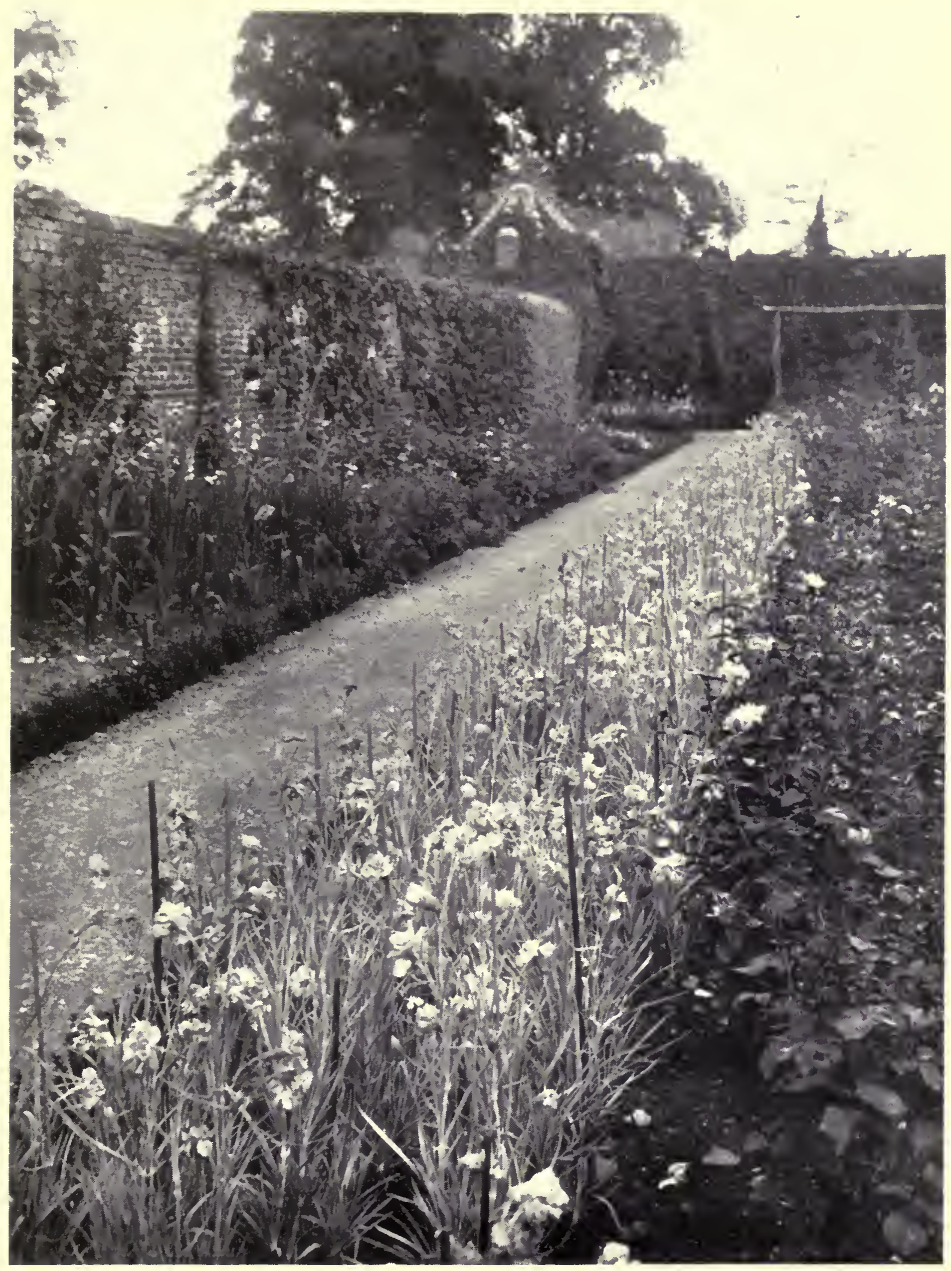

$\triangle$ IARGIN OF CARNATIONS IN AN OLD ENGLISH GARDEN. 


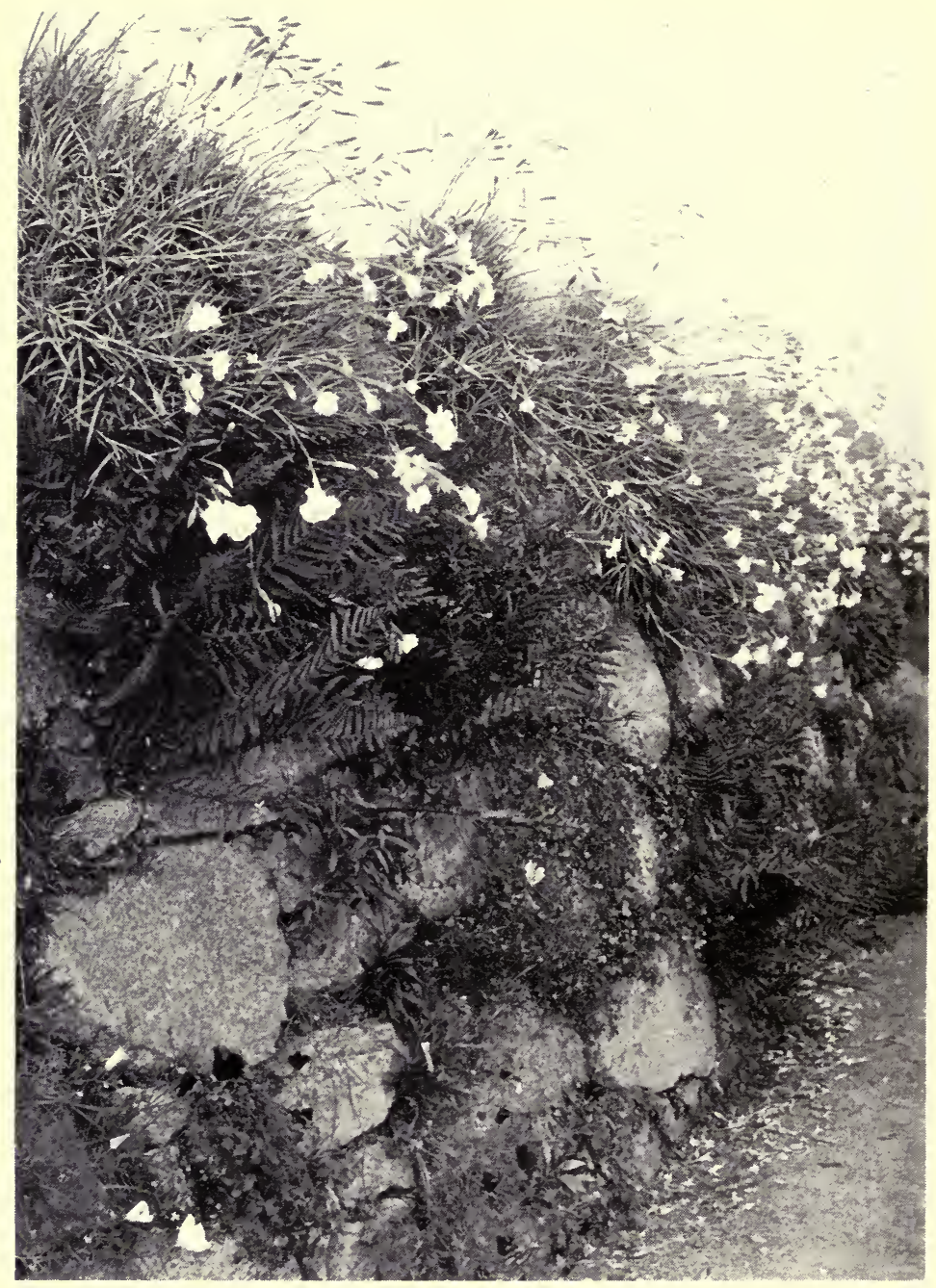

CARNATIONS ON TOP OF DRY WALL. 


\section{CARNATION IN THE GARDEN 9}

some of our exhibitors would find the quality of their blooms enhanced were they allowed to hang down in this way, and no one who has visited Spain in late spring will deny the beauty of this mode of growth. Carnations are found growing wild on crags and on ruined walls, so it is evident they do not prefer a low and flat situation, though at first they may make very strong growths in such a position when the soil is rich. Autumn dews and winter rains will cause these vigorous and sappy shoots to canker and rot off at the base by another spring, thus disappointing the gardener who looked for success in the summer.

The real difficulty in Carnation culture is the short duration of the plants. What is uglier than a nurseryman's bed of rooted layers planted in rows in a bed, each with its flower stem stiffly tied up, and the buds probably severely disbudded! and this more or less must be true of all freshly planted Carnations. The object, then, of picturesque Carnation growing is to keep the old plants in health for two or three years, when a luxuriant mass of growth and flower is produced. When this is achieved the beauty of the Carnation is undeniable.

It is certain that a Carnation plant will last longer in health when its collar is screened from damp by stones, or by any such protection as is afforded by steeply sloping ground. Extremes of heat are quite as injurious as winter cold, for the Carnation prefers an equable climate that is neither hot nor cold, such as is found over the greater part of our Islands. 
So, then, if the Carnation is to last long in the garden you love, plant it on banks with plenty of big stones about to screen the collars of the plants from moisture and cold, and rendering the temperature equable. Let the aspect be east or west rather than south, and let the wind blow freely over it, for no plant enjoys wind more than the Carnation. Most gardens have a wind-blown corner. Why not plant the Carnations there? When you can, let the flowers and foliage hang down naturally, and in the second summer a tangled mass of flower and foliage will result quite unlike the conventional Carnation bed, and infinitely more enduring.

The so-called Tree Carnation is the most useful for autumn flower beds, as the handsome but more formal and summer-flowering florists' Carnation does not continue more than a month or six weeks in flower, and, moreover, does not strike so readily from cuttings as the tree varieties do.

By the sea and on sloping banks the spicy Cloves endure for years, and need only an occasional layering, so where there is the opportunity of making a dry wall with plenty of earth behind, moist and yet well drained, there is the place for a long-lived display of Carnations, which will give the amateur several years of pleasure before it needs thorough renewal or overhauling.

No one regrets more than I do the impossibility of the culture of Malmaison Carnations in the open garden. So fragrant, so beautiful, so large and handsome, it seems quite a mistake that they will not exist 
save under very special conditions. Will the gardener of the future provide us with a race of hardy Malmaisons? If so, I think he will gain a good reward in thanks and in gold. Carnations are particularly acceptable in the old-fashioned kitchen garden herbaceous border; their beauty is not suited to the formal garden, and when planted formally should only be used for cut bloom and for propagation, two things that are indispensable in the modern garden.

Moderate disbudding I would always allow. Some varieties indeed require it ; the flower buds are so congested that all cannot expand freely. It is, however, a matter of individual taste, and should be left an open question.

How best to determine what Carnations shall be grown is another matter that needs judgment. The varieties that grow well on the strong and cold soils of the northern portion of England do not like the hot and light soils of the south, while some of the yellows and soft reds or pinks do best in the last mentioned. The old and fragrant Clove is apt to die out in the south in hot seasons, while in the north a wet year (like I903) causes heavy losses the following winter. There are a few extra enduring named varieties I will mention, such as the wellknown Raby Pink, that is well to the fore after more than three-score years' wear and tear, but its flower is small as well as deeply fringed, a fault in some folks' opinion, though not in mine.

Of whites I still put Trojan as the most reliable 
of border Carnations, fine in every way save its lack of scent. Of pure scarlets there is a greater choice; indeed this colour is always of hardier growth than any other that I know, and it is a matter of opinion whether the very smoothed edged varieties are as effective as the rougher edged sorts. Of deep crimsons I have found Mephisto the most enduring and hardy, and of pure yellows there is nothing to touch Miss Audrey Campbell as far as I know; and of rose reds, no variety is more enduring and handsomer than Belladonna. Of orange shades Midas is still the finest; and of lighter buffs, Mrs. Reynolds Hole is yet worth a place, though not good on strong soils.

The Picotees, especially the modern ones raised by Mr. Martin Smith, are very vigorous and hardy, but after a few years they are apt to lose vigour when grown in the open border, while those grown in pots retain their health to a far greater degree, which proves that much water in winter is death, more or less lingering, to the Carnation.

The Tree or Perpetual Carnation is not enough planted for summer use in my judgment. It is far more amenable for bedding purposes, and can equally be propagated for summer and autumn flowering as for winter culture under glass. With an edging of Phlox Drummondi pegged down outside the Carnations an uncommonly bright display can be achieved, and the long sprays of bloom are lasting for cutflower purposes. Perhaps some one has already tried some of the strong-growing American varieties in 


\section{CARNATION IN THE GARDEN I3}

this way. The Carnation is always so welcome as withstanding rain when half open, that it must prove very useful in stormy autumn weather until winter is upon us and the hardy Chrysanthemum is ready to supply the demand for cut flowers. 


\title{
CHAPTER III
}

\section{THE BORDER CARNATION}

\author{
By W. A. WatTs
}

THE following notes from Mr. W. A. Watts, 1 Bronwylfa, St. Asaph, an enthusiastic grower of Carnations, contain useful hints for the beginner.

\section{VARIETIES}

A few varieties are mentioned, but not many. George Maquay is considered the most beautiful of all the white Carnations. I have tried many other whites with the highest reputations, but have discarded them all in its favour. Next I will mention Countess of Paris, a lovely blush-white suffused with delicate rosy lilac. These are two of my best varieties; with me they never fail, but are excellent in every way. The yellows I find rather troublesome, especially in a wet season, as the flowers then soon become sodden and brown, and seem to hold the rain much more than those of other colours. I have tried such excellent varieties as Germania, Miss Alley, The Naiad, Pandelli Ralli, and others, but have not had good results from any of them. Probably the soil, which is a rather heavy loam over clay, does not suit them, 


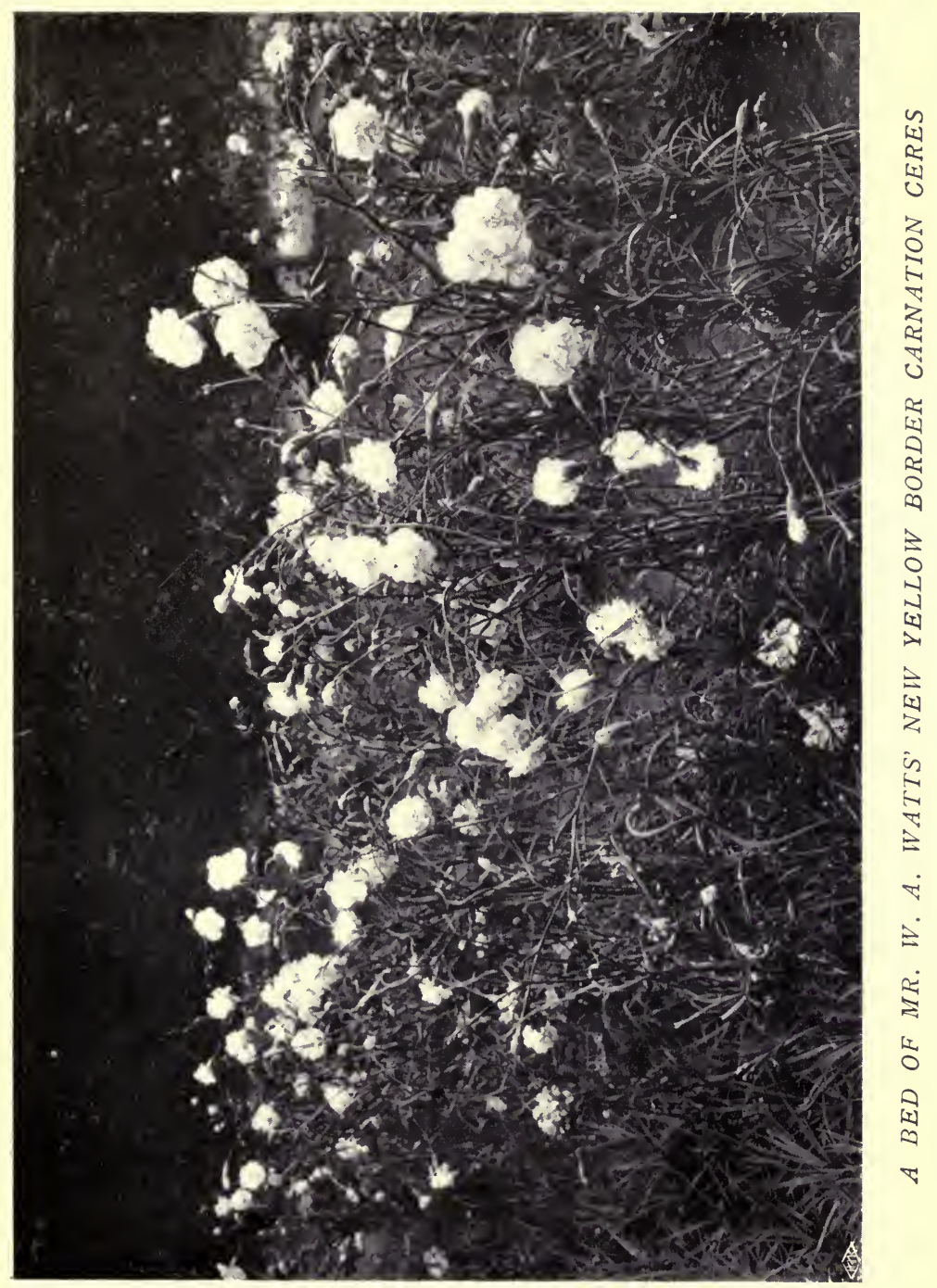




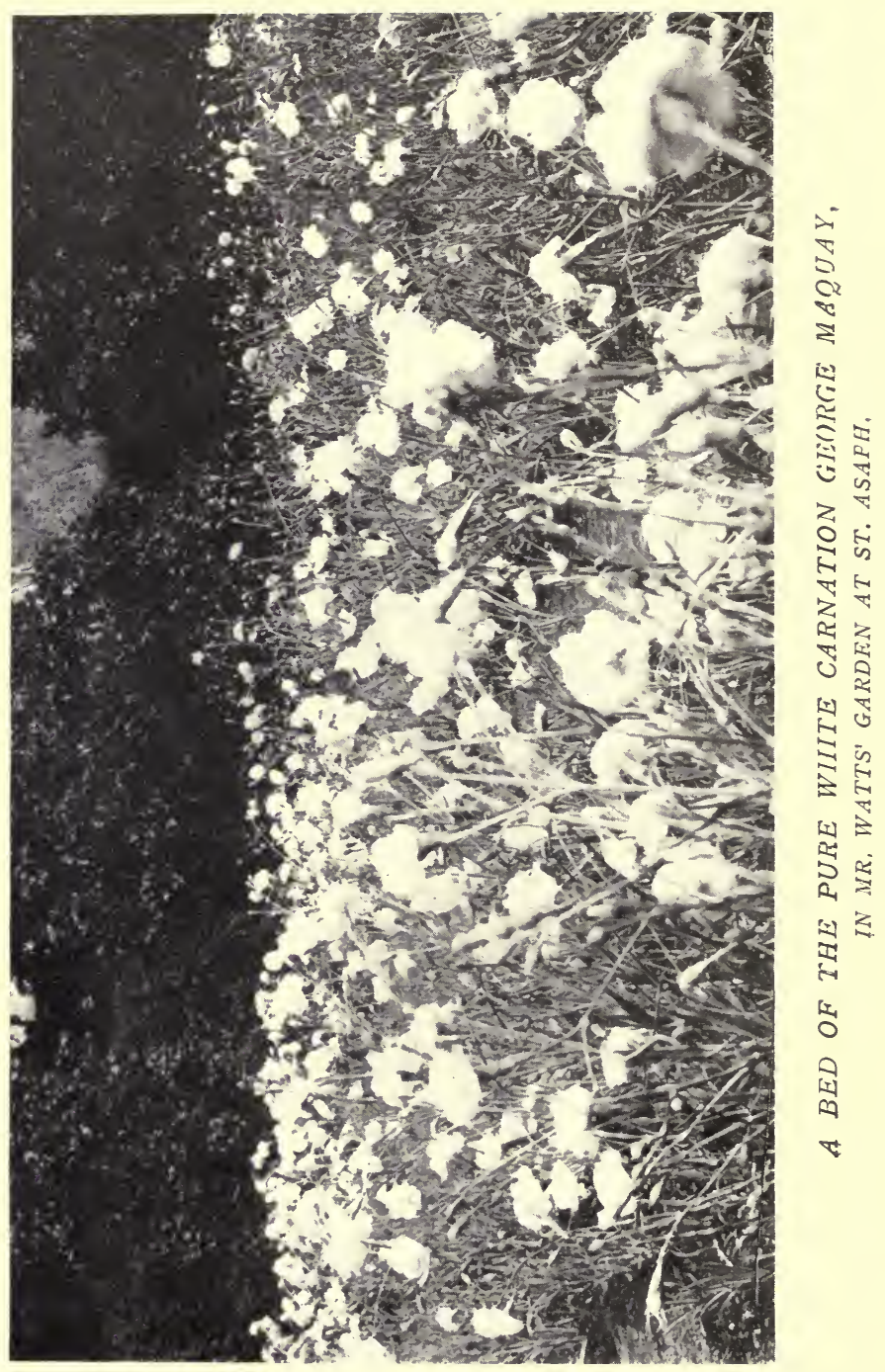


Duchess of Fife is a very nice flower, of a delightful pink, but it has a weak stem. Belladonna has a large red flower, but is rather inclined for this reason to burst. Hayes' Scarlet is very good. Of the heliotropecoloured flowers I consider Garvel Gem to be the best. Many of the fancy and yellow-ground Carnations can be grown successfully in the open, and Tenella is one that I find does well. Raby Castle, so well known, is a good hardy salmon-pink, most useful for cutting, but it bursts rather badly; and I must not forget the Old Clove and Uriah Pike, both dark crimson ; although the latter is strictly a Tree Carnation, it nevertheless does well as a border plant. It is a great mistake to grow too many varieties, one or two of each colour being, I think, sufficient, except of course for the purpose of trial.

\section{HYBRIDISING IN THE OPEN}

I will first say a few words about this. Carnations can be hybridised in the open, although results are more certain with plants under glass; so if you wish to try hybridising amongst the border plants, do not expect too much, as in an unfavourable season and a late district it is almost impossible to ripen the seed. If, however, the seed-pods do ripen, the seed will be as good or better than that produced under glass, as the conditions under which it is ripened are more natural.

The first thing will be to decide upon the varieties to use, and endeavour to select as seed-parents only 
the strong, healthy, free-growing, and free-blooming plants which are of compact growth, with flowers that do not burst, and carried on stout, erect stems. Choose those, in fact, which not only give flowers of fine colour and form, but which are also satisfactory in other ways, and try and supply the shortcomings of one by crossing it with another which has those good qualities which it itself lacks.

When the flowers of the plant intended to bear the seeds open, wait until the stigmas, which rise from the top of the ovary (the ovary is at the base of the flower, and contains the embryo seeds), usually two in number, but sometimes more, are fully grown and show themselves well beyond the petals; they then resemble the antennæ of a moth, and are covered on the outer edge with soft down. Now the pollen must be searched for in the other flower selected for crossing with, some varieties giving very little pollen, and others plenty. However, look amongst the petals for the stamens, which are thread-like stems rising from the ovary and terminating in small curved cups, lightly poised on the ends. There are the anthers, which it is hoped will be covered with very fine dust (pollen). Either collect this dust on the point of a fine camel's-hair brush and apply it to the stigma of the flower first selected (this should be done about midday, when the weather is dry and sunny), or pull out the stamens carefully with a forceps and apply the anthers directly to the stigma, rubbing the pollen off one on to the other. This is, perhaps, the better way, as when crossing several varieties the pollen 
would probably get mixed on the brush. After having thus fertilised the flowers they should be marked, and for this purpose I use red string or tape, which serves as a danger signal to any one who may be gathering flowers, and it is well to acquaint the members of the family with the meaning of such marks. I have had carefully hybridised seed-pods picked off with intentions which, under circumstances, would have been most laudable- that is to say, of concentrating the strength of the plants into the remaining buds.

Make careful notes of each cross, and watch the flowers which have been hybridised. If, on the following day, they show signs of dropping, the work has not been in vain. If they are still fresh, repeat the process of fertilisation.

If the flowers have been successfully hybridised it is advisable, when the weather is at all wet, to pull out the withered petals (but be careful to remove these only), and split the sides of the calyx in order to let the sun and air get to the ovary, and thus ensure the better ripening of the seed. Watch for earwigs, which are very partial to the tender young seed-pods, and any device that will prevent them climbing the stems will be useful. When the seedpod shows signs of splitting and is quite brown, it should be cut off, dried, and the seed carefully stored and labelled. If the necessary time cannot be given to hybridising, or there are no plants to work with, seed saved from the finest varieties, carefully hybridised, can be purchased at a reasonable price from specialists who devote glass-houses to this purpose. 


\section{Sowing SeED}

Few things are more interesting in a garden than a bed of seedling Carnations; they are a source of delight both to the grower and his friends, provide a wealth of flowers for cutting, and there is the chance of some new variety appearing that is more beautiful even than those already in existence. It is most important to procure seed from some well-known grower who saves it only from carefully fertilised flowers of the best varieties. Sow it in a box of fine soil in March, and place it in a hothouse or garden frame, with some gentle bottom heat, where it will soon germinate. When the seedlings have their several pair of leaves, and are of sufficient size to handle, prick them out into boxes of well-prepared soil. Place them in a frame until they show that they have got hold of the new compost, then gradually harden them off. Eventually, about the end of June or early in July, plant them out in beds of deeplydug rich soil, about eighteen inches apart, where they are to flower the following season. During the winter little or no attention will be required. In spring the soil should be occasionally stirred to keep down weeds, and the plants dusted over once or twice after rain with soot mixed with wood ashes. This helps to keep off wireworms, slugs, and other pests, and acts as a good manure also. Beyond this there is only the staking of the flower-stems, and, of course, the necessary watering in dry weather. It is most important not to let the roots get too dry. 
This raising of plants from seed may seem a long process, but patience is everything in gardening, and the reward will come when the plants are showing a mass of buds which are eagerly removed every morning. Now, one word of warning-you must not expect too much; there will be many not worth keeping, owing to the flowers being badly formed, and there will be a certan percentage of singles; but amongst the rest there should be, if the seed has been good, a nice lot of plants that you can layer for producing plants to bloom the next season. These layers will be found for the most part stronger and naturally more likely to suit the climate and soil than layers obtained elsewhere. When it has been determined which of the seedlings come up to expectation, mark them and make a note of their colour and habit of growth.

\section{LAYERING}

Next comes the layering, which is generally done about the end of July or the beginning of August. A sharp knife, layering pins or pegs, and some fine prepared soil mixed with road scrapings or leafmould and sand will be required. The best layering pins are those made of flat galvanised wire, and the "Sydenham" is the best. This has a loop at the top, which serves as a handle and makes it much easier to fix into and remove from the ground. Many other things are used as pegs for layering, but there is nothing better than the pin wires described; they are quite inexpensive (about 
one shilling per IOo), and if cleaned and stored away dry when the layers are taken up, they will last several seasons. A small hand-fork or trowel is also required for loosening the surface soil round the plants, and a soft pad to kneel upon will be a great comfort to the worker. Carefully select the best shoots round the collar of the plant and nearest the ground, and cut away the rest (these, if thought advisable, may be struck as cuttings), thus freeing the plant as much as possible of all growth except the shoots intended to be layered and the flower-stems. Do not attempt to layer too many shoots, since if you do they will be apt to get too crowded when they begin to grow, and so become a prey to disease. Next strip off the leaves from the shoots for layering up to the third or fourth joint from the top. Take the knife and make a clean cut halfway through the joint next below the one to which the leaves have been stripped off, and with a turn of the knife continue it in an upward direction as far as the next joint, thus forming a tongue. Then bend the shoot carefully down and peg it firmly about an inch deep into the soil, which should have been previously loosened to a depth of 2 inches or 3 inches, and have had a little of the prepared soil added to it. Repeat this process until there is a circle of layers all round the plant, then water them well with a fine rose, and keep them watered until they are well rooted and ready to plant out in their permanent places, which will probably be about the end of September or beginning of October. 
These layers will, the succeeding season, make strong plants, and although they will not give the same profusion of bloom as their seedling parents, my experience is that they do better than plants which come from a strain that has been propagated from

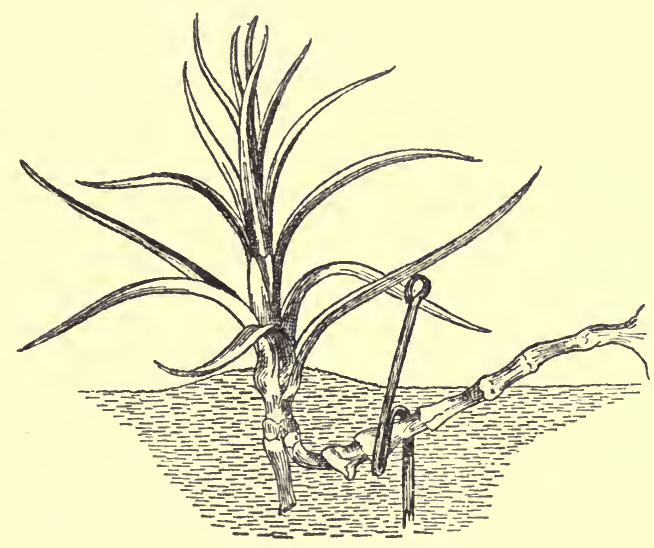

CARNATION LAYERED

layers for a greater number of years. Now, I do not for one moment mean to say that it is wise to neglect the many excellent old border varieties, but supplement the collection with a few seedlings, and I feel sure that you will never regret the little care and attention bestowed upon them.

\section{Cuttings}

If one wishes to strike as cuttings any of the growth that it has not been possible to layer, prepare a bed 
with leaf-mould and road scrapings, or a preparation similar to that used when layering, only with more sand added. Trim off the lower leaves from the shoots, and cut the stem off through a joint. Split the stem slightly, and insert it 2 inches deep in the soil, which should be pressed firmly round the cutting (a position should be chosen where they will not be exposed too much to the sun), and keep them well watered in dry weather.

\section{Work in Summer Time}

The work to be accomplished during the summer months is not heavy. Keep the soil between the plants free from weeds with a hoe, and if the ground is poor give a top-dressing of old well-decayed manure (I do not recommend a top-dressing of manure in autumn, as it harbours slugs). Water the plants in dry weather, and remember when doing this that a little water sprinkled on the surface is useless. Always give a good soaking, so that the water can reach the roots, and damp the leaves as well as the soil, as this helps to suppress green-fly.

\section{Staking the Plants}

Now will come the staking of the plants, or rather the flower-stems, as they grow too tall to support their own weight, and for this purpose the best things I have seen are coil stakes made of strong galvanised wire in spiral form of varying lengths, painted pale green, i.e. the same tint as the foliage of the plants. 
To these the stems are easily adjusted, and no tying is necessary. Simply insert the stake in the ground close to the plant, give the flower-stem a turn round it, and as the stem grows higher it is quite easy to give it another turn or two until it reaches the top. There is only one thing to be careful about in using them, i.e. do not stake your plants too soon, or you will find the soft stem will be liable to get bent at the joints if any of the side shoots become fixed in the spiral twists of the stake during their growth. This will not happen often when you get accustomed to them, and I must say for neatness, or rather invisibility, there is nothing to equal them. Next will come the

\section{DisBuDDING,}

and it is quite a matter of taste whether a quantity of rather small blooms or fewer larger ones are desired. I think when a plant has a great number of buds on each stem it is better to thin out, say, half of them. This should be done when they are quite small. Where there are two or more buds close together, pinch, or rather twist, or break off the smaller ones, an amusement I find ladies are rather fond of. The flowering season will now be fast approaching, and the keenest interest is taken in the blooms as they begin to show colour and gradually open, especially where there is a bed or two of seedlings. Among the latter especially several will be noticed with buds of varying shapes and sizes, some very thin and long. These will be single flowers. Others, again, will be 
thick and stumpy, and these will produce double blooms with probably far too many petals, which will cause the calyx to burst before or as they are expanding. Both of these will be worthless. The bud which will produce the best shaped flower is that of medium girth, long, and shaped like a Filbert. This will be a double flower, with sufficient petals to form a good bloom, and not too many. I may say that careful watering will do much towards preventing the blooms bursting.

\section{By James Douglas}

The following information is the result of $\mathrm{Mr}$. Douglas's ripe experience :-

Many readers may well inquire, What is a border Carnation? Some are under the impression that only self-coloured varieties can be thus described, though I believe that most lovers of this beautiful flower prefer the "selfs," as they are usually named in books and catalogues, but this does not make them border Carnations to the exclusion of other types. Any Carnation that will grow and flower freely in the open may be a "border variety." In this respect I may be pardoned if I draw a little on my early experience. I have to go back to the year I855, when I well remember the flaked and bizarre Carnations being cultivated. I had to do with planting and layering them in the gardens of Lady Eleanor Balfour, grandmother of the Prime Minister. This lady was devoted to Carnations and Pinks, which were grown in the kitchen garden 


\section{THE BORDER CARNATION}

borders, the flower garden in those days being filled with Verbenas, Pelargoniums, and Lobelias in beds. All the flowers fit for cutting, such as Pinks, Carnations, and Roses, were crowded into the kitchen garden, but the soil was deep, well manured, and well tilled, with the result that the Carnations were excellent and worth a whole garden of bedding plants. This was in the county of Roxburghshire.

"A year or two later I was in Fifeshire, and delighted to have charge of Carnations again. There was an old garden within half a mile of the Firth of Forth, a part of which was sacrificed to the almost universal appreciation of bedding plants, but two long rows were reserved for Carnations. In summer, when the plants were in bud and full bloom, nothing could equal them in beauty, and in winter the grey foliage had a quiet charm. Since those days I have grown Carnations in the open garden, in pots, and in all ways, but am satisfied that success may be assured in any district and in any class of soil if care is taken to give the plants the necessary attention. The Carnation cannot fight successfully for itself in an ordinary mixed border. Planted within half a yard of a Phlox or Pyrethrum, it would soon be overpowered, but given a chance among plants of equal vigour, it will do well in a border of this kind. I have grown such delicate varieties as Painted Ladies in a mixed border in Essex, but Carnations are worth a border to themselves, and thousands of amateurs provide a border specially for the flower. I often hear of failures, but this is usually through some fault in culture or starting with a stock 
of plants wanting in constitutional vigour. If the plants are not strong to begin with, they will certainly not recover out of doors."

\section{Preparation of the Bed}

This is the first consideration. It is better to have a small bed with fifty plants well grown than a large one with five hundred dragging out a miserable existence. If the ground is not suitable, make a bed of good material. A medium clayey loam is best to which has been added a sixth part of decayed manure, but when the ordinary garden ground will suffice, trench it to the depth of eighteen inches or two feet, and if the bottom soil was not previously at the top, throw it up, digging up the bottom spit, which should be mixed with manure. Keep it at the bottom. If well incorporated with the manure it can be thrown to the top the following season. Mortar rubbish is excellent to incorporate with the soil; indeed if the subsoil is clay, I would put six or nine inches of mortar rubbish in the bottom of the bed. This with loosening the soil to the depth of eighteen inches would raise the bed about a foot above the surrounding level, and this even in a dry season would be favourable to the growth of the Carnation and development of the flowers. In a wet season it would perhaps keep the plants from being flooded, a state of things that cannot fail to be injurious. The bed being prepared, the best time to plant must be considered. 


\section{Planting}

In a dry district and light soil I would plant out early in November. For many years I grew the plants successfully in Essex, and they were always put out about the second week in November. The late Mr. Edward Adams, who had his garden in Northumberland, assured me that the florists in his district always planted out their stock of Carnations in November, and that the most suitable manure was obtained from the cattlemarkets in Newcastle. The market authorities were glad to get rid of the sweepings, and the florists were pleased to receive them. I have always been surprised at the large size and bright colour of the flakes and bizarres grown in that district, and I visited several florists' gardens in which the flakes, bizarres, and white ground Picotees were treated entirely as border plants. Most of the owners were cottagers working in coal mines or foundries, but gardening was thoroughly done. The soil worked easily, and had been under vegetable culture for many years. No turf was added, and in such a soil wireworms were never seen.

Although I recommend autumn as the best time for planting out in dry districts where the soil is light, and therefore does not hold the water long after heavy rains, autumn is not the season to plant when opposite conditions prevail. When the soil is heavy it is wiser to pot up the plants and keep them in garden frames during the winter ready to be transferred to the garden in March. If decayed turf is 
used to make up the Carnation beds, take care that it does not contain wireworms. Pasture land is the breeding ground of wireworms; they evidently thrive on the roots of grasses, but the Carnation is their favourite food. If one wireworm is in the soil of a large pot containing three Carnations, it will be strange if it does not kill the lot. When it has cleared out the centre of one it will frequently find its way to another before the mischief is detected.

The distance between the Carnation plants should be fifteen inches, and they should be made firm in the soil. If planted in March they will grow away freely at once, but those put in during the autumn require some attention in winter, frosts and thaws alternately having a tendency to throw some of them out of the ground with each frost. When the frost disappears look over the plants and press those that require it into the ground. Some of the varieties are tall and slender in growth, and these should be supported with a stick to prevent the shoots snapping close to the surface of the soil. Slugs and the leather-coated grub consider the Carnation their favourite food ; they both feed at night, and can be readily detected with the aid of a lamp. Electric lamps recently introduced are excellent for the purpose; they are clean, not troublesome, and the extra expense would not stand in the way with the majority of Carnation growers.

\section{VARIETIES}

A bed planted with one variety only is a striking sight. I well remember a mass of some six hundred 
p.

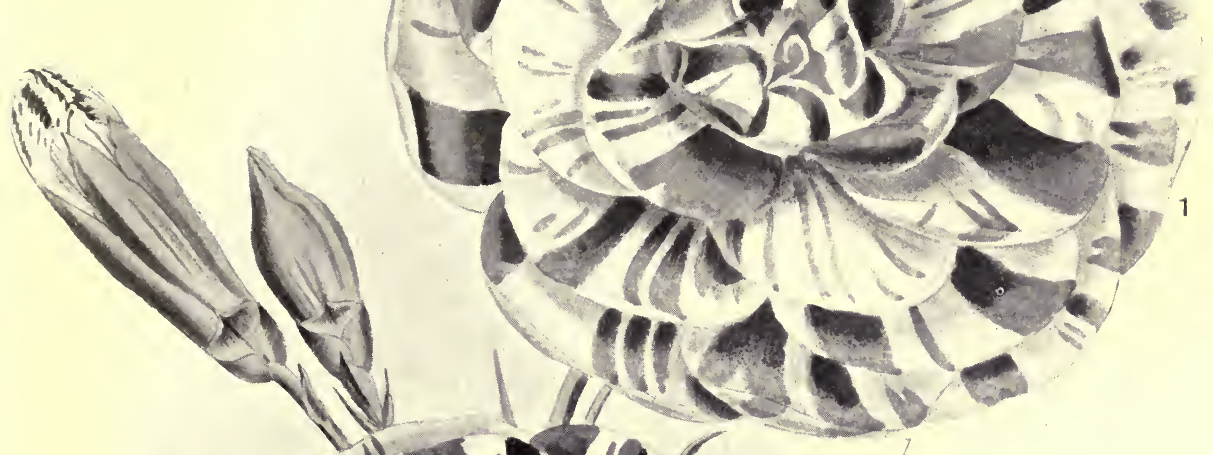




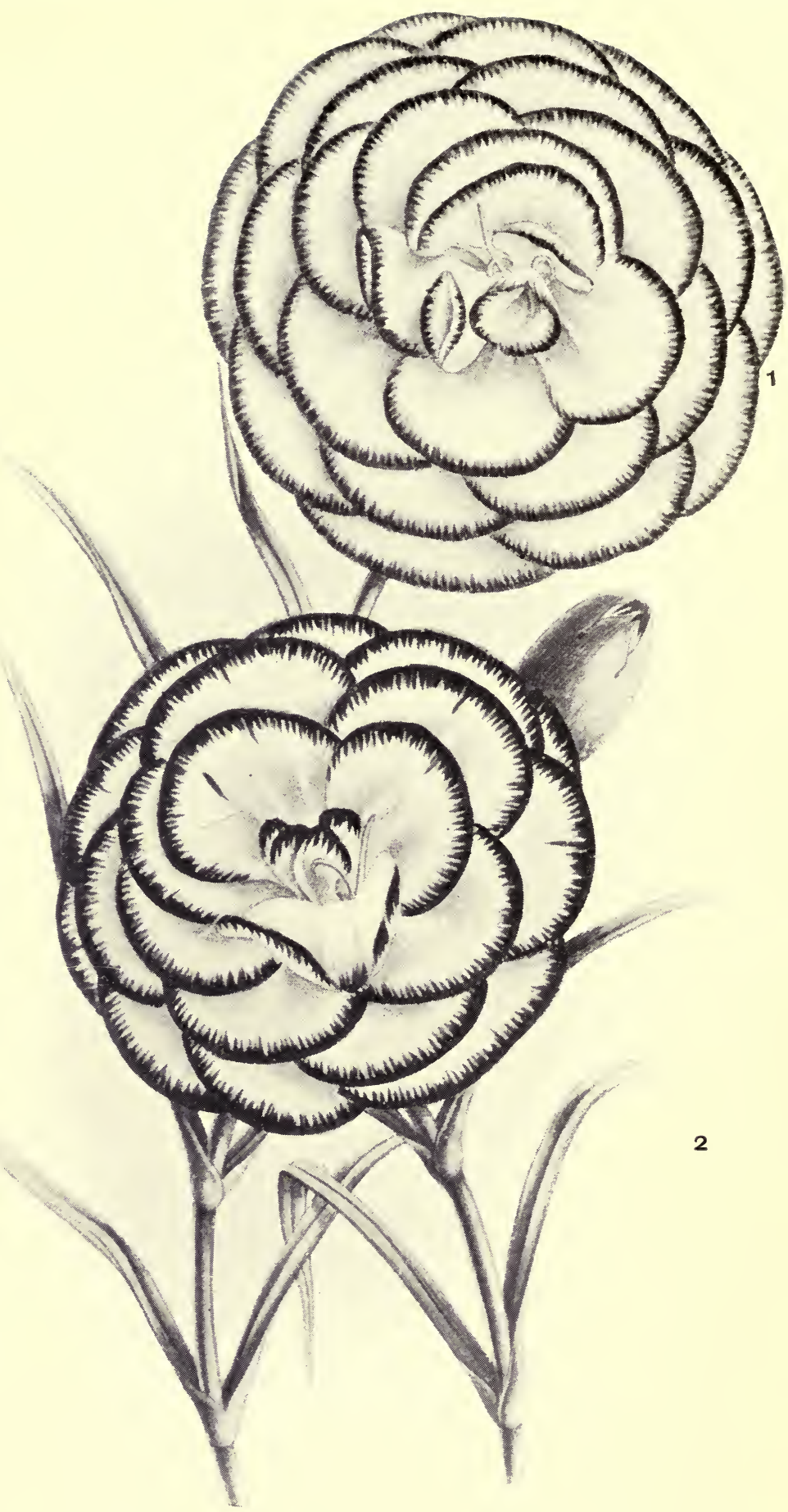

OLD TYPES OF WHITE-GROUND PICOTEES.

1. ALFRED. 2. MRS. NORMAN (THE "FLORIST," VOL. IV., 1851). 
plants of Burn Pink in full flower in the garden at Brougham Hall in Cumberland. The best varieties for this purpose are The Burn, pink; Miss Audrey Campbell, the best yellow; Trojan, white; Seymour Corkran, light amber; Midas, or Copperhead, dark apricot; Agnes Sorrel, crimson; and Mephisto is also a fine border variety of the same colour, for the north; and Banner and Lady Hindlip, scarlet. To make up a list of two dozen selfs, add Bookham Clove, white; Ann Boleyn, salmon; Benbow, buff; Boreas, crimson; Cecilia, yellow; Comet, crimson; Gil Polo, crimson; Lady Hermione, rose; Mrs. Eric Hambro, white; Triton, maroon; Herbert J. Cutbush, scarlet; Ketton Rose, rose-pink ; Miss Shiffner, pink ; and Mrs. Sydney Diver, reddish scarlet.

\section{FAncy CaRnations}

may be described as varieties not included in any of the other classes. The flowers have generally two colours on a white or yellow ground. The best twenty varieties are Horsa, Professor Cooper, Sunset, Yeoman, Artemis, Brodick, Charles Mantel, Don Juan, Evangeline, Galileo, Goldilocks, Guinevere, Hidalgo, Mrs. Charles Baring, Orient, Perseus, Persimmon, Rayon d'Or, Sweet Lavender, The Baron, Yolande, Duchess of Roxburgh, Melbourne, Stadtrath Bail, and Monarch.

\section{Bizarres and Flakes}

The best twenty-four varieties are as follows:-Of the former-Scarlet: Admiral Curzon, Dr. Hogg, 
Edward Adams, George, Robert Houlgrave, Robert Lord. Crimson: Arline, C. F. Thurston, J. S. Hedderley, Master Fred, Phœbe, Thaddeus. Pink and purple: Fred Phillips, Harmony, Melody, Sarah Payne, Squire Penson, William Skirving. Flakes.-Purple: Charles Henwood, Earl Stamford, George Melville, Gordon Lewis, James Douglas, Squire Whitbourne. Scarlet: Alisemond, Flambeau, Guardsman, John Wormald, Matador, Sportsman. Rose: John Keet, Lady Mary Currie, Mrs. Tom Lord, Mrs. Keen, Pandora, Thalia.

\section{White Ground Picotees}

The best twenty-four varieties:-Red edged (light): Acme, Grace Darling, Mrs. Bower, Mrs. Gorton, Thomas William, Violet Douglas; (heavy), Brunette, Dr. Epps, Etna, John Smith, Ganymede, Mrs. Lovatt. Purple edged (light): Amelia, Amy Lord, Harry Kenyon, Lavinia, Pride of Leyton, Somerhill; (heavy), Amy Robsart, Calypso, Fanny Tett, Mrs. Openshaw, Muriel, Verlina. Rose and scarlet edged (light): Ethel, Fortrose, Grace Ward, Mrs. Rudd, Miss Lee, Liddington's Favourite; (heavy), Duchess of York, Little Phil, Mrs. Beswick, Mrs. A. R. Brown, Mrs. William Barron, and W. H. Johnson. 


\section{CHAPTER IV}

THE PICOTEE-WHITE AND YELLOW GROUND

By James Douglas

I T may be as well to state at the outset that there is really no difference between a Carnation and

a Picotee except in the colour of the flowers. Both of them have descended by ordinary generation from one primal source, the well-known Dianthus Caryophyllus, a plant which was to be found growing presumably in a wild state on the walls of Rochester Castle, and it may still linger in similar positions in England as it does in Normandy. Carnations were cultivated on the Continent of Europe before they were appreciated in England, and doubtless they were brought over in many ways, principally by merchants trading with European countries from France to Constantinople. Indeed, the yellow Carnation was introduced from Constantinople by a London merchant, Master Nicholas Leete, in Queen Elizabeth's reign, as stated by Gerarde in his "Herbal," published in $\mathbf{1 5 9 7 .}$

It may be seventy or eighty years since the white ground Picotee had reached its high standard of 
excellence, and the work has been handed down from one generation of florists to another. At one time it was a point of honour amongst florists to do something in the way of seedling raising and to make an improvement in one direction or another, but a standard of excellence was probably not set up until the year 1834, when a sub-committee of the Cambridge Horticultural Society was appointed to draw up this standard for all florists' flowers. The names of this sub-committee were James Twitchett, Richard Headly, Adam Fitch, Frederick Finch, Samuel Widnal, and Edward Catling. The result of their conference was published in the "Floricultural Cabinet" for the year 1834 (p. I44). The following refers to the Carnation and Picotee :-

\section{CARNATIONS}

"The flower large, consisting of a number of well-formed petals, neither so many as to give it a crowded appearance, nor so few as to make it appear thin and empty, the petals broad and stiff, the guard petals well rounded, and should rise a little above the calyx, and then turn off gracefully in a horizontal direction, supporting the inner petals, which should gracefully taper towards the crown. Bizarres should have three colours in every petal, flakes two, colours strong and bright, the fewer freckles or spots the better, all the colours nearly equal, or the most brilliant colour should predominate, the white pure and bright." 


\section{Picotees}

"The same qualities as to size, petal, crown, and clear white ground as the Carnations, edge of petals smooth and well rounded. Those flowers which are free from blotch or stripe down the petal below the coloured edging are greatly to be preferred to those which are marked and pouncy."

A perfect white or yellow ground Picotee should have no spots or marks of any kind upon the pure white or clear yellow ground except the colour on the margins of the petals. This is sometimes in the form of a fine line like fine wire; sometimes there is a broad margin of deep red, rose, scarlet, or purple.

In the year 1839 there was a list of I Io varieties of white ground Picotees. None of them are in existence now, but they were doubtless very fine varieties, and a few years later coloured plates of Picotees were published by Mr. Andrews of the true type in form and colour. Probably none of them were free from exaggeration, as most of this artist's flowers were highly coloured.

\section{VARIETIES}

The yellow ground Picotee was a favourite flower early in the nineteenth century, and Hogg in his book on the Carnation informs us that the Empress Josephine had an admirable collection of yellow ground Picotees at Malmaison, and adds that Queen 
Charlotte and the princesses had a superb collection of yellow Picotees at Frogmore; but we are not left in doubt as to their quality, for Hogg gives a coloured illustration of one. The colour is a good yellow, but in no respects can it be classed as a true Picotee. The petals are fringed, and the colours, red and maroon, dash from the margin in flakes and stripes.

It was not until $185^{8}$ that real yellow ground Picotees were introduced. Mr. Richard Smith, of Witney, Oxfordshire, produced some varieties which well complied with the florists' standard. Mr. B. Simonite, of Sheffield, who saw them, informed me that they were of great excellence. About ten years later Mr. Perkins introduced a variety named Prince of Orange; it had an excellent constitution, as I cultivated it for twenty years after it was sent out. Mr. Standish, of Ascot, also produced a very fine variety, named Ascot Yellow. I did my best to get some vigour into this variety, but it also failed like many more yellow grounds. Prince of Orange is the parent from which have sprung most of the fine varieties now under cultivation.

Most of the new ones are of vigorous growth, and as the varieties are not numerous, only those of robust constitution should be grown. It is only within the last five or six years that we have produced yellow ground Picotees equal in beauty to the white ground group. Mr. Martin R. Smith has given special attention to the improvement of this section. Childe Harold has all the qualities of the 
best white ground varieties. Lord Napier is another fine variety, and the new Mrs. Walter Heriot is superior to both. Lady St. Oszuald is even better than Childe Harold as a garden flower, but it is not so perfect. Abbot is an ideal Picotee, and has a purple margin. Kate Coventry, Lady Sophie, St. Just, and Rabelais are also yellow grounds with purple margins. This colour has been plentiful for years amongst white grounds, but is new in this class.

Another quite new type produced at Hayes are the varieties with broad crimson margins. The best of these are Mazarin, Othello, and Dalkeith. Some of the choicest of recent date are Mrs. Walter Heriot, with rose-coloured margin ; Acme, rose-red ; Mrs. FoxPitt, large flowers, with reddish purple margin ; Alladin, broad margin, purple in colour ; Merry Duchess, rose-red; Astarte, medium edge, reddish-purple; and Lady Avebury, a fine variety, with a light red edge. These are the latest introductions, and the following is a list of twenty-five of the finest older varieties. All of them are from the Hayes seed-beds: Alcinous, purple margin; Aldeboran, rosy-scarlet; Amphion, rose-red; Argosy, red scarlet; Bordever, bright red; Caracci, rose ; Childe Harold, deep rose ; Daniel Defoe, rose-red ; Empress Eugenie, rose ; Evelyn, bright rose ; Gertrude, rose-red ; Glee Maiden, clear rose ; Hesperia, rosy-lilac; Lady Bristol, deep red; Lady St. Oswald, bright red; Lauzan, purple; Mrs. Durrant, deep red; Mrs. Tremayne, scarlet; Mohican, rosy-red; Onda, deep rose ; Pamela, rose lilac; Professor, scarlet; Voltaire, rose; Wanderer, rosy-red; Pilgrim, red; and 
Picotee to perfection.) Therefore let there be two layers in a $7 \frac{1}{2}$-inch pot, and for two of the strongest layers $8 \frac{1}{2}$-inch size. The potting soil is of considerable importance. I use one of four parts good fibrous yellow loam, one of decayed stable manure, and one of leaf-mould. The best material to keep the compost open is ground oyster shells. These may be obtained ready grounded or pounded or ground up. See that the soil is free from wireworms, as one of these pests may kill both plants. Pot firmly, and place the plants in frames, or they may be transferred out of doors if the work is done in late March. Sticks must be put to the plants early in May or even late in April, and in June place them under glass, fumigating at once to destroy thrips. 



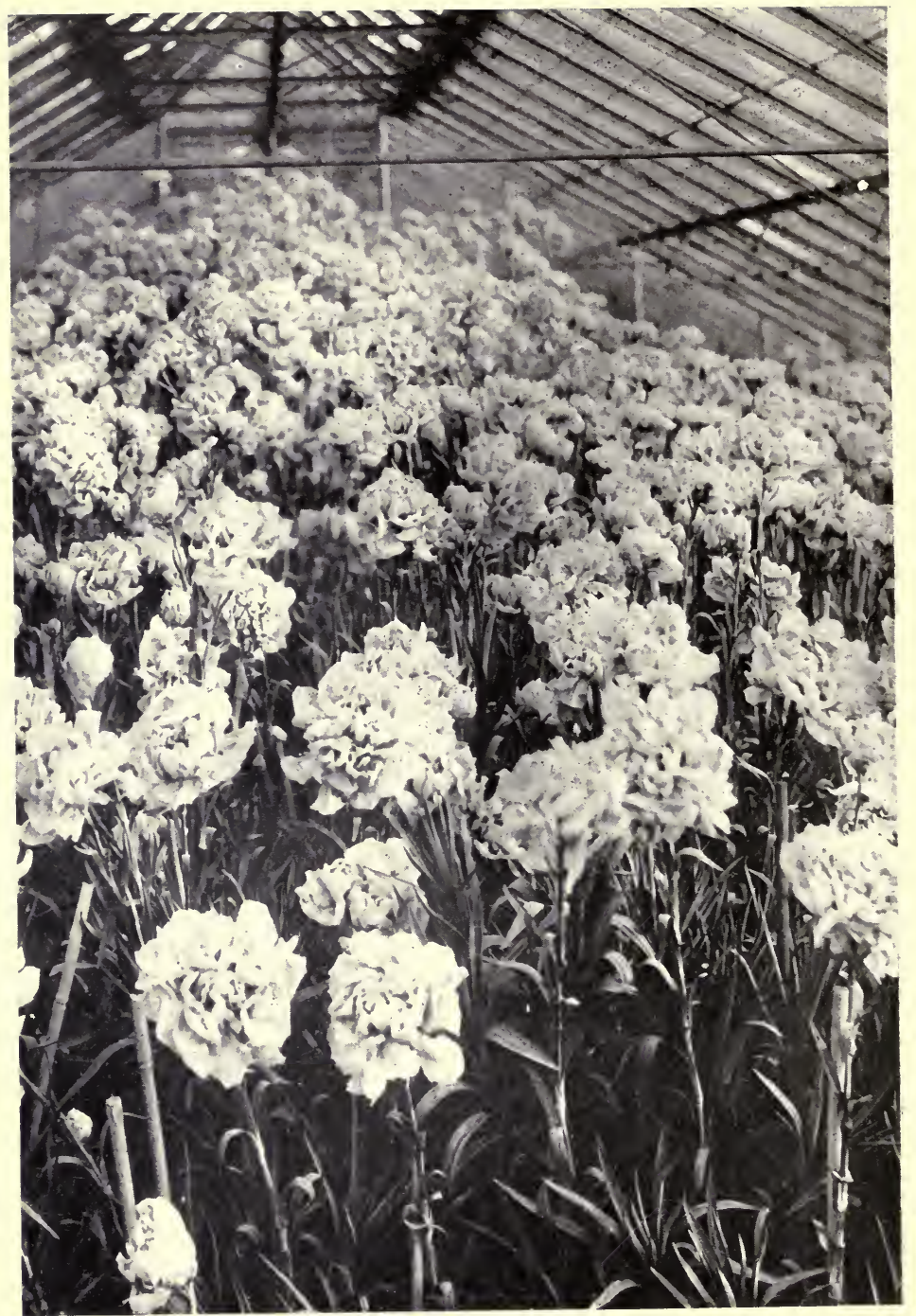

A HOUSE OF MALMAISON CARNATION PRINCESS OF WALES. 


\section{CHAPTER V \\ THE MALMAISON CARNATION}

By James Douglas

I HAVE been frequently asked to give the origin of the Malmaison Carnation, the correct name of which is Souvenir de la Malmaison. The flower and plant are so different from that of other Carnations that it would be interesting if its origin could be traced. The Empress Josephine was an ardent cultivator of Carnations, and her gardens at that time were under the superintendence of the botanist Bonpland. He may have raised it and named it after Malmaison, the residence of the Empress. This is the most probable solution of the question; it may have come as a chance seedling. It has been certainly many years in cultivation, longer indeed than any Carnation known to me. About twenty-five or thirty years ago it became very common, so much so that the late Mr. Charles Turner informed me that he threw away a houseful of plants because no one cared to purchase them. Some years after the same houseful would have been bought at a high price. So much for the vagaries of fashion in flowers as in most other things. 
The old Malmaison is widely grown, but in recent years a revolution has been effected in Carnations of this type. Mr. Martin R. Smith turned his attention to the cultivation of the Carnation in his garden at Hayes, Kent, about twelve years ago. Previous to this there had been sports from the original blush form, pink and crimson. The pink form is most esteemed. Mr. Smith, by a system of cross-fertilisation with varieties that would seed (the Malmaison will not), some two hundred seedlings were obtained, and a selection of varieties made from them. I had the honour to introduce them to the public in 1894 for the first time, and these first-fruits of an amateur's work are still equal, if not in some respects superior, to the later productions.

\section{VARIETIES}

They were Lady Grimston, pinkish white, delicately marked with bright rose, vigorous in growth, and sweetly scented; Lord Rosebery, a handsome variety, very dark rose, and sweet; Mrs. Everard Hambro, large massive flowers of rosy crimson; Nell Gwynne, pure white, large and handsome flowers; Prime Minister, bright scarlet, one of the most vigorous; Princess May, rich rose-this fine variety continues to flower through the winter; Sir Charles Freemantle, immense flowers, deep pink in colour; Sir Evelyn Wood, salmon ground, with stripes of deep pink ; The Churchwarden, large full flowers, rich crimson in colour; and Trumpeter, flowers large, deep scarlet in colour, 



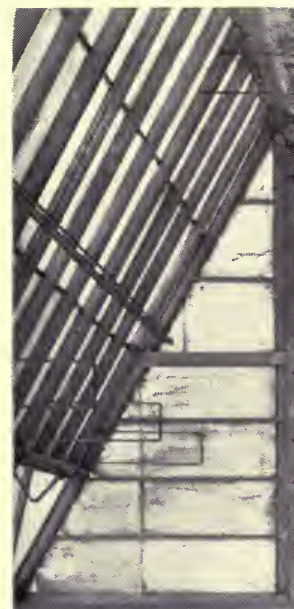

$\lim _{3}$

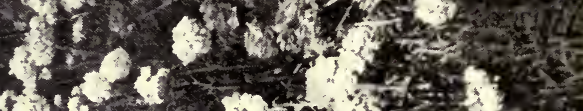

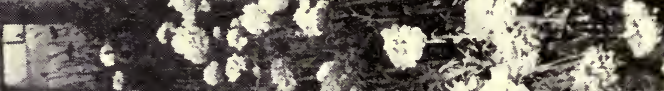

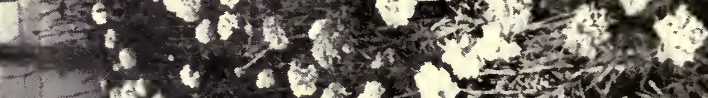

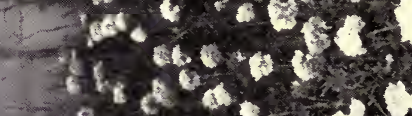

$$
\text { (3) }
$$
$1+5,-23$

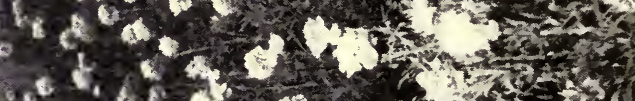

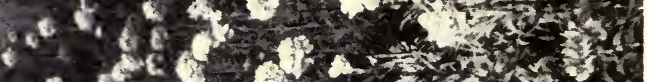

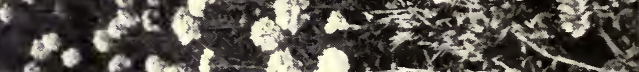

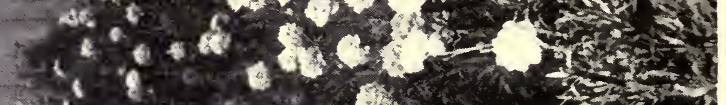

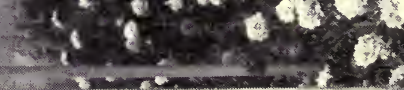

H

․․

112

111

Novis

1213

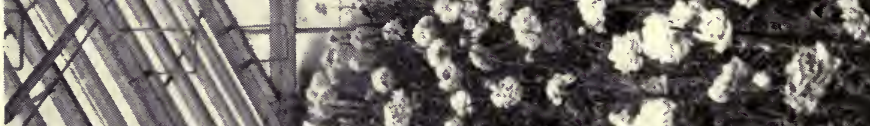

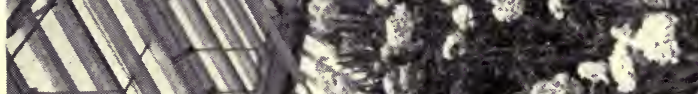

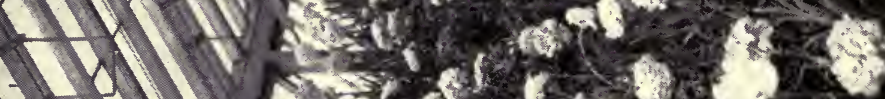

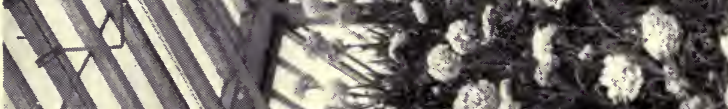

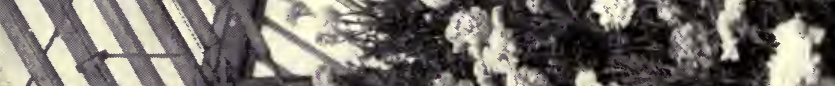

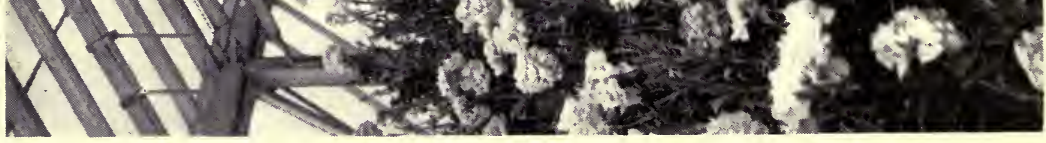

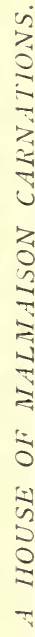




\section{THE MALMAISON CARNATION 4I}

and sweet scented, growth vigorous. This is a full list of the early productions at Hayes.

Other very fine varieties have been raised and sent out since; the best of them are Albion, deep salmon; Calypso, large, blush; Horace Hutchinson, rich scarlet; Iolanthe, bright rose; King Oscar, crimson; Monk, salmon; Mrs. Martin Smith, large, blush; Mrs. Trelawny, dark salmon; Nautilus, flesh colour; and Thora, blush, changing to white. The above are known as the Martin Smith Malmaisons. Maggie Hodgson and Mary Measures are beautiful Malmaisons of a distinct dark crimson colour, and raised, I believe, in the garden of Mr. Measures.

All the Malmaison Carnations are greenhouse plants, and it is not worth while, except in favoured situations, to plant them out of doors, although I must freely admit that in some seasons they grow and flower freely without the protection of glass. When the flowers are not dashed by the rain they are very fine. Prime Minister is the best variety for the open garden, and it is the easiest to grow either outside or inside the greenhouse. Some amateurs purchase Malmaisons thinking to get a good display in winter, but for this purpose, with the exception of Princess May, they cannot be depended upon.

The richest flowering season for the Malmaisons is during the months of May, June, and a part of July, before the time of the Picotees and border Carnations (if left to out of doors or cool house culture all the hardy border Carnations and Picotees bloom after the middle of July, and they continue through the month 


\section{2}

CARNATIONS AND PINKS

of August), and make a splendid display. I fill a house about one hundred feet in length with them. The delicious perfume and rich colours, from deep rose and pink to scarlet, crimson, and maroon, or the softer shades from white and blush to rose and pink, are grateful. Each flower growth would produce from, say, six to twelve blooms, but to have really fine flowers it is best to remove all the side buds and allow the centre one only to develop. Of course large two-year or even threeyear old plants will produce a mass of flowers, one large one for every growth the plant makes. The potting soil does not differ from that used in the case of border Carnations; indeed the treatment is the same throughout, except in regard to the size of the flower-pots. One layer is put into a 3 -inch or $3 \frac{1}{2}$-inch flower-pot, according to the vigour of the layers. When well established it is again re-potted early in the year into a 6-inch pot, and the soil made firm. In addition to the compost I have recommended some growers use artificial manure, and to meet the demand what is called a "Carnation manure" has been produced by a few dealers. I do not use this or any other artificial manure now, as my experience is that it causes a coarse, sappy growth, and renders the plants liable to the attacks of rust and other diseases.

\section{PROPAGATION}

The Malmaisons are propagated in two ways, by slips or cuttings and layers. Some varieties do not 
strike root freely from cuttings, but they can all be propagated by layering. The cuttings should be taken off in May, but only those too far removed from the base of the plants to be easily layered. They do best in a propagating frame in a forcing house, but with a little bottom heat in May artificial warmth is unnecessary. The cuttings may be struck in sandy soil in boxes or in pots, or one cutting may be inserted in a $2 \frac{1}{2}$-inch pot. They take from four to six weeks to strike out roots, and when well rooted they may be transferred to 3 -inch pots. Layering is done in June, so that it can be finished before the border varieties are layered in July and August. Get good strong layers. Some amateurs strip off too many leaves; this is a grave error, and not necessary for the production of strong, handsome plants.

The best Malmaison Carnations are obtained from layers cut at a point where the wood is moderately ripe, but is neither too hard nor in the least sappy. It is only necessary to cut through the joint. Cut the part to be layered close to the joint, and peg it firmly in the surface soil. This should be loose and sandy, and into which the rootlets will enter freely; but upon the whole the finest plants result from the following practice. There are generally exhausted cucumber frames that have been made up with stable manure and leaves. The spent cucumbers are removed, some soil suitable for layering is put into the frame, and the Malmaisons turned out of their pots and planted in it. 
This gives the best of all positions for layering; indeed, some varieties of tall growth, such as Mrs. Martin Smith, Calypso, \&c., cannot be layered in pots owing to their tall and sometimes straggling growth. It is not well to leave the layered shoots long attached to the parents. They should be taken off in good time and potted in 3 -inch or $3 \frac{1}{2}$-inch flower-pots. The plants require to be left in a close frame or greenhouse and shaded from bright sun until they have made fresh rootlets, when air may be given freely. Do not let the plants become potbound, but transfer them to a larger size as they require it. It is better for the plants to be re-potted into $4 \frac{1}{2}$-inch and 5 -inch pots, to be again re-potted in 6-inch or $6 \frac{1}{2}$-inch size afterwards. Place sticks to the plants in good time, so that they are not broken, and if early flowers are desired a temperature of fifty degrees as a minimum is required about Christmas, rising to fifty-five degrees in January. This is a sufficiently high temperature. Rust is the most troublesome enemy of the Carnation. Few collections are quite free from it. The plants may be apparently clean, but the enemy is probably lurking somewhere. The only advice to give is, Watch! and as soon as the least trace of it is seen cut off the diseased part and burn it, without wasting time on washes, solutions, or dippings. Red spider will appear in hot and dry weather, and sometimes when the temperature is neither one nor the other. Syringe the Carnations on the mornings of fine days, especially the under surface of the leaves, and use clean rain water 


\section{THE MALMAISON CARNATION 45}

if it can be obtained. Green-fly is troublesome, but this is easily destroyed by fumigating with XL All.

Malmaison Carnations must be watered with the greatest care, and should only be done by a man with some experience. One who really understands and loves his plants will make no mistake. When a plant is very dry the soil springs from the sides of the pots and watering then is useless, as the water runs down through the open space. The only way under these conditions is to soak the soil in a pail of water for half-an-hour. It is easy to ascertain if a plant has been over-watered, as the pot when rapped with the knuckles or a stick has a dull sound, and when lifted feels as heavy as lead.

In Mr. Brotherston's excellent "The Book of the Carnation," p. 35 , is the following interesting reference to the origin of the Malmaison Carnation : "There long remained the utmost uncertainty accompanied by the vaguest guesses as to where and when the original Souverin de la Malmaison with its blush coloured flower originated. It is now clear that it is not nearly so old a plant as some have conceived, it having been raised from seed by M. Laine, a Frenchman, in 1857. Mr. David Thomson cultivated the plant at Archerfield in I864, having received the stock from Mr. William Young, of Edinburgh. I have been at some trouble trying to secure trustworthy evidence as to the time when, and the place where, and of the sports originated, and I think I may safely aver that 'Lady Middleton' appeared at Luffness, in East Lothian, in the year I870, and 


\section{CARNATIONS AND PINKS}

the pink Malmaison a few years later (1875), in a garden near Musselburgh. It is a curious trait in connection with this trio, derived from a common stock, that the last named is accounted the easiest to cultivate, and 'Lady Middleton' the most capricious." 


\section{CHAPTER VI}

THE TREE OR PERPETUAL-FLOWERING

\section{CARNATION}

\section{By James Douglas}

THIS type of Carnation has not been established so long in England as the others. I can well remember the varieties in cultivation about the middle of the last century, as one of my duties was to nail the plants to the wall of the nurseryman's dwelling-house where I served my apprenticeship. The plants were three feet and four feet in height, veritable trees, and at that period the name conveyed much truth, but the varieties grown now have nothing of this character. They are, however, well called perpetual flowering, and to confirm this I selected about twenty-four plants of six varieties, and for twelve months they were never out of bloom. A perpetual-flowering Carnation is known by the growths or side shoots which emerge from the main stem, even before the first flowers are cut. When the leading flowers are gathered, the side growths bloom, and in this way a succession is obtained.

Many Carnation growers ignore this class; they are 
satisfied with the border varieties. Some have an idea that this section is composed of tender plants requiring a greenhouse, but this is an error ; they are quite as hardy as any other group. Good flowers, however, cannot be produced in quantity in winter unless the plants are in a warm atmosphere. They are easy to manage if kept growing, but this is exactly what many forget to do. You go into a garden and ask to see the Carnations. After some search they are found scattered amongst the greenhouse plants, a third of the soil has been washed out of the pots by careless watering, green-fly is infesting them, and they are suffering from an absence of light and air. No good flowers can be obtained in this way. I have proved that with twenty-four well-grown plants it is possible to have Carnation flowers all the year round, but to do so the following instructions must be observed. Suppose we begin in January with either seeds or cuttings; some grow both, but I find that seedlings are the more easily managed, while there is always a chance of a choice variety occurring better than anything in existence hitherto.

\section{Propagation}

The usual way of propagating border Carnations is by layers, and perpetual-flowering varieties may be increased by this means; but the growth of the plant does not lend itself well to this method. If the growths were principally near the surface of the soil they could be layered as easily as the border varieties. 
The better way is to take off the side growths from the main stem and plant them in small flowerpots in sandy soil. This should be done in January to obtain plants that will begin to flower in September and continue through October. Later cuttings or slips will produce a succession of flowers until the Malmaisons are plentiful in May and June, and during July and August the border Carnations are in full beauty. The cuttings or slips taken off in January must be put in any house heated to a temperature of fifty-five degrees. A gentle bottom heat of eighty degrees to eighty-five degrees should be provided, and plunge the pots to the rim in decayed cocoa-nut fibre refuse or leaf-mould, and keep them near the glass. If a propagating frame is not available, a square or two of glass placed over the pots in which the cuttings are and resting on the labels will do very well. I have propagated hundreds in this way, and seldom lost a cutting.

As soon as the roots are well formed the pots should be removed from the bottom heat and placed in an airy part of the house for a week or ten days, when each plant may be potted off separately into thumb pots or small sixty size. They soon begin to grow freely, and require re-potting again in six or eight weeks, and by the end of May they are ready to be placed outdoors in an open position, or in a very wet season keep them under glass, giving an abundance of light and air. The glass is only required to protect the plants from drenching rains. Carnations one year old will flower well in pots five inches or six inches 
across, under measurement (measure a little below the rim). It is useful also to remember that whatever is worth doing at all, is worth doing well.

\section{Potting}

Get the best potting soil obtainable, such as good fibrous loam partly decayed and free from wireworm. Tear or break it up, and to four parts of loam add one part of leaf-mould and the same of decayed stable manure. This should be well mixed together, and if the loam is not sandy add to it an 8-inch pot full of ground oyster shells to every barrow load of compost. If this is not possible, coarse white sand may be substituted. Dirty flower pots must be avoided. The pots should be scrubbed clean outside and inside, and use clean crocks also, putting them in carefully with the concave side underneath, a few larger pieces in the bottom, and over these the smaller bits to the depth of an inch. This is of course for the pots in which the plants are to flower (one crock only is sufficient in the bottom of the smaller ones). Over the drainage place some fibrous turf, and pot firmly. Do not mind a little extra trouble, as one well-grown plant is a thing of beauty, but one badly grown is a perpetual eyesore. Large specimens may be grown by re-potting some of the best of the oneyear old plants in large pots; 8-inch are of sufficient size, and very fine Carnations may be grown in them, if well trained and kept clean. An abundance of flowers is the result in the autumn months. 


\section{THE TREE CARNATION}

\section{Seedlings}

These may be treated in the same way as named varieties. Sow the seed about the end of January or the first week in February in a little bottom heat, and in the same house as the cuttings are struck. The young plants will appear in a week or ten days, and as soon as the seed leaves (cotyledons) are quite developed the plants should be pricked out at once into seed pans or boxes. They may be planted out in the garden when the weather is favourable and they have become inured to the open air, or they may be grown and flowered in pots. The best plants are those grown on in pots until the flowering stage. All of them have flowers worth cutting for room decoration. Some of the varieties will have single flowers, but not many; one or two in a dozen perhaps, but for some forms of indoor flower decoration single flowers are better than the double.

The seed should be obtained from cross-fertilised flowers; and the produce will be sure to give satisfaction. There is also the additional pleasure of anticipating the opening of the flowers on the seedling plants. I have constantly urged upon amateur growers the wisdom of raising seedlings. Writing as I do now for the instruction of amateurs, I can freely add that a great part of the pleasure I derive from the growing of the Carnation has been in watching the development of seedlings. I have tried all the classes, and have been successful in most. Perpetual-flowering Carnations are not liable to "rust," but green-fly 
is the most troublesome pest; it is easily destroyed by fumigation. Careful watering and cleanliness in the house throughout will ensure success if the above instructions are carried out.

\section{VARIETIES TO GROW}

It is not necessary to grow a large number of varieties. For a small collection six are sufficient, and the six I would recommend are America, salmonscarlet ; Countess of Warwick, crimson; Lady Carlisle, bright pink; Mlle. Therese Franco, delicate pink; and William Robinson, rich scarlet.

If twelve are wanted add General French, a large crimson flower; Duchess of Devonshire, the colour is defined as crushed strawberry; Lord Roberts, the best yellow, but it is not a true perpetual; Mrs. Thomas Lawson, pink ; Lizzie McGowan, white, very free; and Sir Redvers Buller, rich scarlet, large flowers.

It would be a mistake to omit to mention the varieties raised in America. They are very numerous, and in a recently published work on the American Carnation no less than 720 varieties are enumerated. Three of those I have named were raised in America, namely, America, Lizzie McGowan, and Mrs. T. Lawson. There are a great many raisers of Carnations in the United States, and scores of new varieties are annually introduced. The type of Carnation preferred is the fringed petalled. Governor Roosevelt is a recent addition; the flower measures four inches across, and the margin of the outer petals is like a 



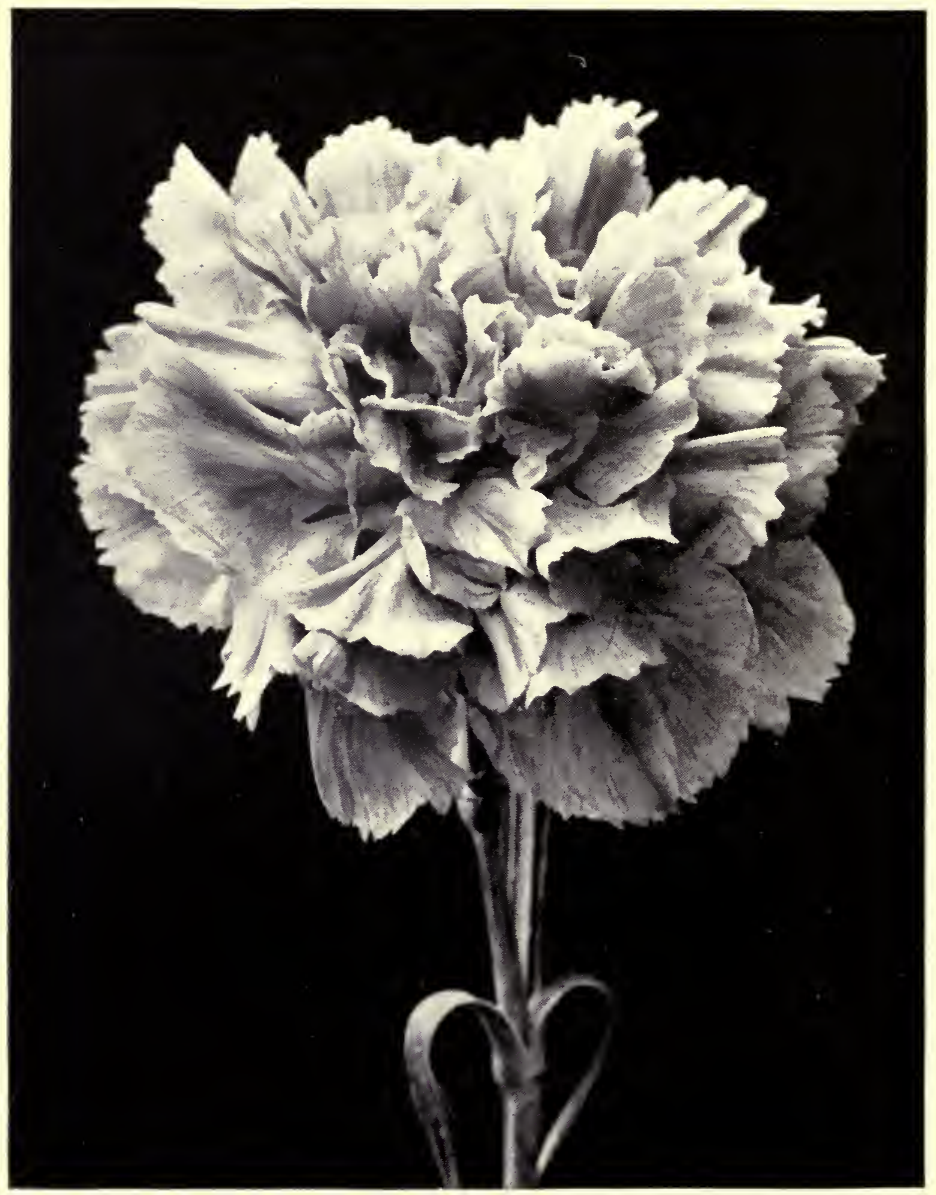

THE FAMOUS AMERICAN CARNATION IIRS. T. IV. LAWSON. 
badly set saw. Mrs. Theodore Roosevelt, Governor Bliss, Alpine Glow, raised by Mr. Ward. Enchantress and Governor Wolcott are the latest productions of Mr. Peter Fisher, the raiser of Mrs. T. Lawson. Mr. Frederick Dormer raised Alba, Stella, Apollo, and Dorothy Whitney. These are the more recent varieties. Other raisers have done good work from their own standpoint, but the great thing in America is to raise hundreds of thousands of plants-indeed it is computed there are two thousand establishments given up principally to Carnation growing. From seven to eight million plants are grown annually in these establishments, and upwards of one hundred million flowers are produced for the markets of Canada and the United States. The American climate is not like ours, and the system of culture is adapted to it. The plants are put out in fields, and when well established they are lifted and planted out on benches. 


\title{
CHAPTER VII
}

\section{CARNATIONS FOR EXHIBITION: A YEAR'S WORK}

\author{
By R. DEAN
}

JANUARY

$\mathrm{HE}$ plants are now at rest, as it is the month of
the year when vegetable life seems at its lowest
ebb. A firm ash bottom on a cold frame is a favourable position for the plants, presuming they were potted at the usual time. The Carnation is thoroughly hardy, and there is a great advantage in potting up the rooted layers of the previous summer as early as possible, so that the plants may be well established in their pots before winter. Some protection should be given from cold winds, rains, and severe frost; the lights of the frame will suffice, giving some air on the leeward side, unless severe frosts prevail, when close the frame and cover over with mats. Little or no water should be given except in drying weather, and the time to apply it is in early morning when there is no danger from frost. The leaves should not be wetted when water is given. The plants should be gone over on favourable occasions, dead leaves removed, and cleanliness observed. 
In mild open weather full exposure may be given with advantage. Losses may occur even when the most careful attention is given to the plants, as some varieties are of poor growth, whilst others have the germs of disease in them.

Growers of Carnations in pots transfer their plants to the pots in which they are to flower as early as possible in February, consequently the soil is prepared in December or during the first week in January. A good compost may be made up as follows: threefourths of good brown loam if procurable, one-fourth of leaf-mould, with some coarse sand or grit, and well decomposed manure free from grubs. This can be placed in the open, but kept covered in rainy or snowy weather, and be turned occasionally to sweeten it.

\section{FEBRUARY}

Signs of growth will now be shown by the plants, and before being placed in the pots for flowering in they should be gone over and thoroughly cleaned. Water should be given during mild weather to any plants requiring it; the lights should be drawn off from the frame, and the plants fully exposed. By the third week, should the weather be open and drying, the plants may receive gentle showers falling from the west and south-west, care being taken that they do not become too much saturated, in case there may be a change to frost. Screen the plants from blustering and cutting winds, but give some air even in time of frost. Any plants lost during the winter should be 
replaced. Prepare the necessary pots and have everything in readiness for potting, and if a spell of suitable weather should set in, begin potting at once. Pots varying in size are used, such as six, seven, eight, and also nine inches in diameter. If old pots are used, let them be thoroughly washed; if new ones, they should be previously well soaked in water. A well-known amateur grower thus sets forth the process of potting : "I place two or three inches of crocks (not too small) at the bottom and cover them over with dry leaves. I then fill the pots about three parts full with the compost, putting into each pot as I proceed a handful of finely broken charcoal. The plants are gently tapped out of the small pots and placed on the soil, and the spaces between the plants, and to within a half-inch of the rim, filled in with more soil, and the whole thoroughly shaken down and pressed firmly." One, two, or three plants should be placed in a pot, but this is regulated by the vigour of growth of the variety, some being much more robust than others. Firm potting is necessary, and over-potting should be avoided. In the case of early potting it is well to place the plants in a cold frame for a time; if there is no such convenience, potting should be delayed until March, so that the pots can go into the open air at once.

\section{MARCH}

Such potting as was not done in February should be completed this month. If placed in the open, some shelter from chilly winds should be provided, and, if 
it can be managed, protection also from heavy rains until the plants are well established. If the soil used for potting be nicely moist without being sticky, water will not be required for some days. Plants intended for border decoration can be put out without delay, placing some fine soil about their roots to encourage quick action. Stand the potted plants out in the open on a deep ash-bottom or on slates to prevent the ingress of worms into the pots.

\section{APRIL}

Any tall-growing plants should have their shoots tied out carefully to stakes, as high winds are apt to snap off the growing stems. If warm weather sets in with drying influences the plants should be freely watered, and it is under such conditions of weather that green-fly is apt to gather on the plants. It should be dislodged by fumigation or otherwise. Any decaying leaves should be removed, and no weeds permitted to grow on the surface of the soil. Seed may now be sown in well-drained pans or pots of fine soil, and placed in a cold frame.

\section{MAY}

The necessary operations during this month greatly depend upon the weather. The plants should be fully exposed, but if possible screened from the action of boisterous winds. Should the weather set in warm and dry copious waterings will be necessary, otherwise the water-pot should be used with caution. Keep 
the plants free from any harmful insects. Towards the close of the month stakes to support the flowering stems should be placed in the pots. Stir the surface of the soil frequently; it should not be allowed to remain close and hard, whether from watering or rains. The plants will now grow rapidly, and in tying the flowering stems to stakes do so with judgment and not too tightly. As soon as the young buds are large enough some disbudding may be done. Great care should be taken that weakly plants are not over-watered, as it delays their growth, few roots are made, and an imperfect bloom results.

\section{JUNE}

With the advanced growth there must be careful attention to tying to the stakes. With rare exceptions, all shoots starting for bloom beyond the leading stem should be stopped. In a few cases, however, the cultivator will find that the stopping of one shoot is merely the precursor of the starting of another, and thus his anticipation of increase is threatened with disappointment. In such cases it is well to permit a second or even a third stem to rise for bloom, allowing such stems to carry a single bud only, and thus the rampant vigour is subdued. One who is a leading grower for exhibition states that he leaves only the main bud, but this rule cannot be regarded as a fixed one, as he has found some varieties lose refinement if allowed to throw all their energies into one bloom, a statement which is quite true of other florists' 
flowers. Green-fly and spittle-fly should be watched for and destroyed. Syringe liberally. During warm weather nothing conduces to the cleanliness, and consequently the health, of the plants more than a free use of the syringe, but applying it less to the weak growers than to the strong ones. A top-dressing of equal parts of yellow loam, leaf-mould, and well decomposed manure is given by some growers about the last week in the month, or weak liquid manure may be sparingly applied as the buds swell.

\section{JULY}

July and the early part of August have been termed the "florist's paradise," for it is then he can enjoy the reward of his labours, but to do so to the fullest extent the plants should be placed under cover to preserve the blooms in all their purity. Span-roofed houses are constructed, from the sides of which the glass can be removed, so that the air can freely circulate among the plants. Early in the month disbudding should be attended to if exhibition blooms are to be secured. An old florist states that the practice to be observed "depends upon the habits of the variety and the condition of the plant. If of strong growth, three buds may be left; if of moderate growth, two buds; and if of weakly growth, one bud only. As a rule, the buds to be left will be the main bud, and those proceeding from the third and fourth joint counting from the top; but the operator must be guided in his selection by the appearance of the 
buds-their vigour, healthiness, and regularity in form. A full flower may be anticipated where the young buds have a broad obtuse top; whilst a variety which produces a thin flower has a sharp and longpointed bud." It is usual as the buds swell to tie a piece of soft bast or raffia round them. Watch carefully for green-fly, as many a fine bloom has been spoilt by these insects getting under the points of the calyx. Water liberally as required, and be careful the plants do not suffer from drought. The earwig is also apt to be troublesome.

\section{August}

Sometimes, when a dry spring and summer occurs, the growth is ripe for layering in July, but August is the month in which the bulk of the work is usually done. As the plants go out of bloom those in pots should be placed in the open air, so that the shoots may become hardened ready for layering. Layering is an important work, and the earlier it can be done in August the better. When layered, the layers should have full exposure, care being taken that the soil in the pots be kept sufficiently moist to ensure the putting forth of roots; keep the surface clear of weeds, and watch for any attacks by insects. Earwigs are likely to be harmful.

\section{SEPTEMBER}

Soil for potting off the layers should be prepareda good sandy loam, with the addition of a sixth part 
of leaf-mould; this should be well mixed, and kept dry until required for use. Potting can be done as soon as there are indications that the layers are sufficiently rooted; when potted, place them on a dry bottom in a cold frame, shading from the sun, and giving plenty of air. A pair of layers can be placed in a 4 -inch pot, but any valuable varieties should be potted singly in small pots, and have as much attention as possible; see that ample drainage is provided.

\section{OCTOBER}

The potting up of layers should be completed without delay, as it is all-important to have them established in pots before dull, wet, autumnal weather sets in. The layers should be free from decaying foliage, dust deposits, and insects before they are potted. When potted, they should be watered as needed; it can be more freely given as roots are put forth. The plants should be protected from high winds and heavy rains, but not to the exclusion of air night and day.

\section{November}

By this time the plants should be well established in their pots, which should stand on a hard bottom, so that any excess of moisture can get away quickly. Watering is best done in the morning, and only when required. The plants should have ample room, so that air can circulate among them. Crowding often 


\section{2}

means much evil, and leads to an outbreak of spot. Water is best withheld in damp and foggy weather, but given when the air is dry and keen. Cleanliness is all-important; and there should be a keen lookout for the mischievous maggot. A northern aspect is considered best for the plants during winter. Tilt the lights back and front in favourable weather, but keep them nearly closed when wet and stormy.

\section{DeCEMber}

The plants are now practically at rest, but they should have constant attention from the cultivatordrought, insect attacks, dust, stagnant moisture, or lack of fresh air are all conditions to be guarded against. With such necessary attentions the plants may be confidently expected to go through the winter in safety, and be in a proper condition for potting in March. 



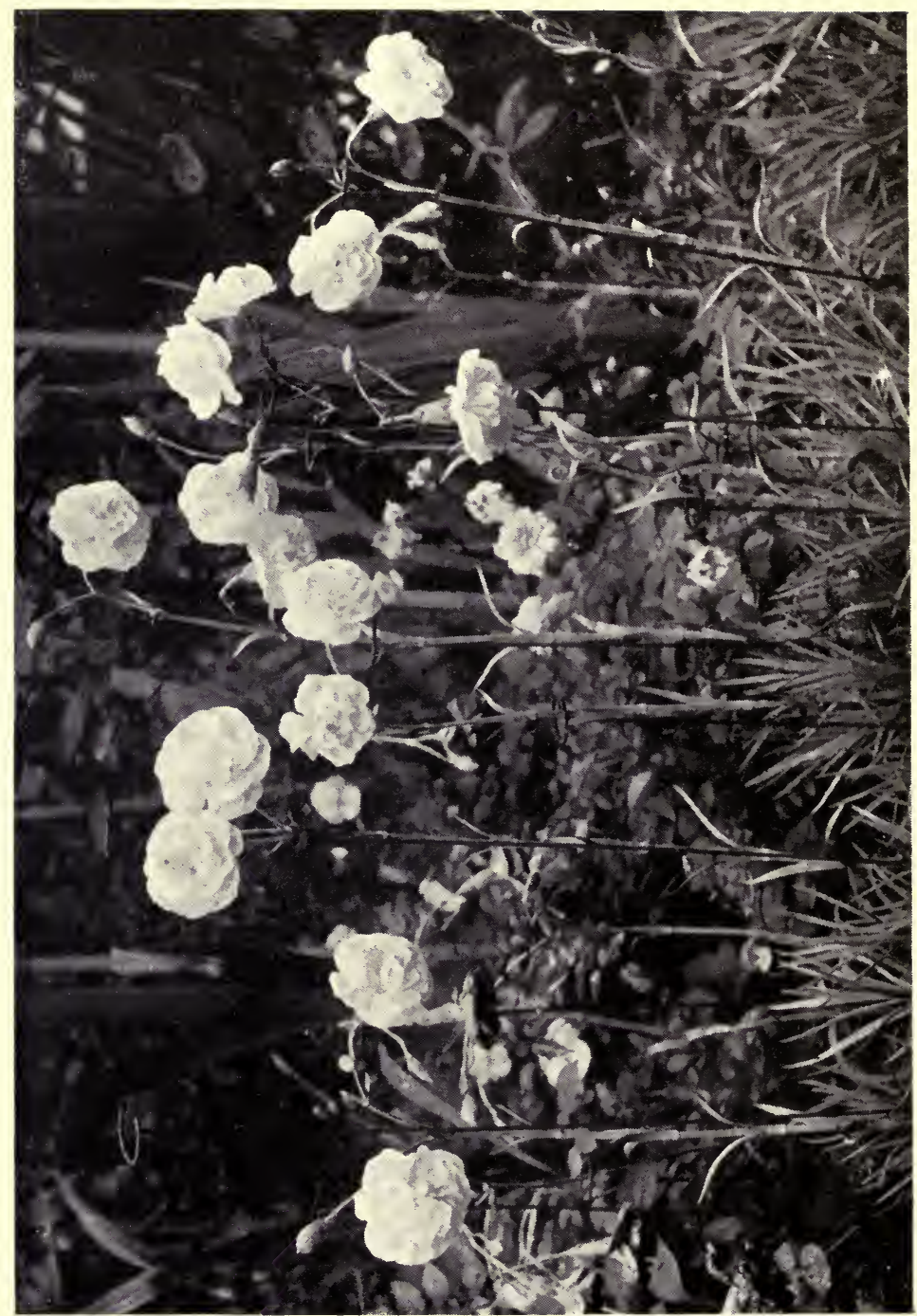

ל 


\title{
CHAPTER VIII
}

\section{CARNATIONS IN TOWN GARDENS}

\author{
By H. Thomas
}

T

HE Carnation is a flower for the town as well as the country garden. It even seems to relish the smoke of a large city, and sometimes the plants, the Old Clove as an example, are as full of flowers in the neighbourhood of London as in the sweeter air of a seaside village, except for an absence of clearness and freshness in the colouring. A well-known amateur grower in a southern town, largely populated, says, "The Carnation and Picotee will thrive while other flowers fail. Of course it is well known that a clouded and impure atmosphere dims the freshness of the petals of most flowers, but Carnations do not mind the smoke." The following is the experience of a town gardener with Carnations : "The soil of an ordinary town garden can be made suitable with reasonable cultivation and manuring. When it is sandy or gravelly improvement is more difficult to achieve, but the repeated addition of road scrapings, dead leaves, with the garden refuse and annual dressing of farmyard manure, will work wonders." The town garden, however, is generally too heavy and 
wet, and poor also, that is, deficient in plant food. Artificial manures are helpful to heavy soils, but poison to those that are wet. They are best given as a top-dressing during the period of growth and in showery weather, so that the manure is at once washed down to the roots.

To improve poor and heavy soil dig it well in autumn and leave it unbroken during winter; frost pulverises the large lumps and makes the soil friable and promotes root-growth. Manure should be dug in at the same time, and buried about six inches beneath the surface. In early spring dig the soil over again, and the partially decayed manure will be thoroughly mixed with the soil and render it richer for the plants.

\section{IMPORTANCE OF SPRING Planting}

Autumn is usually considered the time for planting Carnations, and for country gardens where pure air and suitable soil can be enjoyed this season is preferable, for then they become well established before winter. Butfor Carnations in the town garden spring should be chosen for planting. If the plants are put in the ground in early autumn it is true that they are well rooted before winter, but few of them grow satisfactorily when March comes, many of them having lost their centres, or the leaves are diseased. Hundreds of Carnations are lost in town gardens during the winter as the result of the centres of the plants decaying; the wet gets in the axils of the leaves, and 


\section{CARNATIONS IN TOWN GARDENS 65}

remains there for days or perhaps weeks, owing to the absence of the sun. It is not frost that kills them, but damp.

Choose March for planting, and a dry day for doing so. It is unwise to plant when the soil is wet, for it is impossible under these conditions to work the soil well among the roots, and this is essential. Put the plants in the ground sufficiently deep to prevent their swaying about from the base or "collar" as it is called, as when planted too shallow they never take a firm hold of the soil, and in consequence the growth is unsatisfactory. If the base is buried too deep the roots are too far beneath the surface, and air cannot reach them. It is not necessary to cover any of the leaves, except the basal ones, which may be partially hidden with soil. Make the soil fairly firm about the roots, either with the hand or with the trowel used in planting. Carnations root most satisfactorily in moderately firm soil. The soil need not be rich, as when too full of manure the growth is sappy and the flowers few, but if the growth is firm the plants may be kept for another season, when the display will not be much inferior to that of the first year. It is advisable to propagate every year, as an exceptionally wet winter might kill nearly all the old plants, or so cripple them that few flowers would result.

\section{Summer Treatment}

Weeding is the first duty to attend to. Where everything is favourable to plant growth, that is, in good soil in country gardens, Carnations are less 
affected by the growths surrounding them; not so, however, in town gardens, where all the light and air possible are needful. Begin weeding early, before the weeds flower and rob the soil of nourishment, and also keep the ground loose, especially in dry weather. Perhaps most important of all is a mulch of manure when the buds are showing, and place it round the clump of plants, as it keeps the roots moist, stimulates growth, and improves the flowers. Staking will also need attention, but with the improved appliances now this is a simple business. The best stakes are made of twisted wire, and the stems of the Carnations should be intertwined; tying is not necessary. Paint the stakes a quiet green colour, and let them give sufficient support without obtrusion. This is easily accomplished with a little practice. The old wooden stakes were always painfully evident, and the Carnation garden is not beautiful where an array of white sticks almost hides the flowers. Watering is a very important operation in the town garden, and in summer the soil dries more quickly than in the country. Choose the cool of the evening for watering, and give plenty to prevent the ill-effects that come from driblets. It is almost better not to water a plant at all than to merely sprinkle the surface, which simply means that the roots are attracted to the surface and burnt by the hot sun. It is far from our wish to discourage the town garden, but unless the rules set out here are followed, it would be better to gravel over the beds and borders and save much vexation of spirit and wasted outlay. 


\section{VARIETIES}

Those that have been mentioned already will succeed in the town garden, but we strongly advise the raising of seedlings, which, when from the finest varieties, are very beautiful. But the following list has been recommended to the town garden as containing varieties of exceptional excellence in a murky atmosphere: White, George Maquay, Gloire de Nancy, and White Star. Red of shades, the Old Clove, Paul Engleheart, which is a dwarf form of it, and Uriah Pike. Scarlet, Dundee Scarlet and Quentin Durward. Salmon Pink, Raby Castle. Dull Rose, Francis Wellesley. Yellow, Miss Audrey Campbell.

\section{PROPAGATION}

This has been described elsewhere, but a slightly different treatment is advised for the town Carnations. Instead of transplanting the layers to a border prepared for them, put them in small pots in a soil containing a fair quantity of leaf-mould, and transfer to a garden frame, there to remain until March, when they may be planted out. Another plan is to plant the rooted layers direct to a bed of light soil, nine inches deep, without potting, but the pot system is the more satisfactory. It is difficult to keep a mass of soil in the right condition of moisture, but Carnations must not be kept too damp during winter, else will all the labour be in vain. A cold frame is inexpensive, but of the utmost value in sheltering not 
only Carnations, but many other things which dislike the damp and frosts of an English winter.

As to raising the plants from seed we have already written, and it should appeal strongly to the town gardener, as in this way winter protection is avoided. Sow the seed in January in a warm house (this is a necessity), and encourage the seedlings to grow fairly quickly in an intermediate temperature (not higher than sixty degrees, or the tiny plants will be weakened). The result should be good plants for planting outdoors in May, when flowers will appear only a little later than those propagated in the previous year. This plan of flowering the plants the same year has much to commend it to the town gardener, for all winter trouble is at an end. The only drawback is the need of a heated greenhouse or frame. Without one or the other it is impossible for the seedlings to grow with sufficient rapidity. Most suburban gardeners, however, possess a small greenhouse, and a portion of it could not be devoted to a better use that by raising seedling Carnations. In late autumn the flowers will be welcome for cutting. One of experience writes : "In a garden within a very few miles of Charing Cross hundreds of plants are grown in this way, and the gardener is able to gather handfuls for the house." One of our best Carnation growers states that plants flowering from seed sown in March of the previous year will produce from Ioo to 150 blooms each. It can hardly be expected that so many flowers would be gathered from plants flowering the first year from seed, but they too give a very satisfactory harvest. 
Among singles there is always a certain percentage of single flowers; but supposing the Carnations are required for home decoration only, the singles are as great a success as the doubles; in fact, when arranged with them they rather improve the display than otherwise.

\section{Carnations in Tubs and Window Boxes}

If border space is limited Carnations may be successfully grown in tubs or boxes. Tubs well filled with Carnations, however, form attractive objects in any garden, and are especially suited for arranging on the top of steps, on low walls, \&c. In this way Carnations may be grown in a garden even where there are no borclers. Tub gardening is a phase of horticulture that is little practised, but which has great possibilities. It may be turned to good account by the town gardener as well as by those whose gardens are larger and more fortunately situated. If the culture is successful the plant will grow and flower so well that the tubs are almost hidden from view. Paraffin casks, cut in half, do admirably for growing the Carnations in, but if these are used some of the plants must be placed at the edge of the tub and inserted in the soil sideways, so that the growths and flowers will droop over the sides. Pinks may be used as an edging instead, and Carnations planted so as to fill the rest of the tub surface soil. The best results from this method of Carnation culture occur when the tubs are a good size, nearly four feet high, and with holes round the sides, so that 
when planted and the plants fully grown the tubs are furnished all round. The plants are put in during March, and must be carefully planted, especially those in the holes around the sides. Make them firm, and see that proper drainage is provided so as to allow superfluous moisture to pass away. This may be secured by placing two or three drain-pipes on top of each other so as to form a channel in the centre of the tub, and making holes in them here and there for the water to run through. Much watering will be necessary during the summer, for one tub will need a good many plants to furnish it well, and they must have a good supply of water, mixing guano with it when the buds begin to show. It is not wise to keep the plants in the tubs for more than one season. By the following year they would be untidy, and the soil also would want renewing. The tubs or boxes should not be stood upon the ground, but on two or three bricks placed underneath so as to raise them.

It is surprising that Carnations are not more generally grown in window boxes; they bloom a long time, and are delightful flowers to have in front of the window. "In Switzerland," says Canon Ellacombe, "they are grown (especially the Crimson Clove) in the window boxes of the chalets, and are allowed to hang down, and so grown they are very beautiful."

Carnations do not mix very well; they always look best when alone, rather than amongst other flowers, therefore it is well to have one window box filled with 


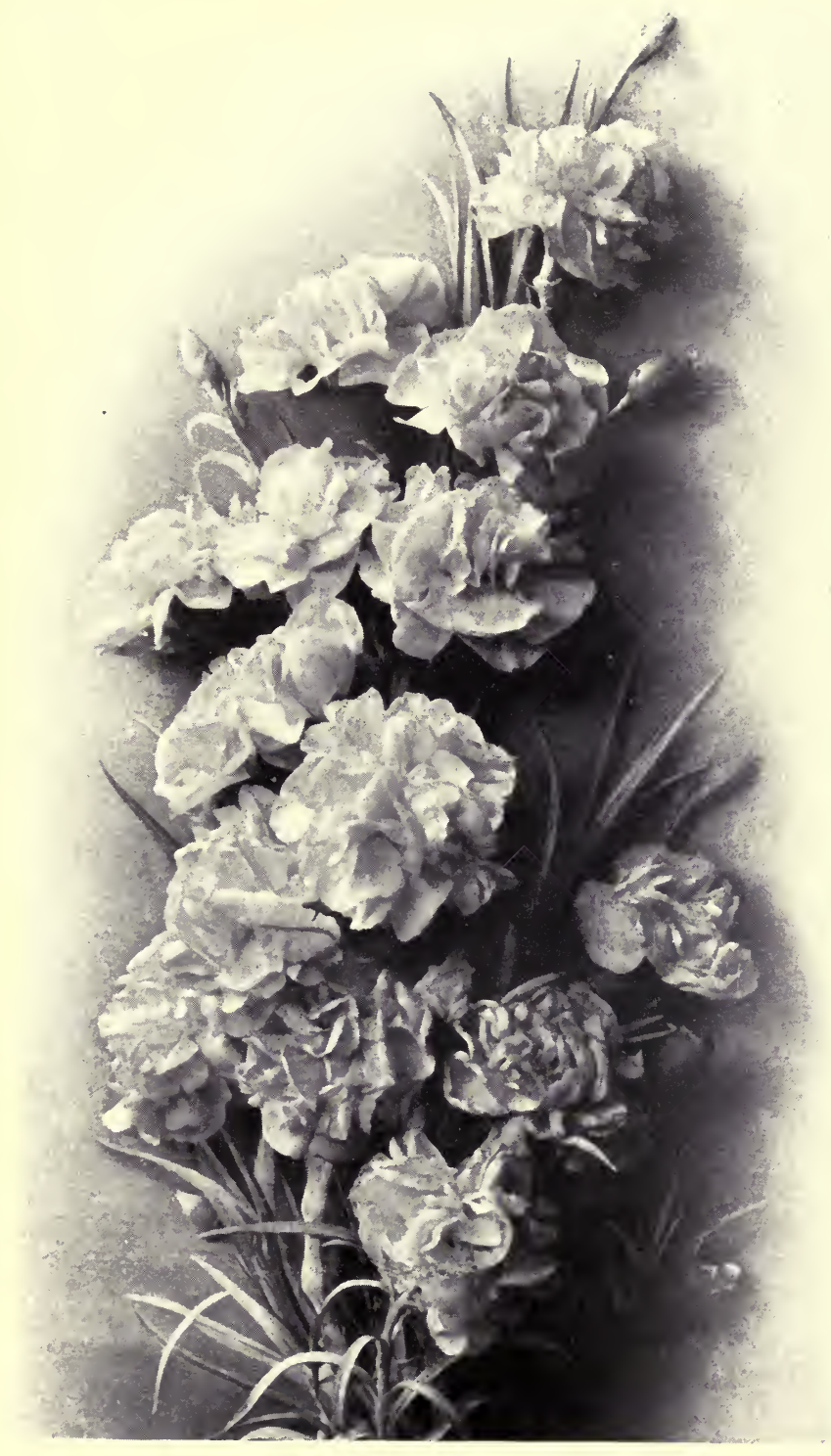

THE YELLOW CARNATION MISS AUDREY CAMPBELL. 


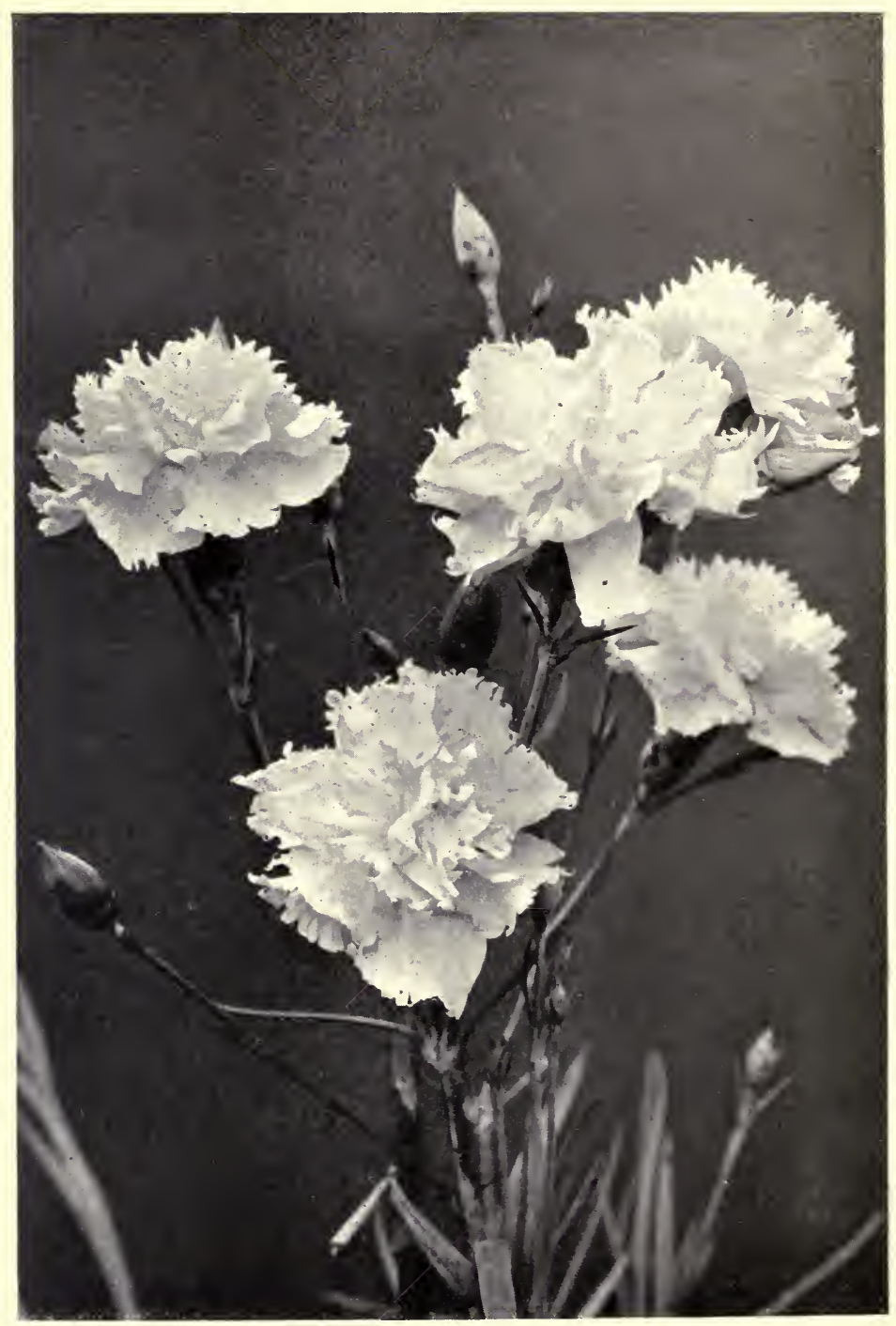

"THE MARGUERITE" CARNATION (SLIGHTLY REDUCED). 


\section{CARNATIONS IN TOWN GARDENS 7I}

nothing else. Some may be supported by means of the green wires already mentioned, and those planted near the edge of the box allowed to droop naturally, or the edging may be of white Pinks.

\section{Marguerite Carnations}

This group of Carnations represents a new race, obtained apparently by crossing an early-flowering type with Dianthus chinensis (the Indian Pink). It is practically an annual, though in a favourable season the plant may reveal something of a biennial character. Certainly they should be in the town garden, as they will begin to flower within six months of sowing the seed, and this is a brief space to wait for flowers so sweet in perfume and rich in colouring. Sow the seed in February and March, pot on the seedlings when this is necessary, and gradually harden them off so that they may be placed out of doors in April or May. The flowers will appear about August. They may be either planted out in the border or kept through the summer in pots. The finest flowers come from pot culture, but of course when growing the plants in this way close attention is needful to watering. If the plants are lifted from the garden borders and brought into a warm greenhouse they will continue to bloom more or less until Christmas, the degree of success depending in a large measure upon the weather and the attention they receive. Weekly applications of guano-water are a great help to their continued flowering. If seed is sown in autumn the 
plants will bloom the following spring; thus by sowing seed in spring for flowers in autumn, sowing seed in April or propagating by layers (border varieties) in July and August for flowers the following summer, and by sowing seed in autumn for blooms for next spring, it is possible to have Carnation flowers almost or quite the whole year.

Mr. A. Hemsley writes as follows of the Marguerite Carnation :-

"This is a very distinct and useful class, but there has been some misconception regarding its origin. In the first place, it certainly appears to be more related to the Indian Pinks (Dianthus chinensis) than to our ordinary Carnations (Dianthus Caryophyllus). This is only a detail, yet it is important to understand that they are far better when treated as annuals; and by sowing seeds at various intervals a succession of flowering plants may be had, if not wanted for seed; as soon as flowering is over, they may be thrown away to make room for others; this is more satisfactory than keeping the old plants over, or trying to propagate from cuttings. Marguerite Carnations have frequently been recommended for cutting, and if cut before the flowers are fully expanded they may last fairly well; but as soon as the anthers burst the flowers are fertilised and the petals die off. I have found this when fertilising ordinary border Carnations. If the flowers go off quickly, good seed-pods may be expected. The variety Miss Joliffe has always failed to seed with me, and in this the flowers last much longer than with any that seed 
freely. The Marguerite Carnations certainly make very good pot plants. If a good strain is secured, the flowers will be quite double for the most part. In a batch of seedlings, some of the straggling flowers (if there are any) may be weeded out when potting on the young plants. The seeds may be sown in January for the earliest batch, and any time onwards to the end of April, and a sowing early in August will give good plants for early spring flowering. The seeds may be sown in good loam with a little sand added. The seeds should be sown thinly, otherwise the seedlings will be liable to damp off. The seed pots should be placed in a light position; if kept moist it will do no harm for the sun to come fully on the pots. They should be potted singly as soon as the seed leaves are well developed. The point is to keep the plants short and sturdy from the start, and for this purpose plenty of light and air is necessary at all times. When potting into larger pots, a liberal addition of manure may be used with the loam and the soil made moderately firm. Liquid manure may be given freely as soon as the flower-buds begin to show. From seed sown in March or April flowering plants may be had in about three months. They give a great variety of colours, some of which are very bright, and they have a pleasant, if not a powerful perfume. There is no other class of Carnations so easy to cultivate, but I would say again that it is a mistake to class them with the ordinary border or winter flowering Carnations, and I know that many have been disappointed to find they cannot 


\section{CARNATIONS AND PINKS}

succeed in keeping the same plants over from year to year. Seeds are produced freely, and by selecting a few of the very best to save the seed from, the strain may be much improved; but to keep them true to colour, the different colours should be isolated, and each fertilised with their own pollen, or with that taken from another of the same shade. Even then there may be considerable variation in the colour of the seedlings; though by persistently fertilising with pollen from the same colour there will be less chance of much variation, and in time the colours may become fixed."

Marguerite Carnations will flower for cutting if the plants are not neglected. Guano or Clay's Manure occasionally sprinkled on the soil is a great help, especially if the ground is poor. It is necessary also to thin out the buds to allow the remaining ones an opportunity of free development. 


\section{CHAPTER IX}

\section{CARNATION GROWING IN AMERICA}

$7 \mathrm{HE}$ following communication is from $\mathrm{Mr}$. Herrington of the Florham Farms, Madison, New Jersey. He is President of the American Carnation Society, and writes with authority on the cultivation of the Carnation in the United States. It is interesting to know the names of the varieties grown in that country, especially in view of the trials made in the British Isles of the much favoured varieties raised or cultivated in America. "The Carnation stands only second to the Rose in extent of culture in America, and without available statistics it may still in truth be asserted that millions are grown annually, some enormous establishments being devoted solely to Carnations. Any one of these has an annual output of flowers running into hundreds of thousands. The varieties are all of American origin, and belong to the tree or perpetual-flowering race. Their progenitors were French varieties of the Alegatiere strain, imported about thirty-five years ago, and from these has been evolved a race of winter-blooming Carnations surpassing anything in Europe. Four years ago I visited some of the great Carnation gardens in the 


\section{CARNATIONS AND PINKS}

South of France, where the culture is extensive and well done, but the varieties are poor, splashed or striped, and wanting in colour, and most of the flowers 'bursters' of the worst description. In those same places it is reasonable to assume our American Carnations should succeed well.

"In England it is doubtful if they will ever show their full beauty and freedom, owing to the absence of sunshine in winter. At the Royal Horticultural Society's Hall in February of last year I saw exhibited there flowers of three of our Carnations, 'Mrs. T. W. Lawson,' 'Maceo,' and 'The Queen,' and it is no exaggeration to say that I would not have recognised them except for their labels, although I grow all three. The flowers shown there would not have been accepted as a gift by even the street flower-sellers of New York. This fact is not mentioned in a derogatory sense, but to show the effects of condition and environment. We can do nothing here with English Malmaisons, nor with the grand outdoor varieties, and similarly our Carnations raised and grown continuously beneath bright winter skies make a sorry display under the adverse conditions of the English climate in winter.

"The varieties favoured here are selfs of clear and distinct colours, from white through shades of pink to rose, red, and dark crimson. They must have good stems from eighteen inches to thirty inches in length, and no toleration is shown to bursters. A variety that bursts its calyx is useless for the cut-flower market. Great improvements have been made in our Carnations 


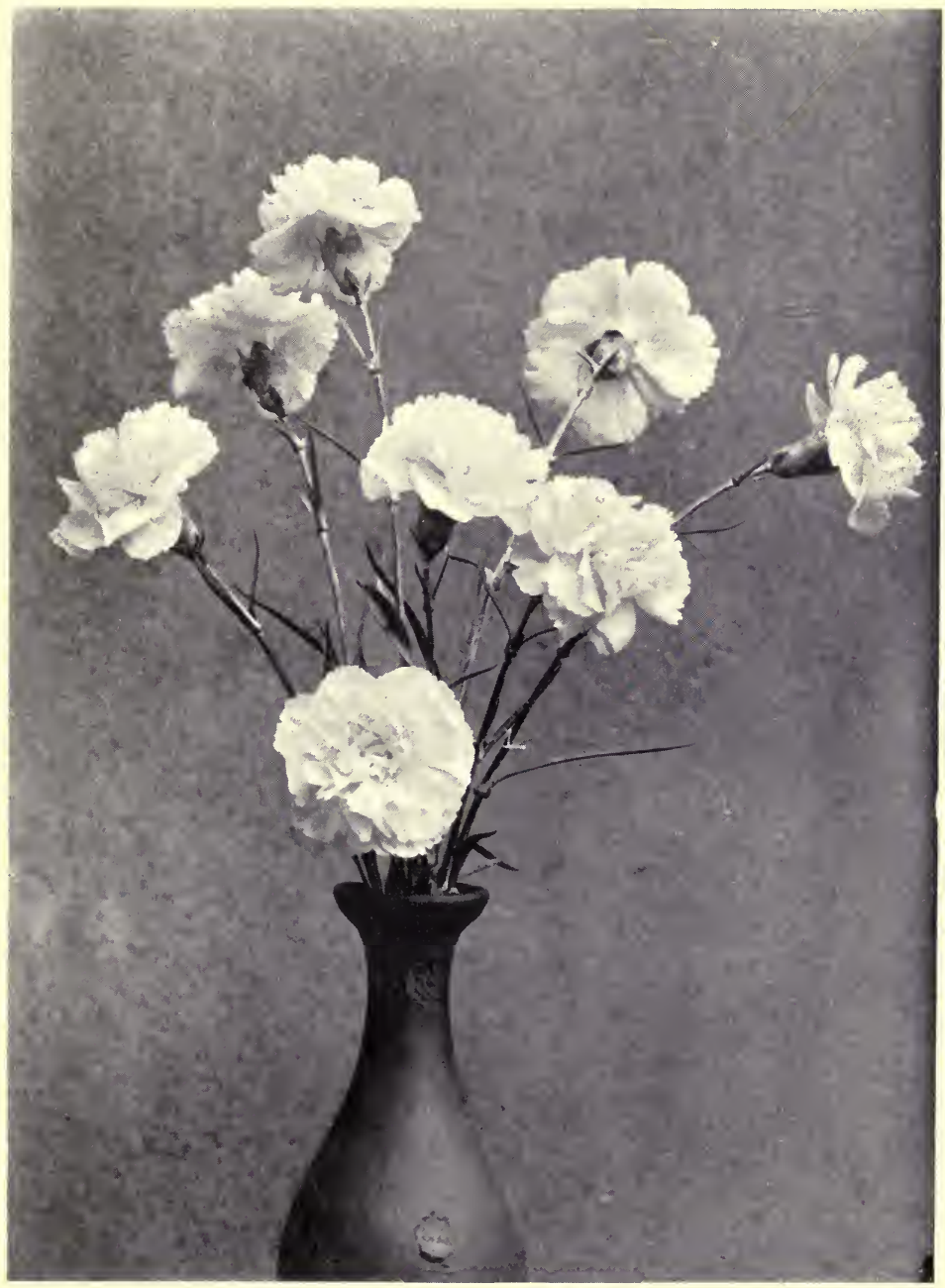

THE NEW AMERICAN CARNATION THE BRIDE (REDUCED). 


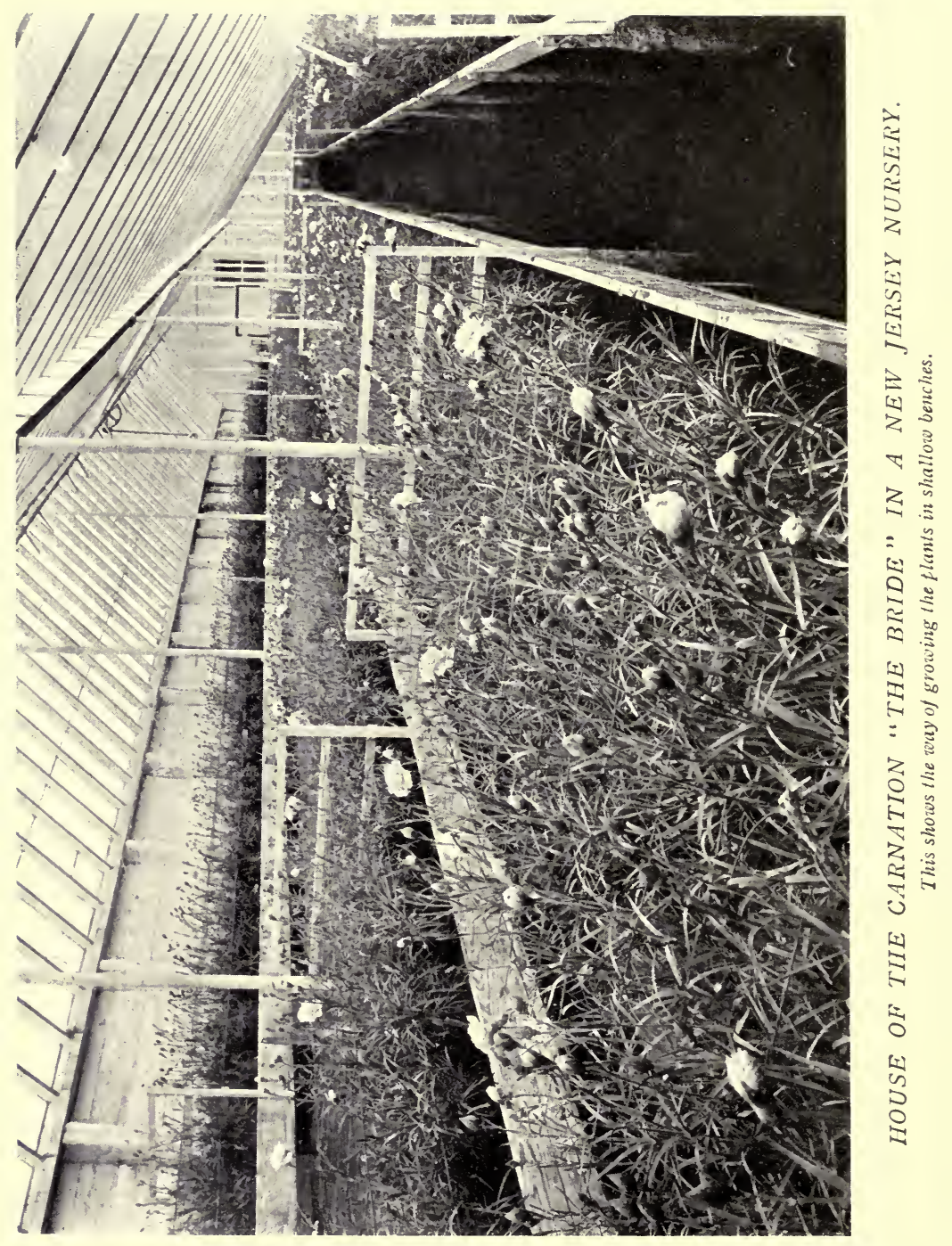


during the past few years, and the popular varieties of to-day are giants in comparison to those of a few years ago. A great deal of this is due to the American Carnation Society, which is admittedly one of the best and most active societies in the States. It meets in February or March of each year in one or other of our large cities, and holds an exhibition on some magnitude. The best testimony to its efficiency is the extent to which raisers seek to secure its certificate of merit by exhibiting their new varieties at its annual meetings. It would be difficult to name a single variety of any prominence that had not official endorsement before its distribution. The scale of points by which they are judged is as follows: Colour, 25 ; size, 20 ; stem, 20 ; form, I5 ; substance, Io ; calyx, 5 ; fragrance, 5 . A variety must score 85 out of a total of roo to secure a certificate.

"The cultural methods are practically the same everywhere, in small private gardens as in the great commercial places, and that is the Carnations are planted out upon the greenhouse bench in $4 \frac{1}{2}$ inches to 5 inches of soil. The young plants are all propagated from cuttings. January and February are the two best months for propagation. Strong young shoots at the base of a flowering stem are chosen and inserted closely in a bed of 4 inches of sharp sand in a propagating house, which is kept at about a temperature of 55 degrees. With ordinary care and attention every cutting roots. In some commercial propagating houses batches of 100,000 cuttings may be seen, out of which not more 
than 2 per cent. have failed. In about a month the cuttings are sufficiently rooted, and are then taken from the sand and planted in light and rich soil in flats and placed in a light and airy house, or planted on the benches. This applies to those growing large numbers, as the grower who has a small quantity would pot them up. They are encouraged to make a sturdy growth in a temperature of $5^{\circ}$ degrees, and gradually hardened off to prepare them for planting out. Early in May they are planted in the open ground in rows, having a space of at least 18 inches between them to admit of hoeing on the surface of the soil. The main shoot is pinched to induce side breaks either before or after planting, as the strength and condition of the plants warrant. A second or third pinching may be given to induce a bushy plant having a number of shoots that will grow up later and flower.

"Whilst the young plants are in the field the houses are prepared for their reception. The old plants that have occupied the benches during the winter are thrown out about the end of June, the benches being thoroughly cleaned, repaired if necessary, and given a good coat of lime-wash. They are then refilled with fresh soil, which is prepared in advance. Those who only require a small stock usually make up a compost heap late in the previous summer, using turf if procurable, and cow manure in proportion of about four of soil to one of manure. Many of the growers with large stocks have no available turf, but take the top soil from their land, and previous to winter give it a heavy 
dressing of stable manure and plough this in. In spring the ground is again manured, usually with bone, and wood ashes are in much favour; or in some cases lime only is used, and the soil is ploughed two or three times during the early summer months, then carted to the houses and wheeled in upon the benches.

"A critical time for the grower is when the plants have to be transplanted from the field to the house. The time varies according to the date at which it is desirable to have flowers, but of late years, and independent of this, growers are planting earlier than formerly. Some begin in July, and the majority now plant in August. The plants are carefully lifted, taken to the house, and planted upon the benches about I foot apart, the distance varying a little either way in accordance with the growth of the variety. Care must be taken not to plant them deeper than they were originally, and as soon as planted they must have a thorough watering. A light shade is given for a few days, a minimum of ventilation, and a moist atmosphere maintained until new growth is apparent, when the shading is gradually removed and additional ventilation is given. When once established they will enjoy all the light and air that can be supplied, with a night temperature of 55 degrees and a rise of ro degrees by day. Several very successful growers are now experimenting with a view to obviate planting in the open ground. They have cleared out their houses at an earlier date, and transferred the young plants direct to newly filled benches. The 
results during the past winter (1904) have been wonderful.

"According to the date of planting, cutting begins. The early flowers are a little short in the stem, but from November until June long-stemmed flowers are in the market in large quantities."

Many American varieties are now grown in English gardens, and the following notes from Mr. A. Hemsley are useful: "Mrs. T. W. Lawson has improved rather than otherwise with those who grow Carnations. Ethel Crocker, which I grew from newly imported stock, did not come good at first, but later on we had fine blooms. Royalty appears to be identical with the above. Adonis and Flamingo are the best scarlets, and of the deeper shades of pink, I think Floriana is one of the best; the flowers are larger and very sweet scented. Enchantress is certainly one of the best. Alpine Glow is another good blush pink. Melba is an older variety, especially for early spring flowering. The deep crimsons are plentiful; it is difficult to select the best. The President, Governor Roosevelt, and Harry Fenn are good. Harlowarden and General Maceo are also good. Of pure white varieties, Norway, Lilian Bond, Lady Bountiful, and the White Lawson are well spoken of. Fiancée, pink, is good." 


\section{CHAPTER X}

\section{DISEASES OF THE CARNATION}

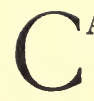

ARNATIONS, Picotees, and Pinks are not without their enemies, but in this they suffer with plants in general, and therefore can command no special sympathy. While the plants disappear wholesale, a mysterious dying away at the point of reaching their ripest beauty, the thought occurs how foolish it is to waste twelve months for the fruition of one's work, and at the moment of realisation it is destroyed. Many pests attack the Dianthus group, and unfortunately with the greatest virulence. The grower is sometimes responsible for regrettable mishaps. The plants are barely grown, or over-manured in the desire to reap a reward of abnormal flowering. There is, however, this fact to remember, that no plant can retain healthy vigour and flower abundantly unless it is closely watched that nothing preys upon its leaves or its roots.

\section{Carnations Dying OFF}

A few years ago there was a considerable correspondence in The Garden as to why Carnations die off suddenly, and the question asked is as 
follows: "I am writing to ask if you could tell why border Carnations are so liable to collapse at this time of year. Towards the end of July and the beginning of August I have them layered, and every autumn I have a first-rate lot of layers (rooted). As soon as they are fit I have them detached from the parent plant, and plant them out on a piece of ground that has been well dug, with a fine dressing of well-decayed manure and a liberal sprinkling of lime, and as a rule these go on satisfactorily until spring, when the trouble begins. They keep going off, and the remaining plants look very sickly. I ought perhaps to have said that the piece of ground they are planted in is an old strawberry bed." We sent this letter to Mr. James Douglas, the well-known Carnation grower at Great Bookham, and his reply was: "This frequently occurs when the plants are in full growth, and it happens to those in flower-pots as well as those in the open border. I had a sad experience with it a few years ago. The man who had charge of my Carnations had a liking for artificial manure, and applied it so freely that the growth of some of the Malmaisons was extraordinary. This vigour was the cause of much congratulation until the growths were almost ready to be layered, when to our disgust plant after plant died off ; some died even after layering, before the layers were rooted. From that time I have dropped the use of artificial manure for my Carnations. I get better layers, and there are few deaths-perhaps one in a hundred. The same thing happens to Carnations outdoors when the arti- 


\section{DISEASES OF THE CARNATION 83}

ficial manure is used, or if farmyard manure comes into contact with the roots. Carnations like rich soil to grow in, for good flowers cannot be expected from plants in poor ground. I advise trenching the ground for Carnations to a depth of, say, eighteen inches or two feet. A layer of manure is placed on the bottom of the trench, and another layer six inches to nine inches below the surface. The roots will soon reach the first layer, even at nine inches, and it is not injurious at this distance. Your correspondent complains that his plants die off after being planted on well-dug ground dressed with well-decayed manure. If the ground has been merely dug the manure will be in direct contact with the roots at the time of planting, but when the plants are put out immediately after digging that is not so satisfactory, as the ground should be exposed to the air for a month or six weeks. It is also a mistake to give a good sprinkling of lime with the manure. Mortar rubbish is excellent if dug into heavy soils. Double digging or trenching of the ground is advisable, so the manure should be put at least six inches below the surface. This should be done some time before planting to well expose the ground to the action of the atmosphere. Omit the lime; also an exchange of stock is needful. If the same stock is grown year after year in the garden the plants degenerate." Mr. W. J. Godfrey, of Exmouth, also places great stress on the necessity of a change of soil. In his case "no fresh manure is ever applied, but when forking between the plants in April, and moving the soil again in May, a good 


\section{CARNATIONS AND PINKS}

sprinkling of mature guano is given, which seems to have a desirable effect. Constitution, however, has much to do with the success of border varieties. Scores of new varieties are introduced every season, a large number of which have been certificated by the National Carnation and Royal Horticultural Societies. The majority of these sorts are quite useless to the garden, that is, to stand our mildest winters and produce fair blooms in the open beds or borders." The general opinion is, that the mysterious dying of the Carnation is due to the weakly stock and an over-rich soil. One contributor to the discussion suggested much the same cause, namely, killing of the plants by over-kindness. "Is it not possible that we kill our Carnations by over-kindness in giving them a too strong soil to grow in? I have never seen finer flowers than those in a small sunbaked Jersey garden where the soil was almost pure sand. We are told not to put strong manure close to the roots, but from my experience I find the plants do best in maiden loam without any manure at all."

GREEN-FLY is very troublesome, and inflicts more damage than anything else. Plants outdoors are not so ready a prey as those under glass. The best way to destroy these is by fumigation, but if this is not possible, dip them in a solution of soft soapy water. A large collection can be kept quite clear by fumigating at intervals. Prevention is certainly better than cure. The

SPITTLE-FLY will also cripple Carnations, but this is so easily detected that only carelessness on the part 


\section{DISEASES OF THE CARNATION 85}

of the grower is responsible for its presence. The spittle-fly is so named for the froth or spittle which it exudes. Remove this and the insect, which resembles a large green-fly, will be found inside. A little water should be used to wash off the effects of the spittle.

CARNATION MAGgOT.-This is the larvæ of a fly known as Hylemyia nigrescens. It bears a great resemblance to the common house fly, but is not a pest to trifle with, although it is insignificant and apparently harmless. Few of the enemies of the Carnation are capable of greater mischief, and it is the plants in the borders that suffer most severely, especially seedlings and layers, but layers under glass escape. The flies may be seen busy among the plants in April and later. They deposit their eggs at the base of the leaves, and a small maggot is hatched out which eats its way down the leaves into the very heart of the plant; it works its way down the leaf under the membrane, a whitish line showing the path it has taken. If this tract is followed the maggot may be captured, and if its presence in the centre of the plant is discovered, pick out the pest with a needle and destroy it. It may be found in the form of a small white maggot or in the chrysalis state, when it is of a brown colour. The centre leaves are often quite eaten through at the base, and when pulled out there is the chrysalis or maggot. The Carnation is generally killed, but destroy the maggot at all cost, as the chrysalis may speedily develop another fly, which in its turn may be the parent of a fresh brood 


\section{6}

CARNATIONS AND PINKS

of maggots, to work destruction in autumn and winter. There is no other way of dealing with the Carnation maggot except by hunting it out in the way suggested. The grubs are about one-eighth inch in length, legless, and white with dark heads. The

EARWIG (Forficula auricularia) will sometimes do much damage. It makes a snug retreat inside the calyx of the flower, where both shelter and food are available. This familiar garden pest, a bugbear to the Dahlia grower, and an annoyance to all who garden, does not touch the root or leaf of the Carnation, but eats through the petals at the base inside the calyx, and one knows it is at work by the petals falling out. Nothing in the work of the garden is more annoying than to find the flower beauty destroyed before it is possible to save them, but careful scrutiny of the plants from the first will prevent much disappointment. Bean stalks placed between the flower stem and its support form a hiding-place for the earwigs, and hundreds may be trapped in this way. This is the general plan adopted for getting rid of these pests on Dahlias. The

EELWORM is not common, for which the Carnation grower may well be thankful. Its presence may be known by the crippled appearance of the plants, leaves not half their usual length, and a much swollen and whitish base. These are the result of small nematoid worms inside the leaves, and sometimes one or two layers are attacked, the pest leaving the others alone. The only way to get rid of these worms is by removing the affected layers bodily and 


\section{DISEASES OF THE CARNATION 87}

burning them. Mr. G. S. Saunders writing in the "Century Book of Gardening," p. 495, thus describes the eelworm: "The Stem Eelworm (Tylenchus devastatrix) has only lately come into notice, but this is due to a considerable extent, I expect, to their minute size, for they are quite invisible to the naked eye when among the tissues of the plants they are attacking, though they may be detected with the aid of a strong magnifying glass. A large number of different kinds of plants are known to be infested by them, even those of such diverse natures as Clover, Hops, Carnations, various corn crops and bulbs, so that most things are probably liable to be infested. This eelworm is about $\frac{1}{25}$ inch in length, very long and narrow, being only $\frac{1}{1000}$ inches in diameter, and tapers gradually to a fine point both at the head and tail. When under a microscope with a low power it looks like a thread of clear glass. As these creatures live and breed in the tissues of the plants it is impossible to reach them with any insecticide, so that practically the only way of destroying them is by pulling up the plant and burning it, or, at any rate, cutting off the infected parts and burning them. This, with such plants as hyacinths and onions, or where the main stem of a plant is infested, is impossible. A good dressing of suitable manure will, of course, greatly help a plant that is attacked; the vitality of these worms is astonishing, and they have been known to revive after having been dried up for more than two years. They will pass quite unhurt through the body of an animal that has been fed on an infested crop, so 
that it is most unwise to use manure from animals that have been fed with anything the eelworm has attacked."

WIREWORM is one of the most deadly enemies of the Carnation. It is found in the soil, as the eelworm is, and works under ground. It is the larva of certain beetles belonging to the family Elateridæ, which are known under the popular names of skip-jack, snap beetle, and click beetle. The wireworm is well known; the grubs vary somewhat in size, according to the kind, but the largest species is hardly more than $\frac{3}{4}$ inch in length and $\frac{1}{8}$ inch in diameter; they are of a yellowish colour, with brown heads and legs; the latter are yellow, and placed near the head. The click beetles are long and narrow insects, of a dull brown, grey, or yellowish-brown colour as a rule, but some are more brightly coloured. Wireworm is seldom found in ground that has been cultivated for a number of years. It infests pasture land, where the beetles congregate and deposit their eggs, the larve living on the roots until they pass through the usual transformations to the beetle stage. All sorts of remedies have been suggested for their destruction. They may be destroyed wholesale by trapping, but Mr. Douglas writes: "There is no way known to me whereby they may be annihilated." Carrots are the best traps, or, failing these, potatoes will answer. Thick slices of carrot or potato are stuck upon the end of sticks and buried under the ground where the wireworms are to the depth of from three inches to six inches. After a week or so examine them, and the 


\section{DISEASES OF THE CARNATION 89}

wireworms will be found half buried in the tubers or the carrots. Hundreds may be killed in this way.

DADDY-LONG-LEGS OR CRANEFLY.-This insect is quite innocent in the daddy-long-legs stage, but it must not be forgotten that as a grub few pests of the garden are more destructive; it has a voracious appetite, and is generally found browsing on the plants at night. Its eats the leaves and sometimes gouges out the centre. In the daytime it burrows underground, or, if overgorged with the leaves of choice Carnations, will be found at the base of the plants, when it must be caught and destroyed. These grubs are generally called "leather-jackets," on account of the toughness of their skins. This peculiarity prevents insecticides from having much effect on them, and they seem to be indifferent to drought or moisture, and may be frozen until they are quite stiff without being killed. When the grubs are underground no insecticide can be made of sufficient strength to kill them, but a heavy watering with liquid manure, such as a solution of guano, nitrate of soda, or common salt, has been found very useful. It is disagreeable to the grubs, and is of assistance to the plants. The grubs may be trapped with slices of carrot, turnip, and mangold, into each of which a small wooden skewer should be thrust. They should then be buried about one inch below the surface, the skewer being placed uppermost, to show the position of the bait. Leather-jackets are very fond of roving about at night, and if bricks, boards, tiles, slates, or pieces of turf are laid near their haunts and turned over in the morning, these grubs will 
often be found hidden underneath. The other traps should also be examined every morning.

THRIPS (Tliripsadonidum and other species).-This is a well-known enemy to the garden, and if not destroyed quickly spoils the flower. These insects are very small, none of the English species being more than $\frac{1}{10}$ inch in length; when the insects are mature they are furnished with two pairs of very narrow and fringed wings, which remain folded over their backs during the period of rest. The injury to the plants consists in the insect sucking out the juices of the leaves by means of a short proboscis. Their droppings, which are glutinous in nature, clog the pores of the leaves and prevent their proper functions from being fulfilled. The thrip must be destroyed in its early stages. Those who grow choice Carnation flowers for exhibition place the plants outdoors, and when the buds are well developed-even before the colouring of the flower is revealed-the thrips get inside, and the rich colours-crimson, rose, scarlet, and other shades-become streaked and blotched with white, which in the flakes and bizarres is a dirty colour, like the dust on the road. Syringing is of assistance in keeping the pests off, but there is a danger of the flowers suffering damage. Mr. Douglas writes: "The best way is to get them into the greenhouse and fumigate with tobacco smoke. By shaking the flowers over the hand the lively little insects may be seen leaping about. A second fumigation is sometimes needful.

RED SPIDER (Tetranychus tellarius) is a troublesome 


\section{DISEASES OF THE CARNATION 9I}

enemy to the Carnation when it is grown under glass. Its presence is detected by the leaves turning to a sickly greenish-yellow colour, which means that they soon lose their vigour. The insect is very small, almost microscopical, and the best way is to syringe the leaves well before much damage has taken place. It appears on the undersides of the leaves first, but soon swarms over them.

\section{Fungoid Diseases}

One of the most formidable of these is called RUST, the proper name of which is Helminthosporium echinulatum. Mr. Douglas writes me: "The appearance of the fungus when it is first seen on the leaves is something like a blister. This is caused by the development of the fungus between the membranes of the leaves. Presently it will burst through the membrane, and the coffee-coloured spores are widely scattered. Now it is evident that no application of any fungus-destroying mixture can reach it before it bursts out, and after the powder is scattered it is too late. The only real remedy is to look over the plants at least once a week, cut off all diseased leaves carefully, and burn them at once." Mr. Saunders writing of Carnations and the fungi which attack them, says: "The leaves of these favourite flowers are liable to the attacks of two or three different kinds of fungi. Cutting off the diseased leaves and spraying the plants afterwards with Bordeaux mixture of sulphide of potassium every ten days until there is no more sign 
of the fungus is the best cure. Care should also be taken that the proper amount of water is given to the plants." It is necessary to be very careful that the fungicides are of the proper strength. Bordeaux mixture.-Dissolve IIOz of sulphate of copper in a little boiling water and add five gallons of water; slake 602 of lime in some water, when it is cool pour it into the solution of copper, and stir well together. To test the mixture so as to be quite sure it will not injure the foliage, hold the blade of a bright knife in it for a minute; if the blade is unchanged it is all right, but if the steel shows signs of a deposit of copper, some lime must be added. Sulphide of Potassium.-Dissolve I02 of sulphide of potassium (liver of sulphur) in a quart of hot water, and dilute it with $2 \frac{1}{2}$ gallons of water.

SPOT.-The name of this disease is Uredo dianth, and it is unfortunately very common, plants both in frames and outdoors suffering severely, but when kept in a well-ventilated greenhouse they are not attacked. When badly diseased, recovery is possible if the plants are placed in the airy part of a greenhouse. Cut off all diseased leaves, and in time the plants will throw off the affection. This does not occur in the case of rust.

BActeriosis.-Mr. Douglas writes : "This disease seems to have been imported from America." Mr. C. W. Ward in his book on the Carnation says: "The disease shows readily upon leaves recently attacked in the form of translucent dots in otherwise healthy foliage. Later on the dots enlarge and run 


\section{DISEASES OF THE CARNATION 93}

together, and the leaf finally turns yellow and dries up. Recent observations of this disease seem to have determined that it is caused by the attacks of various insects, such as red spider, thrips, \&c., and wherever the plants are kept free from these insects the bacterial disease does not seem to develop." "I advise all amateurs who would excel in the culture of Carnations to keep the plants in a healthy, vigorous condition by giving them an abundance of light and air. See that they are kept clean; avoid over-feeding, and, in the case of winter-flowering Carnations, a high, moist atmosphere also. A rather dry, buoyant air is best, with a minimum temperature of about $50^{\circ}$ to $55^{\circ}$. Water carefully, and let there be a free outlet for the moisture."

SPARROwS are a nuisance in early spring, and inflict much damage by pecking off the young foliage. If, however, the plants have been well dusted over with soot after rain they will not touch them.

HARES AND RABBITS.-These are the most destructive of all in winter and early spring, and must be kept out with wire netting. Soot is helpful, but is not reliable. A single hare or rabbit will clear a bed in hard weather in a night or two, and they are sure to begin with the most treasured plants.

GouT.-If the plants show signs of gout-which is the swelling and bursting of the stem near the ground - pull them up and burn. If it attacks a plant of a variety of which there is only a small stock, save some of the growths to make cuttings of if they are healthy. 


\section{CHAPTER XI}

\section{THE PINK}

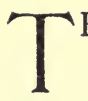

HE sweetest flower in early summer days is the white Pink; its bluish leaves are wrapped in a mantle of white, and a delicious fragrance scents the wind. Those drifts of blossom recall the garden of the cottager and of the squire, and however many new forms may arise, the old fringed white will never be forgotten. First of its race to come in the summer, of delicious fragrance, and with that simple charm that makes some of our garden flowers individually lovable, it will ever be one of the most welcome. It is also one of the best of plants for an edging, not only in summer bloom, but in the depth of winter, when its leaves are in finest colour. Half a century ago the garden Pink was one of the most popular of florists' flowers, and in my early gardening days I was acquainted with many Pink fanciers. The two most prominent were the late Mr. Charles Turner, of Slough, and the late Mr. John Keynes, of Salisbury. Mr. Keynes was better known as a Dahlia grower in the days when single-flowered Dahlias, if they appeared amongst the seedlings, were thrown on the rubbish heap ; Cactus and Pompon varieties were not in existence in those days. I remember Mr. Keynes 


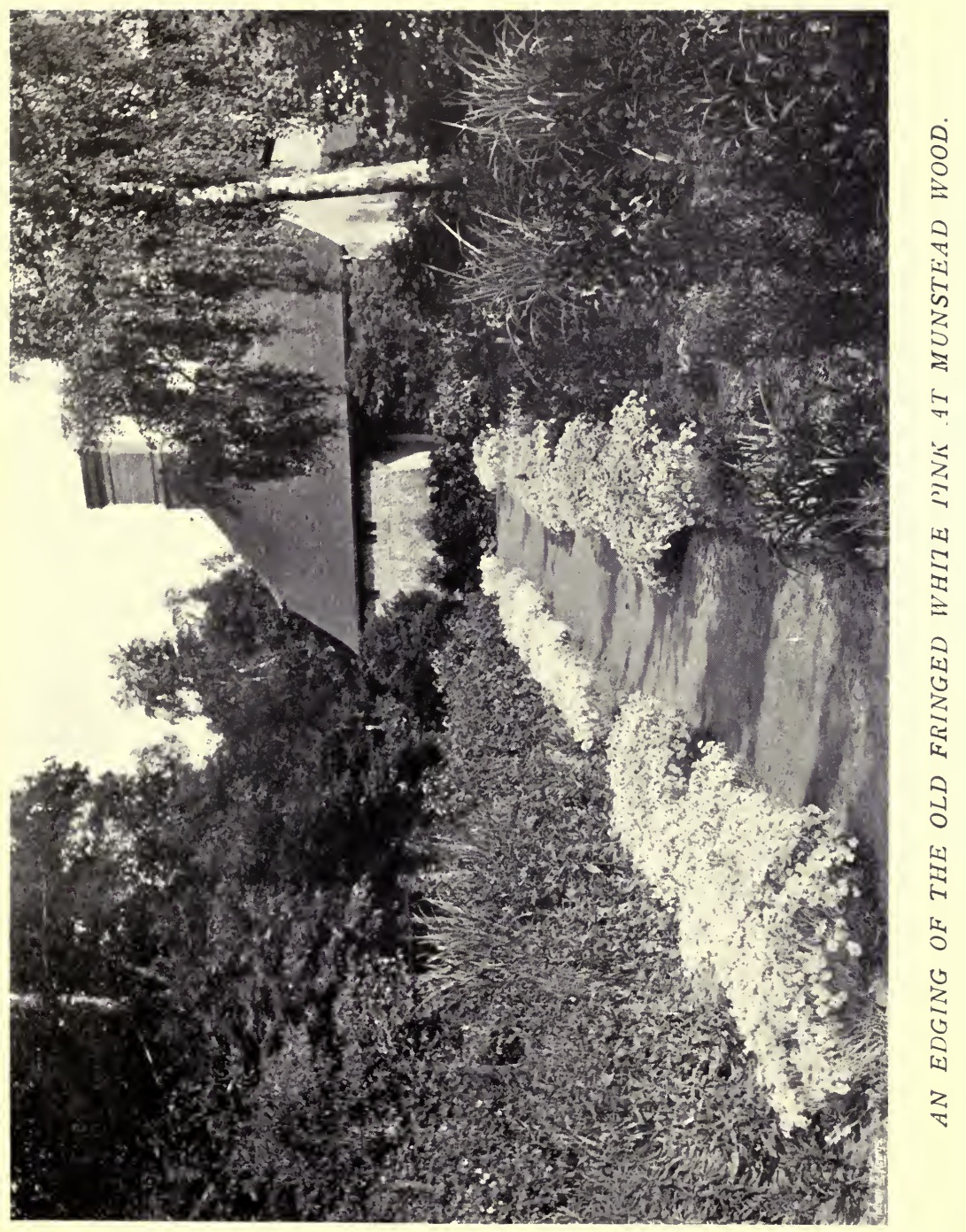




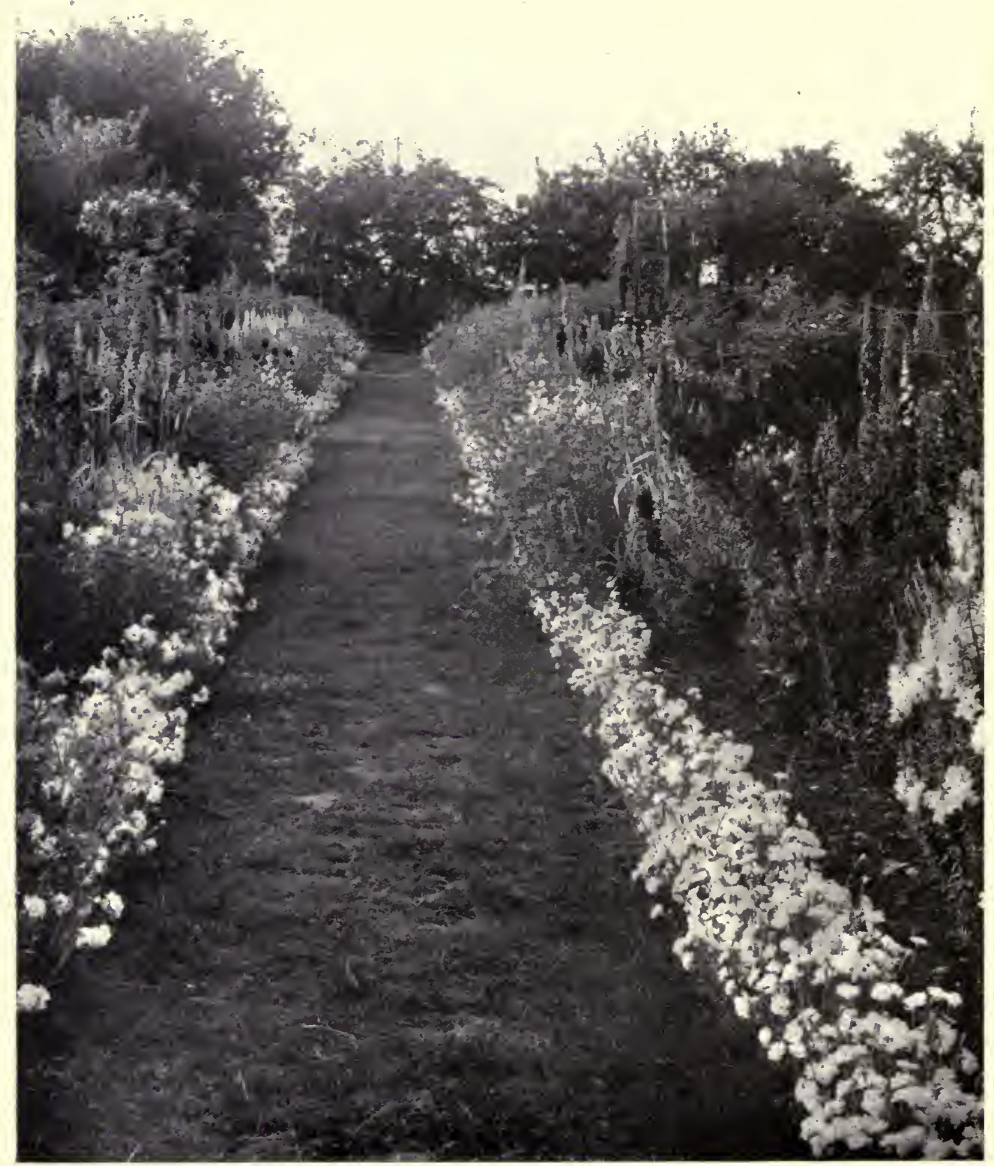

BORDERING OF DOUBLE PINK TO MIXED BORDER. 
stating at one of our meetings that he had known six Pink shows to be held in Salisbury in one year. There were many raisers of Pinks in those days, and nothing was thought of any value that was not perfectly laced. When Thomas Hogg of Paddington published his sixth edition of "Florists' Flowers" in 1839, he wrote a long article on the culture of the Pink. He was a celebrated florist in his time, but he states that "I am neither gardener nor florist professionally, but that I commenced the cultivation of flowers, in the first instance, with a view to amuse a depressed state of mind, and reinvigorate a still more sickly state of body." He was entirely successful, as the fine blooms he produced and the excellent papers he wrote on his favourite flowers abundantly testify. Hogg gives a list of $\mathrm{I}_{54}$ varieties, after discarding the names of many old ones. These 154 varieties have the raisers' names attached, and these number ninety-five. Think of it ! - ninety-five florists, all in friendly rivalry in endeavouring to improve the garden Pink, and all working to obtain one distinct form of it. This precious object had a pure white ground, a pink, red, or dark red centre, with a lacing near the margin of each petal of a similar colour. The old florists were most exacting in their tastes, and rigidly excluded all others. I raise a few hundreds of seedlings annually, and there may be three or four, or perhaps if I am fortunate, half-a-dozen, of these laced varieties. Amongst the remaining hundreds there may be twenty or more that have reverted to the single form, many more semi-double, and a great many very beautiful 
as garden flowers. The seedlings flower so profusely that I have had three hundred or more blooms on a single plant.

\section{Sowing SEed}

To get strong plants sow the seed in gentle warmth in February or early in March. The seedlings appear in a week or so, and should be pricked out in boxes, and gradually accustomed to the open air. Plant them out in beds of rich soil about the last week in May or early in June. They are not expected to bloom until the year after sowing the seed, and a selection can be made from them to be propagated and flowered the following season. There are no Pink shows, and the special Natural Pink Society has disappeared. In 1839 there were ninety-five raisers of Pinks known to us; there were six shows of Pinks in one town in one year. The Auricula, the Rose, the Carnation, the Dahlia, and the Chrysanthemum hold high festival through their special societies, but there seems no room for the Pink. I do not regret this, for it would be dragged from its quiet nook, where it is tended by loving hands. Choice specimens are culled and placed in glass vases or delicate china ones, and the perfume is always delicious. Carnations are sometimes sadly scentless, but never a Pink. For perfume the Carnation is not in it as compared to the Pink, and the latter is the more easily grown, preferring the open air to an atmosphere under glass. I have grown the Pink since I could cultivate anything, and would sadly miss a bed of the fragrant 



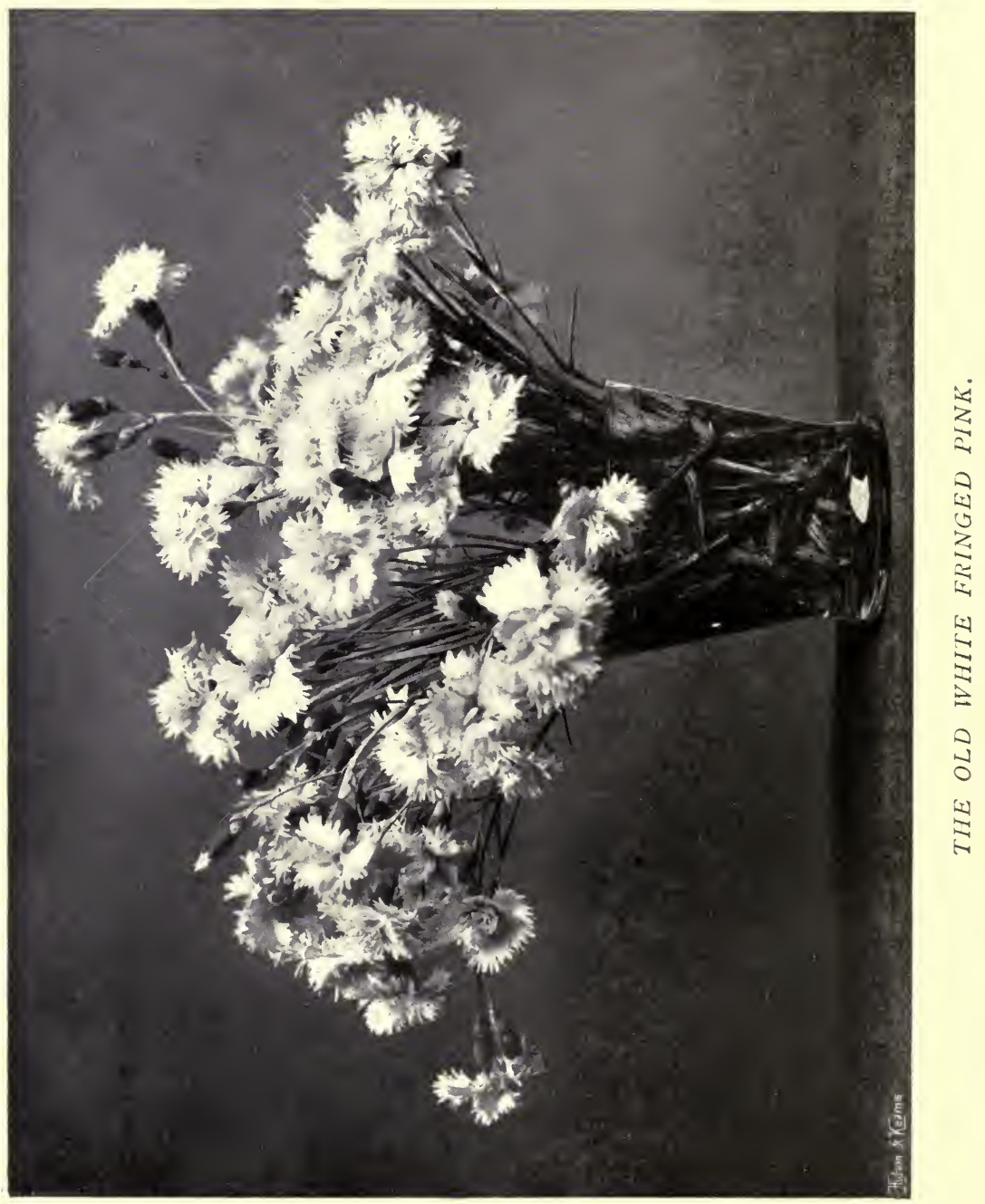


flowers. No glass-houses, frames, or even hand-lights are necessary; they can be propagated either by pipings or layers, and this can be done a month earlier than the Carnations can be layered.

\section{Propagation by Layers and Pipings}

"I believe, on the whole, it is better to propagate the plants from layers. If from slips or pipings," these can be taken off in June, and they will form roots in a shady place outdoors, or, what is better, a hand-light. They will soon root, and may be planted out in beds of rich and deep soil in September or October; if in the bed in which they are to flower, put them about twelve inches apart, but it is better to plant the layers or pipings about four inches asunder until they have formed plenty of roots and gathered strength. Such plants may be put out in the open garden where they are to flower in October. The treatment they require is much the same as that for Carnations, except that they may be planted much closer together. Some attention is required during winter; the ground must be kept free from weeds, and the surface lightly stirred occasionally.

\section{General Treatment}

If rabbits or hares are troublesome, almost the first plants to be attacked will be the Pinks and Carnations. Slugs and the leather-coated grub will also eat the leaves, and sadly disfigure the plants. Wireworms are also destructive. The leather-coated grub also 


\section{CARNATIONS AND PINKS}

burrows in the soil, but unlike the wireworm, which eats into the stem underground, it devours the leaves; sometimes, owing to over-feeding, it will remain at the base of the plant. When the Pinks have made some growth in April, it is wise to give a surface dressing with decayed stable manure, and when dry weather sets in water copiously once or twice a week. The quantity of water required, and the frequency of applying it, will depend greatly on the nature of the soil. If the soil is heavy, and water does not pass away quickly, it might not be often required, or even not at all. On a light soil, over gravel, the maximum quantity of water may be needful. Neat sticks should be used to keep the flowers from the ground. Very little gardening skill is required to grow Pinks.

All that is necessary is good garden soil, well dug up before planting, and the ground between the Pinks should be kept free from weeds. Layering may be accomplished when the plants are in flower, or after their beauty is over. The slips are also exactly right to take off when the plants are in flower. In dry seasons seed may be saved from plants in the open garden, but in wet and cold weather it will not ripen even in the south of England. I cultivated the Pink for many years in Scotland, but was never able to save seed there. The capsules should be dried, gathered, and the seed taken out two weeks afterwards. I may add that one of the Pinks often inquired about is the Mule Pink. One of the earliest, if not the earliest, hybrids raised in England was a Mule Pink. We are indebted for it to an amateur of 
Hoxton, a Mr. Fairchild. This must have been raised about the middle of the seventeenth century or earlier, as Fairchild died in 1667. I believe this worthy man must have instituted the first flower service, as he left a sum of money to the preacher of his parish that he might hold this celebration annually. I have been asked if this Mule Pink is still in existence. I do not know, but I doubt it. I grow a sort named Napoleon III., which is evidently a cross between a Sweet William and a Pink, as Fairchild's also was.

\section{Perpetual-Flowering Pinks}

This is a group which has sprung into existence through the efforts of Mr. Ladhams, of the Shirley Nurseries, near Southampton, and I asked him to tell me something about his varieties. The answer is as follows: "My new race of this charming family is the result of many years' persistent hybridising and selection. At some time or another almost all the different species of Dianthus which gave promise of proving good parents have been used in the work, but of course, when once the desired object was attained, these were largely discontinued. The old Mule Pinks, having strong green leaves, have had a marked effect in creating vigour and freedom of growth, forming, as it were, a groundwork for further improvements. Mrs. Sinkins, as a seed-bearer, was also brought in later, giving size of bloom. The race as it is at present produces stouter flower-stems, freer growth, and more refined flowers than the older border Pinks. 


\section{IOO CARNATIONS AND PINKS}

Quite the most recent of our introductions have, in addition, purer colours. The variety Florence would rival a Carnation in its exquisite form; Marion has very large flowers on strong spikes-as many as a dozen branching buds are found on each growth; Mrs. Monland has a chaste, well-formed flower, clear pink in colour, with chocolate centre, and five or six flowers are often out on a single spike at one time; and Ethel is a variety of graceful growth, the full refined flowers being white, delicately marked with pale purple, and showing no signs of splitting. A few others are also in commerce, and we are selecting and eliminating amongst many other seedlings of several years' proving. We find that plants on stony land enriched with decayed manure are more perennial and the colours are brighter. Of course they are at a disadvantage during excessive drought, and as two acres are grown, we do not pretend to water them, but they recover as soon as rain falls or the cool nights begin, and flower more abundantly for the rest they have taken. Layering as one does the Carnation is the only safe way of increasing stock; but of course they need not be lifted as Carnations are for the sake of protection, as this is quite unnecessary."-E. T. C.

\section{Choosing Garden Pinks}

There is a great deal more to be done in the way of raising useful garden Pinks. They hybridise so freely, and come so well from seed, that it is a matter for 


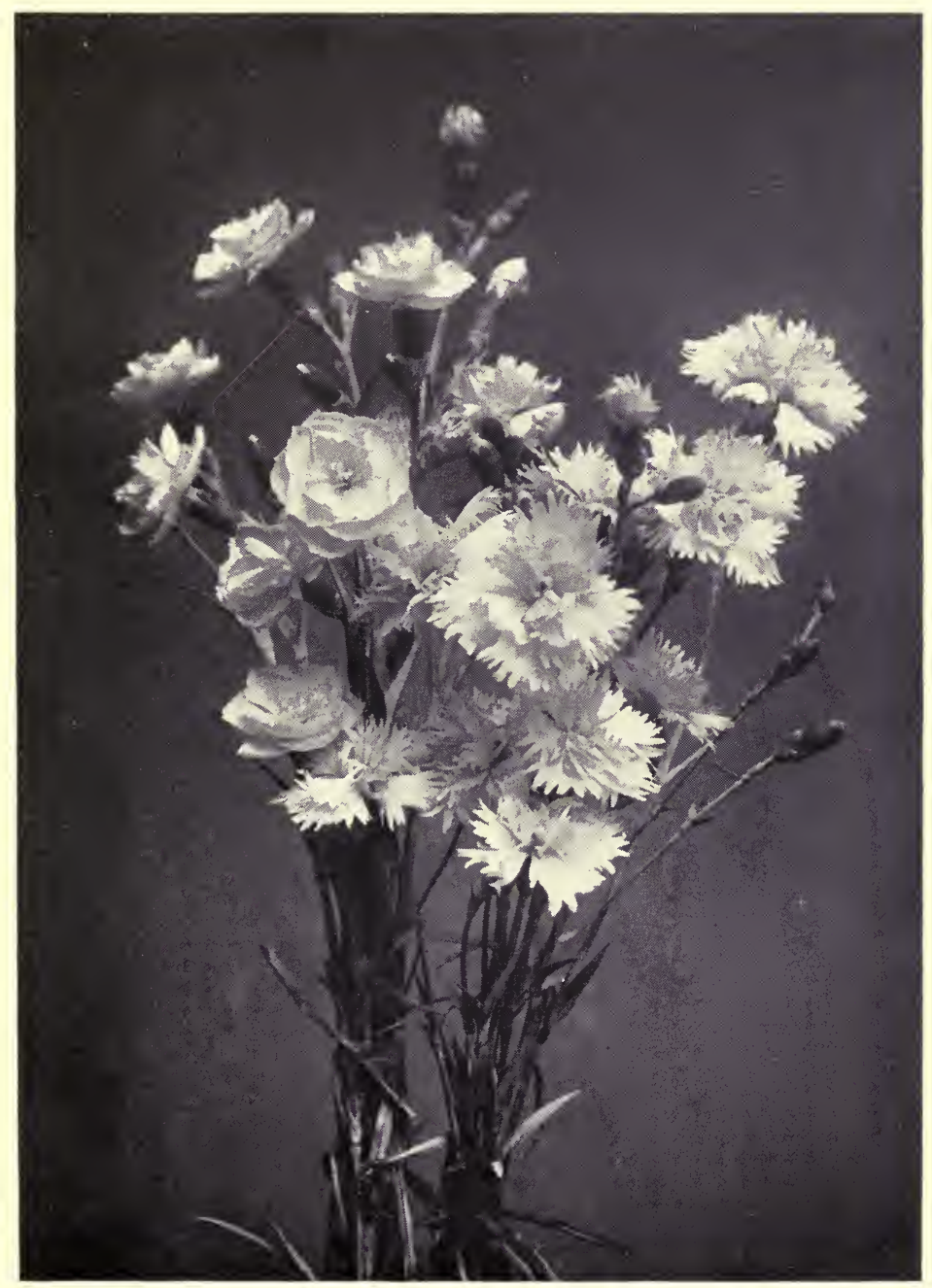

OLD FRINGED WHITE AND SMOOTHED PETALLED PINK. 


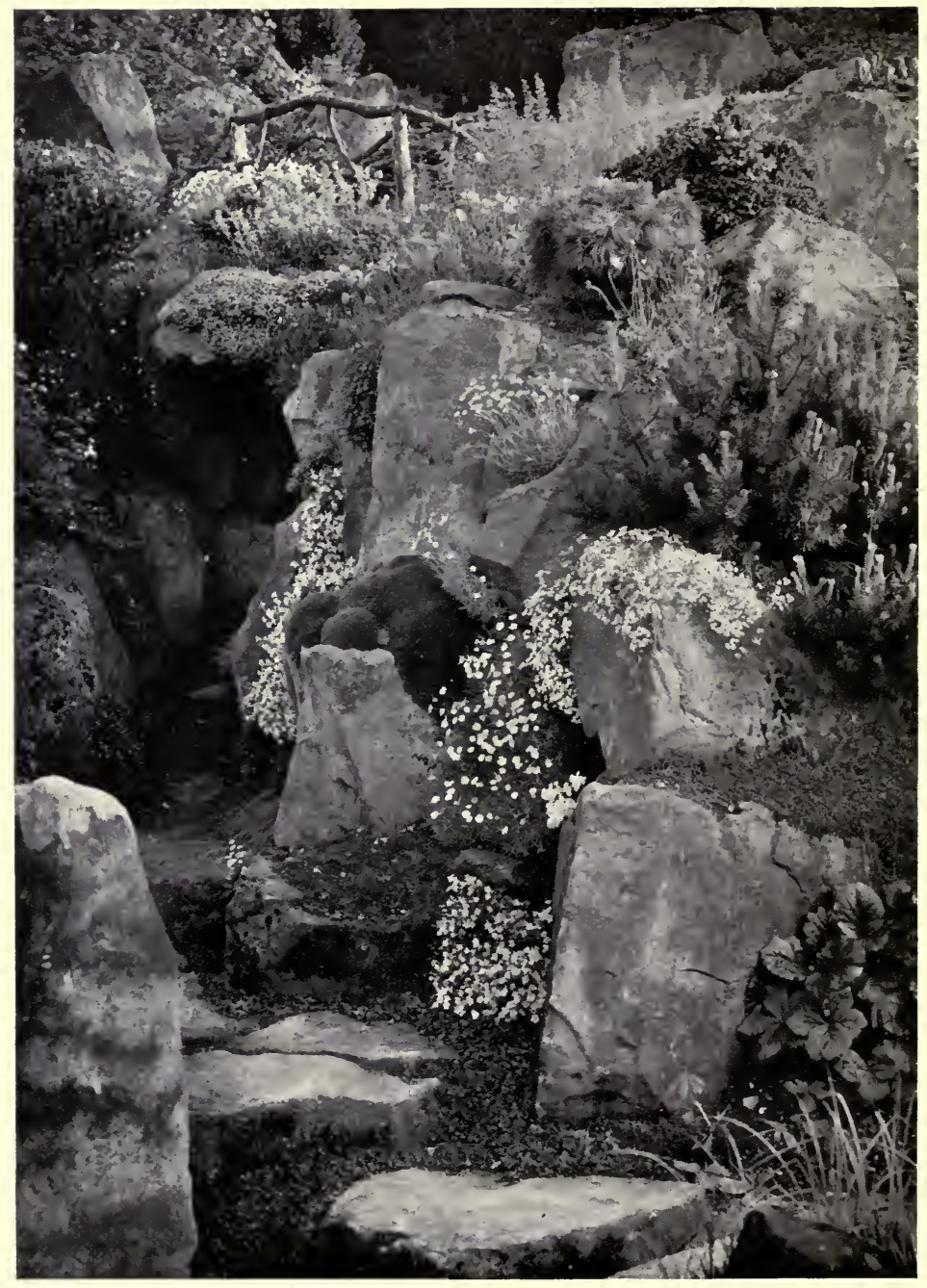

TUFTS OF THE WILD PINKS IN THE ROCK GARDEN, FRIAR'S PARK, HENLEY-ON-THAMES. 
wonder that it has not already been more largely considered. Here and there a good Pink appears, but there is nothing like the number and variety there might be.

Of the florists' Pinks there are but a limited number that are really useful garden plants. Ascot is a good Pink, and we want more of the same type and degree of merit. An Ascot of a rather different tone of pink, clearer, and with less of the purple quality, would be a great gain. The double flowers that come from the old white Pink, such as Mrs. Sinkins and Her Majesty, are capital garden flowers. In some soils they are perfect, but they often burst the calyx from being too tightly packed in the petals. This is a point that raisers should carefully watch; a Pink may easily be too double. These useful varieties are just a little too full. Probably in some soils-calcareous, slaty, or loamy - they may have vigour enough to build up a calyx that does not split, but in the lighter soils that suit them less well the defect is extremely apparent. A white Pink halfway between these and the common white would be a useful plant.

A type that often shows itself in seedling Pinks is sometimes pretty, but not altogether satisfactory. It has petals of flimsy substance, deeply fringed, and much too tightly packed. It generally has a weak purple centre. This deep fringing and thin substance habitually go together.

A good Pink of the old "black and white" pattern is much wanted. Whether this true old plant is still in existence seems doubtful, for repeated appeals to the 
horticultural public that have from time to time appeared in the Garden have failed to bring it forth, the weak flowers just described being nearly always sent for it. The old black and white has petals as firm in substance as a Carnation with a distinct blotch of a chocolate-black colour, turning a little lighter at two days' old. The jags at the edge of the petal are few and blunt, never deeply cut, and the flower is not more than half double, so that the black blotch shows clearly. The white, from the thickness of the petal, is clear and bright.

The probable reason why the greater number of the florists' Pinks are of so little use in the garden is because so much attention is given to the lacing at the edge. This tends to muddle the flower in the mass, whereas a clear ground colour and a strong blotch show out well, and the plant, however full of flower, is bright and handsome. It is one of the many cases in which the show and the garden are at variance. As show rules are more or less arbitrary, it seems a matter of regret that their influence should not always be directed to the making of good garden flowers, so that they might work towards the greater and wider usefulness. To obtain prettiness in a single bloom, or even a single pip of a bloom, as seen in the hand, or close to the eye on the show table, seems a less worthy object to aim at than the obtaining of a beautiful thing for free garden use. Here there is an opportunity for some one to raise up a race that does not split. It is the splitting of the calyx that constitutes one of the chief defects of the garden Pink and the Carnation also, and 


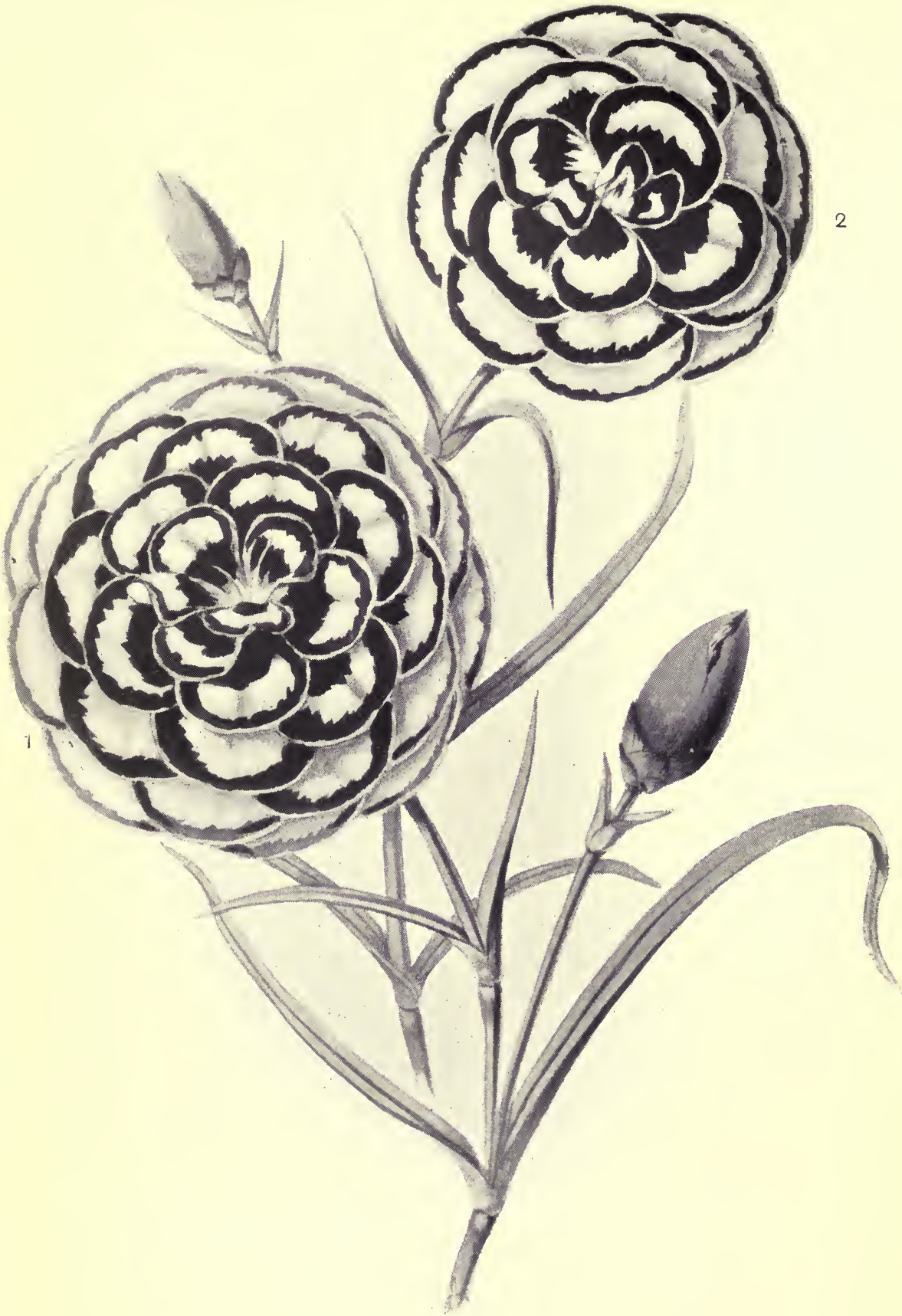

LACED PINKS.

1. COLCHESTER CARDINAL. 2. NARBRO' BUCK ("FLORIST," VOL. X., 1857). 


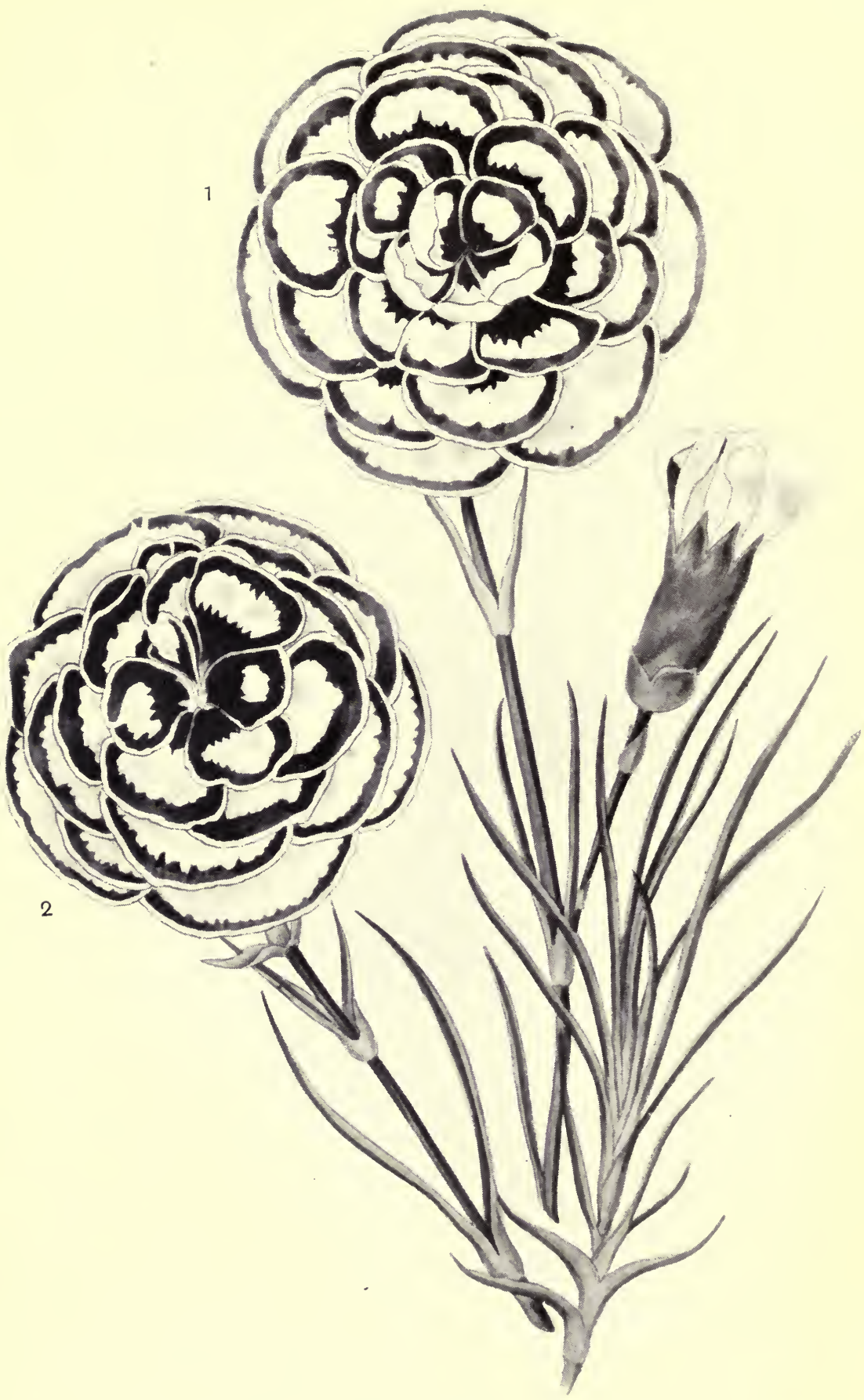


hybridists would do well to make this one blemish to be eradicated in the future. A split Pink as well as a split Carnation is not pretty, and the flower is beaten down by rain, bedraggled in soil, and its beauty utterly destroyed, no matter how clear and winsome the colouring may be. It is stained and soiled and unworthy of our affections. The following selection is not free from faults, but they are the varieties most often seen in nurseries and gardens.

\section{LACEd PInks}

The best of this group are Amy, Boiard, Bueno Retiro, Brackleen, Capo di Monti, Chantilly, Clara, Device, Duke of York, Empress of India, Eurydice, Excellent, Godfrey, Harry Hooper, Jeannette, John Ball, Lupra, Minerva, Mrs. Darke, Mrs. Lakin, Mrs. Pomeroy, Mrs. Welsh, Mrs. Waites, Maggie, Morna, Modesty, Old Chelsea, Pheasant's Eye, Reliance, Rainbow, Sarah, The Rector, Wedgrwood, and Zurich. Of these the following have flowers that rarely split:-Mrs. Lakin, a very useful little Pink, which occurred in a bed of seedlings of laced varieties; the petals are well formed, smooth-eyed, and the calyx does not burst open, while the growth is dwarf, compact, and flowers are borne abundantly. Another excellent variety is Pheasant Eyed; it has been distributed, Mr. R. Dean tells me, under the name of Samuel Barlow; at any rate, the latter, no doubt, put into commerce in perfect good faith, seems identical with it. It has hand- 


\section{IO4 CARNATIONS AND PINKS}

some flowers of medium size, the petals notched, and white with centre of crimson-claret colouring, and it does not split so badly as some varieties. John Ball, Mrs. Darke, and Modesty may also be chosen. These five will probably satisfy the beginner, as having a certain refinement of growth and colouring and not the unruly stems of Boiard, Empress of India, and the majority of this section.

The most elementary forms of the single Carnation of the present day have a disc of colour more or less dark round the eye of the flower. It is reasonable to suppose that in the remote past some of the colour of the centre appeared on the petal margins, faintly and imperfectly at first, but suggesting to the raisers of those days the possibility of continuing the colour on the petal edges, so as to secure what is known as "lacing." How long the period occupied in developing this characteristic is not known, but it is certain that about the year I770 a grower named Major produced in the south of England a Pink with the petals laced in a more highly developed form than had been previously known. It had the name of Lady Stoverdale, and efforts were made to develop this characteristic of lacing, until it became a conspicuous feature of the Pink. The laced Pinks of to-day have no doubt been derived from Major's Lady Stoverdale of I30 years ago, but led on year by year until it has culminated in the perfect lacing seen in the Rector, Duke of York, James Thurstan, and others. 


\section{The White AND OTher Pinks}

There is no more welcome flower throughout the year than the deliciously sweet white Pink. Though it is in most gardens, it is not used in the best ways. Because it is a useful border plant is no reason why it should not be also in the rock garden or rock wall, where it is absolutely in place. In rocky drifts or crowning stony masses, or nestling at the rock foot, its neat tufts are always delightful, while its sunbaked fragrance, here and elsewhere, is one of the charms of early June. No flowering plant is better as a garden edging, and it should not be forgotten how excellent are its leaves in winter, for then their silvery colour is in perfection. Mrs. Sinkins is one of the most popular of white Pinks, but the flowers burst badly in wet weather, and the same fault can be urged against the variety Her Majesty. The Pink that has always behaved itself in the writer's garden is Albino. The flower is not large, but there is a roundness and fulness in the petal which are most commendable traits, and the calyx seldom bursts open to let out the fragrant florets. Mrs. Welsh is a fine sort. Snowflake is another good white, but in thinking of the white Pinks it must be remembered that the old fringed white is as pretty and as fragrant as any, and in the thirst for novelties is likely to be neglected. There are several mule or hybrid Pinks of much beauty, and the way to increase these is by cuttings or by layers. The more important are the following:Dianthus Alice Lee, a double white flower, its best place 


\section{IO6 CARNATIONS AND PINKS}

being the rock garden; D. Atkinsoni is a beautiful Mule Pink, named after a Mr. Atkinson, who raised it in I845. We have frequently stopped to admire the wonderful crimson colouring of the flowers, which are poised on slender stems. Unfortunately the Mule Pinks are very troublesome to increase, but that excellent gardener, the late Captain C. Nelson, brother of the late Rev. J. G. Nelson of Narcissus fame, had a good plan for the renewal of those Pinks that was of especial use in the case of D. Atkinsoni, which so often blooms itself to death. He simply removed all the flowers from some of the plants; these by autumn were fine spreading tufts that could be divided. By this means he secured a yearly supply of flowering plants.

D. Lady Dixon.-This was shown before the Floral Committee of the Royal Horticultural Society in May r9or, and given an Award of Merit; it is said to have resulted from crossing the Sweet William and Clove Carnation. There is something of both parents in the Mule, and the flowers are reddish-crimson in colour, and very fragrant. A good garden plant. It was shown by Mr. P. D. Williams, of Lanarth.

D. Marie Paré is well known to Pink enthusiasts. The flowers are pure white, and make a brave show in the garden.

D. Grievei.-We first made acquaintance with this hybrid many years ago on the rock-garden at Kew. It was raised by the well-known Scotch grower Mr. James Grieve, who crossed a Sweet William and single-laced Pink together with this result. The 
colouring varies from white to rosy-pink, and in the same clusters this difference in shade is noticed. The leaves are like those of the Sweet William.

D. Michael Foster.-A double hybrid, with showy flowers in abundance.

D. Napoleon III.-This is one of the most brilliant of its race, and a clustering of it in the rock-garden or in the border is always pleasant to see. The deep crimson shade of the flowers, and the profusion with which they are borne on the strong but slender stems, makes this a Pink worth growing in all gardens. Unfortunately it is not easily grown, Messrs. Thyne and Paton, nurserymen, of Dundee, being, however, very successful with it, and we give their treatment. "We procure our cuttings as early in the season as possible, which is from the middle of July until the end of August. They are then inserted in boxes in a compost of leaf soil, river sand, and loam, and are placed under a stage in a cold house and allowed to remain until rooted. We then transfer them to 3 -inch pots, place them in a cold frame, and shade for a few days. When they have become established and made a fairly long growth, the tops are taken out with the object of inducing the growth to break before winter; the after-treatment is the same as adopted for Carnations. They are allowed to remain in the cold frame until spring. Plenty of air is admitted when the weather is suitable, and the soil is kept fairly dry at the roots. We generally plant out in April, but before doing so all the tops are taken out that are sufficiently long, and the plants 


\section{IO8 CARNATIONS AND PINKS}

allowed to break before being removed to their permanent quarters, which is on soil of a rather binding, sandy loam, to which we add rough leaf soil, river sand, and old lime rubbish, and in this mixture we find that they do well. To secure fine flowers disbudding should be practised the same way as for the Carnation."

D. Spencer Bickham.-This is a cross between D. cæsius and D. deltoides. It is a plant of quite dwarf growth, not more than a few inches high, and is for that reason suitable for the rock-garden. The colour of the flowers is crimson with a shade of rose in it.

D. superbus.-An unfortunate name for a Mule Pink, as D. superbus is a species. The Mule has very sweetly scented flowers, crimson in colour, double, and it remains in bloom over a long season.

D. Warley.-A beautiful seedling from Cyclops, and raised by Miss Willmott. It is very free, and the flowers are exceptionally brilliant in colouring, which is intense crimson, with a dark base to the petals. 


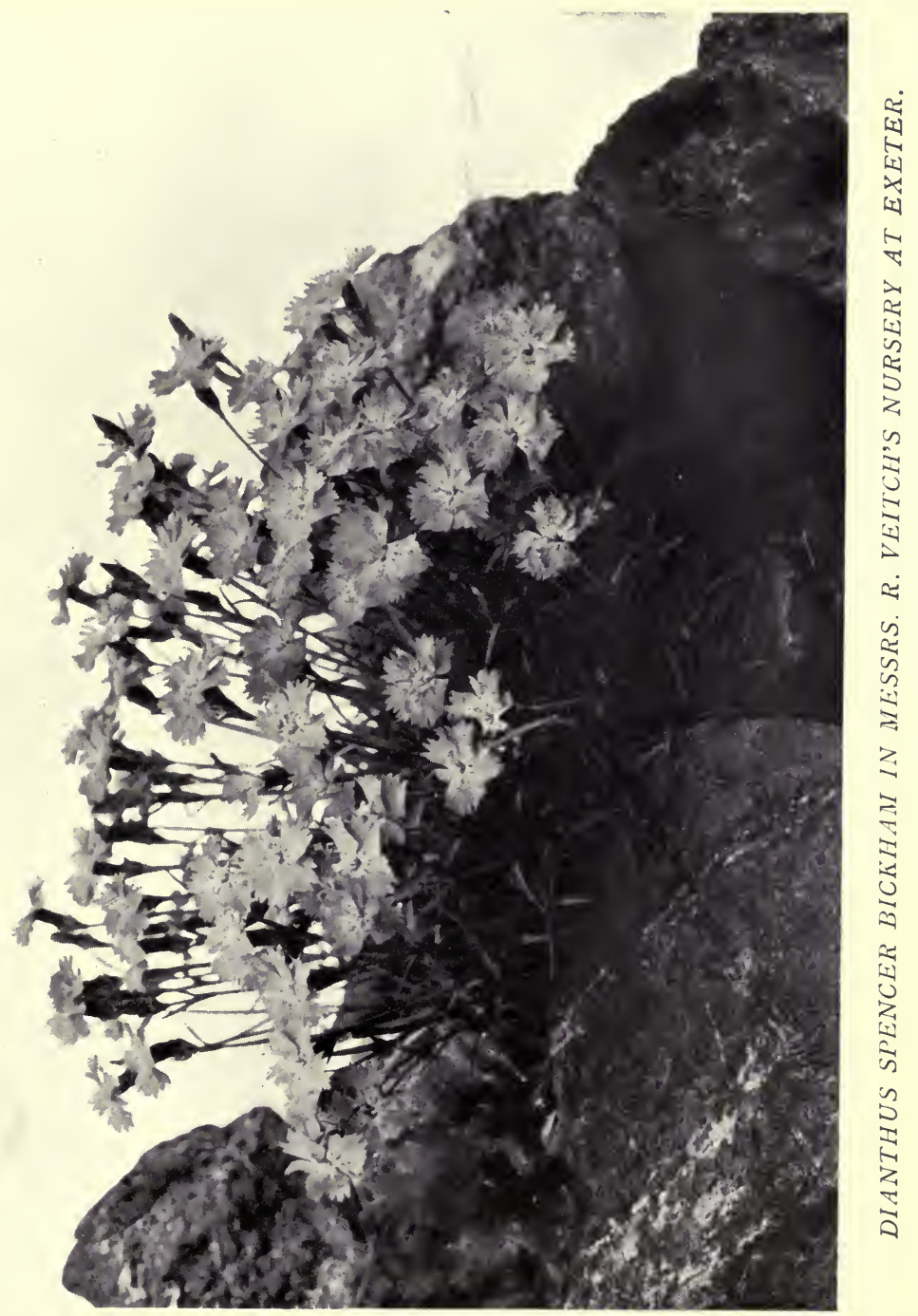




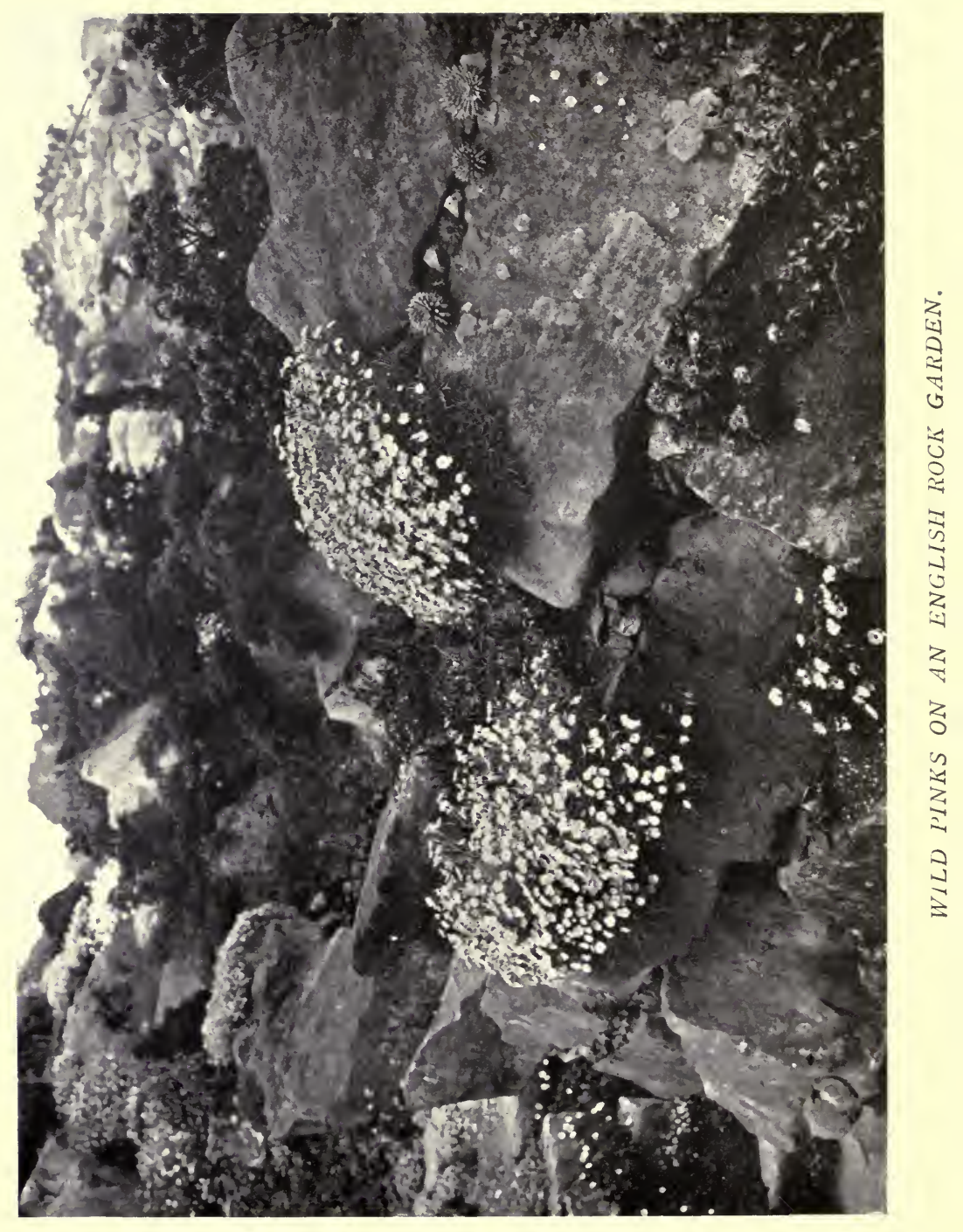




\section{CHAPTER XII}

\section{THE WILD PINKS}

THE wild Pinks are beautiful garden flowers, and from some of the species are derived the Carnations, garden Pinks, and the quaint Sweet William in its many pretty colourings. According to Dr. F. N. Williams in his enumeration of the species and varieties of the genus in 1899 , the family consists of $23 \mathrm{I}$ species, distributed throughout Europe-with the exception of Ireland and Iceland-temperate Asia, and North and South Africa, with a representative in the extreme north-west of America. Most of them are perennials, with grass-like foliage; a few have a tendency to become shrubs, while some are of only annual or biennial duration. Many are the conditions under which these flowers of highland and lowland are discovered. Some delight in the meadows and dry heaths of the plain, a few enjoy the sea-shore, and others gem the alps and glacier, and give a rare beauty to the alpine flora. The wild Pinks are beautiful in the rock-garden, and form tufts of evergreen leaves, quite glaucous in colour, which show their beauty best on ledges, or in some rocky nook where the flowers are not lost in the spring months of the year. Some of the Pinks have large 
flowers, each on a stem a few inches high, others are quite branching, while a few are erect in growth, with several flowers in a compact head on the top of stems varying between one foot and two feet high.

As the species cross readily it naturally follows that natural hybrids are numerous. Nyman, in his enumeration of European plants, mentions thirteen, but this is probably below the right number. Those species mainly responsible for the hybrids are $D$. deltoides, $D$. superbus, and $D$. barbatus. Garden hybrids are numerous, and when several species are grown close together the seedlings are rarely true to name, intermediate forms appearing freely in a batch of seedlings. It therefore follows that it is necessary to increase the plants by cuttings if the species is desired true to character.

The following list includes most of the more distinct species, some being omitted owing, not to an absence of beauty, but to the slight difference that exists from other forms. The genus may be conveniently divided into two great groups, and these may again be divided into two sets.

Group I.-With flowers in heads.

A.-Flowers clustered, furnished with numerous membraneous or coriaceous bracts.

B.-Flowers in approximate heads, no bracts of a distinct character from the leaves.

GrouP II.-With scattered or solitary flowers.

C.-Petals not fringed.

D.-Petals fringed.

A.-Dianthus arboreus.-A shrubby (frutescent) Pink 
from Crete, where it grows on calcareous rocks near the sea. It is of bushy growth, and is thickly clothed with short and fleshy leaves. The heads of flowers are pink, the petals are bearded and dentate at the margins. It flowers in October, but there is this drawback to its culture, and that is, unless the locality is exceptionally favourable and the position a dry one, it will not survive anything like a severe winter in England.

D. atrorubens.-This is a hardy perennial from two feet to three feet high, and bears densely crowded heads of dark red flowers in summer. It is a good border plant when a mass of it is grown, as the flowers are produced with great freedom over a long season, the stems springing from a tuft of long grassy leaves. It is a native of South Europe, and is found in grassy mountain pastures where the situation is dry and open.

D. Bisignani.-This is known also under the name of D. rupicola, and is quite a shrubby Pink, growing on the rocks of the sea-coast of Sicily and Naples. It is showy but only half-hardy, and forms a neat little bush not more than eighteen inches high, the leaves slightly fleshy, but not so densely produced as in D. arboreus. The light-coloured flowers are in a head of from eight to twelve. When grown away from the influence of the sea the leaves are not so fleshy, but the flowers are often larger, and fewer in number in the individual head. It requires a warm and sheltered position, and the flowers appear in November. It was introduced in $\mathbf{1} 825$. 


\section{2 CARNATIONS AND PINKS}

D. capitatus.-This Eastern European species is closely allied to D. atrorubens, but the involucral bracts are much longer and with a long acuminate point; the flowers also are lighter in colour.

D. Carthusianorum.-A plant of erect growth, with tufts of long grassy foliage and stems two feet high; the small red flowers are in densely crowded round heads. Though not so showy as some of the Pinks, D. Carthusianorum may be recommended for the border, where a group of it will maintain a succession of flowers for some time. The petals are bearded, and the margins are crenate. This species is found in barren wastes in Central and Southern Europe.

D. cinnabarinus.-Although frequently offered in catalogues, the true plant is rarely seen. It is a handsome species, tall and erect in growth, shrubby at the base, with tufts of grassy leaves and stout stems bearing compact heads of cinnabar-red flowers; the petals are paler on the under side, and the calyx is also tinted with red. Although a perennial it is short-lived in this country, and does not ripen seed so freely as the other clustered Pinks, which may account for its scarcity. It is a native of the mountains of Greece and Asia Minor, and was introduced in I 888.

D. cruentus.-This is found in Greece and other parts of Eastern Europe. It bears a great resemblance to D. Carthusianorum in growth, but the slightly larger flowers are of a darker blood-red colour.

D. giganteus.-This is a species of tall growth, reaching when the soil is good a height of four feet, 


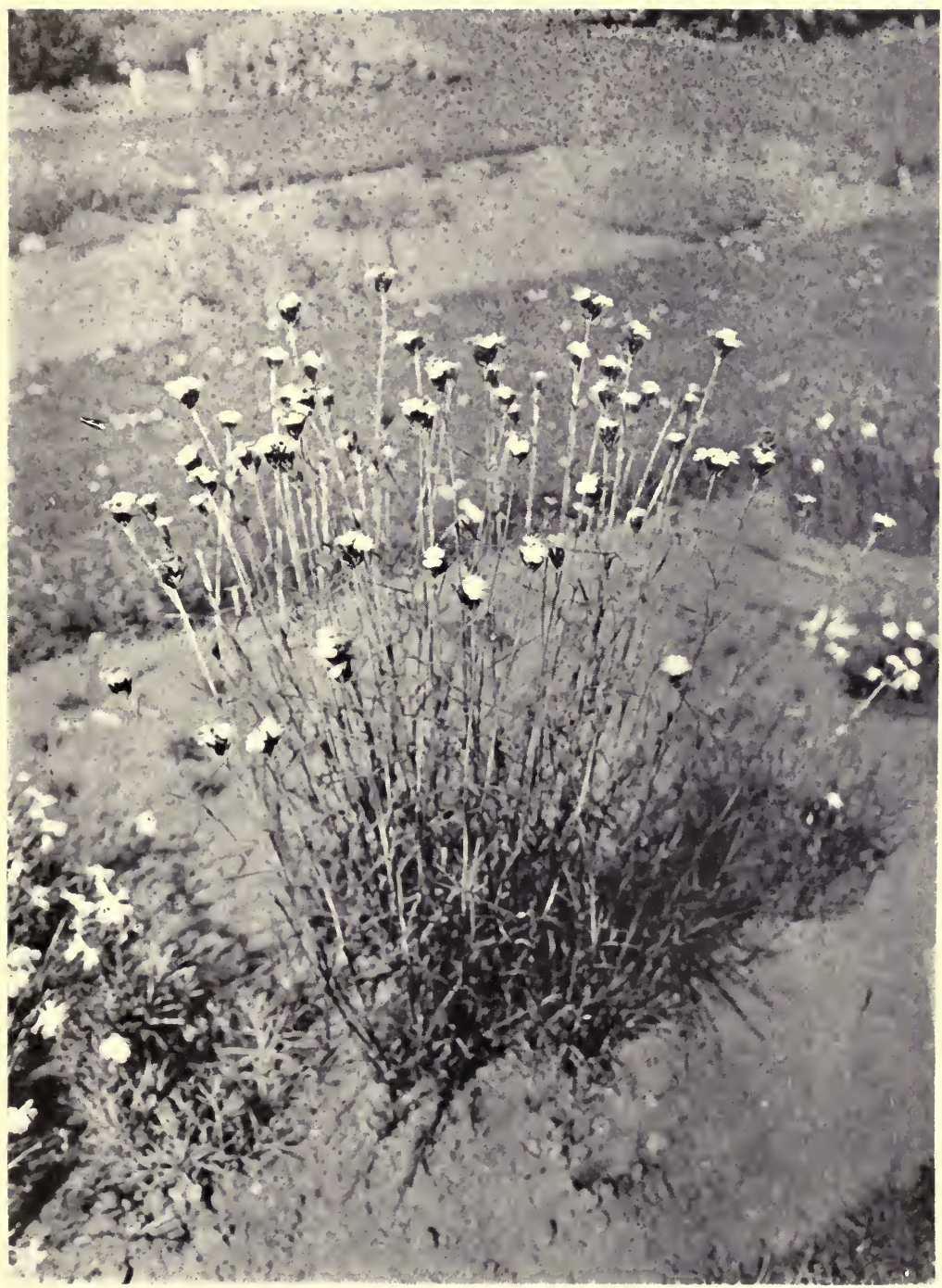

DIANTHUS GIGANTEUS. 


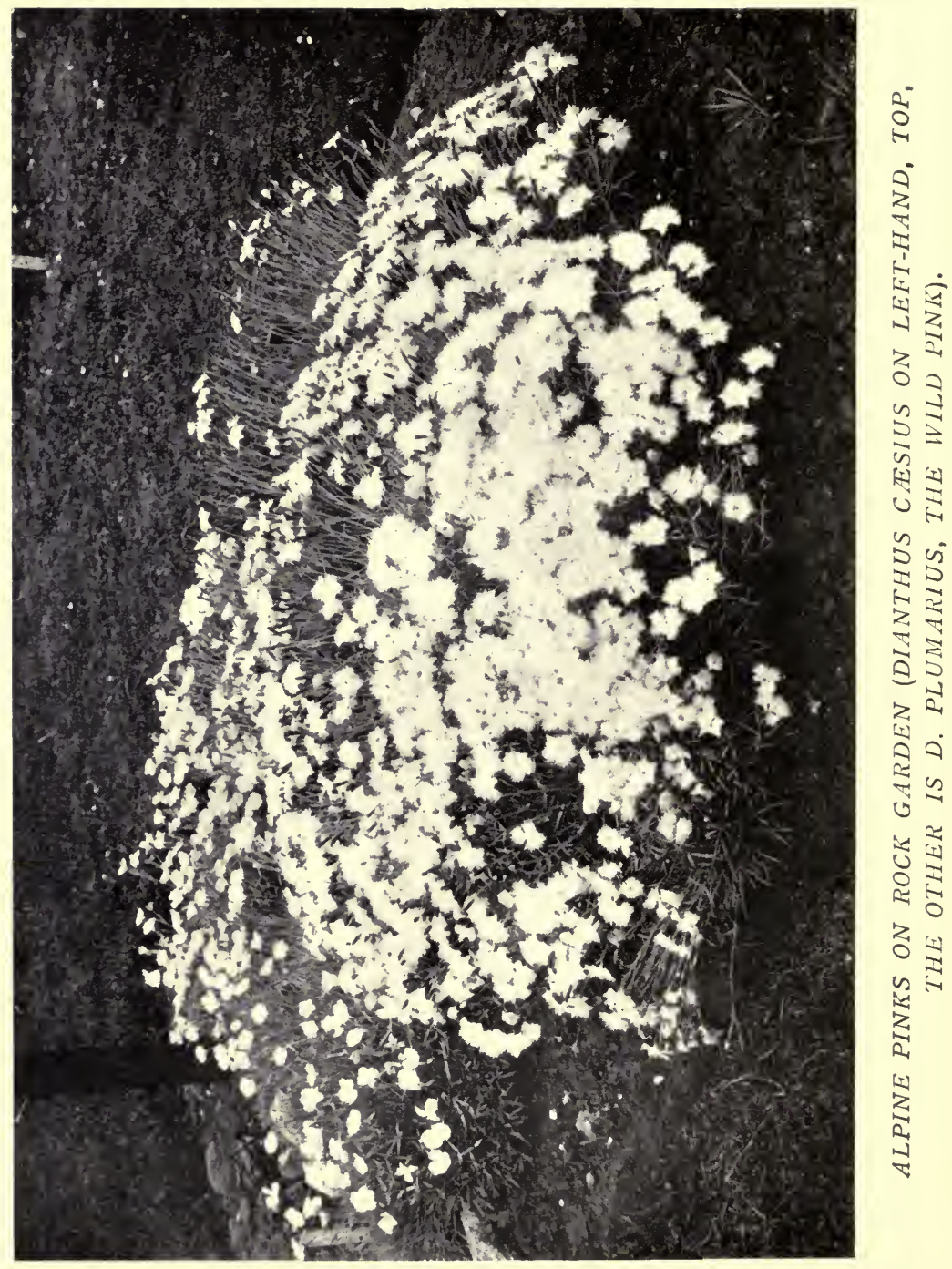




\section{THE WILD PINKS}

the stout stems swollen at the nodes, and clothed at intervals with pairs of long, bright green leaves sheathing the stem at the base. The flowers are numerous, crowded in a dense hemispherical head, and the surrounding bracts are quite leaf-like; the dark red petals are toothed and bearded. It is a perennial, slightly woody at the base, and is found among rocks by the sea in Eastern Europe. It was introduced from Bulgaria in 1828 .

D. intermedius. - This is allied to D. giganteus, and is found on Mount Olympus, in Thessaly, where its rose-coloured flowers are among the sweetest of wildings. The variety called ambiguus is the Servian form of this species.

D. Knappii.-Some authorities make this a variety of D. liburnicus, but it appears to us quite distinct. Although the growth of the plant is loose and straggling, and therefore not elegant, it is well worth growing for the sake of its yellow colouring. It is at home in either the border or in the rock-garden, but especially in the latter. Place the plant rather high up, so that its weak-stemmed flowers may fall over a ledge. It comes from Hungary and the adjoining countries.

D. liburnicus.-A species found by the sea, and first discovered on the shores of the Gulf of Quarnero, in Istria. It also occurs in calcareous soil on the Maritime Alps. The stems are from one foot to two feet high, and the red flowers are in clusters in August, surrounded with leafy involucral bracts.

B.-D. Armeria (the Deptford Pink).-An annual or 


\section{CARNATIONS AND PINKS}

biennial species, reproducing itself freely from selfsown seed. It is generally found wild on dry banks or gravelly pastures, having a wide distribution, spreading not only over a great part of Europe, but extending into Western Asia. It is also naturalised in some parts of the United States. Self-sown seedlings form a rosette of short and broad green leaves the first year, from which the branching stems - two feet highare produced in the following spring. These stems bear loose cymes of red flowers with dark spots. The flowering time is in July and August.

D. barbatus (the Sweet William).-This species, which is known to every country child in its varietal stage, came from the mountain meadows of South and Eastern Europe over three centuries ago. It is from twelve inches to two feet high, the leaves broad and of a fine green colour, and the flowers bearded and in colour red, with a zone near the base of the petals. They appear in large, loose heads. Few biennials are more popular than the quaint Sweet William of English gardens. It is of strong growth, hardy, and has been much improved of late years, many varieties surpassing the wild plant in the beauty of their flower colouring and in the size of the clustered heads of blossom. There are several sections, such as the "Auricula Eyed," and the selfs, but the most telling in groups are those without spots or dots of colour on the petals, simply a pure and beautiful shade; it may be crimson, rose, pink, or pure white, and the salmon shades I think are the most charming of the whole series of Sweet William selections. The 


\section{THE WILD PINKS}

shading is sometimes dark and sometimes light, but always clear and even brilliant, which the brightest sun does not dim, and there is no suspicion of purple or any unpleasant tone. This group deserves to be widely known, and in some well chosen place in the border it is a delight for many weeks. One knows the Sweet William is near from the fragrance that floats through the air even when the sun shines full on the open blooms at midday. The seed may be sown when ripe, which will be in late summer, in a selected spot out of doors, or in pots in a cold frame. Prick out the seedlings when large enough to handle outdoors, and transfer to the border or wherever they are to go in autumn. Another way is to sow in March or early April in a cold frame, pricking out in the usual way, and then transplanting. Another way to propagate is to divide the tufts in September, and by striking cuttings in June from about half-ripened shoots. These should be dibbled firmly in under hand-glasses, watered carefully, and when rooted transplanted elsewhere, and then to their permanent places. The usual way, however, is to increase the plants by seed, and in time self-sown seedlings will appear in profusion; it is interesting to watch these open their flowers. D. b. latifolius is a form with broader leaves and clusters of larger flowers, which are rich crimson in colour, a plant of great beauty. Double varieties are sometimes grown, but they are heavy, and not free from an objectionable lumpiness, and the colours are less pronounced. One exception must be named, the double crimson, 


\section{II6 CARNATIONS AND PINKS}

D. b. magnificus, which is proverbially difficult to keep. It is most contented perhaps in loamy soil, and when it does succeed few flowers are more enjoyable. It is not more than six inches high, and the colour is a deep velvety crimson, each flower a little rosette of much charm.

D. Seguieri.-A branching but erect plant, generally found on grassy hills and in the mountain thickets of South and Eastern Europe; height twelve inches to two feet. The rosy-purple flowers appear on short peduncles. They are sometimes found in summer in loose clusters, and sometimes solitary.

C.-D.alpinus.-This is the Alpine Pink, a little jewel in June for the rock-garden, the plant being a tuft of blunt-pointed shining green leaves, and at once distinguished by this character from other species. It is very dwarf in poor soil, the flowers large, deep rose in colour spotted with crimson, and on short peduncles, but where the soil is richer the growth is taller, and more than one flower is produced on a stem. An open spot suits the Alpine Pink, but the soil must be gritty and with a proportion of lime rubble added to it. It may be increased by cuttings, but comes quite true from seed. The plant is found high up on the alps of Austria and Central Europe on calcareous rocks; it was introduced in 1759.

$D$. brevicaulis.-A little Pink of compact growth, woody at the base, and with very short branches. The wealth of pink flowers is borne on short stems, and not a leaf is visible; at this time it is only about two inches high, and should be planted in crevices 
which the roots can penetrate. A native of the alpine region of the Taurus in Cilicia, and flowers from July to September.

D. cæsius.-This is the Cheddar Pink, and one of the best known of the family. It is a delightful little rock-garden plant, very neat and compact in growth, and makes a cushion of glaucous leaves, from which in May spring the sweet-smelling rose-coloured flowers, each on its own stem, which varies as much as from four inches to ten inches high. It is rather a variable species, and different forms in cultivation bear this name, some being very dwarf with large flowers, while others are taller with smaller ones and branching stems. None of the alpine Pinks are so easily grown; it is at home on old walls, or on sunny ledges in the rock-garden when planted in gritty or calcareous soil. Sometimes it is placed in the ordinary border, and then it is wise to raise the soil above the level with brick rubbish to ensure safety during a damp winter. As old garden walls, and new for that matter, are frequently clothed with flowers, this pretty Pink must not be forgotten in the planting. Sow the seeds in the cracks with a little soil, and tufts are quickly formed. The name "Cheddar" is derived from the place in which it is found in Somerset, where it grows on limestone rocks, but it is common in alpine pastures.

D. Caryophyllus.-The wild Carnation or Clove Pink has given rise to the beautiful flowers that form the chief feature of this book. The wilding may be known by its much branched glaucous- 


\section{II8 CARNATIONS AND PINKS}

coloured stems, and it is found in various parts of Europe on rocks and ruined walls. It is also naturalised in some places, such as on the old walls of Rochester and other castles, sending its long and slender roots into the mortar in the cracks between the stones. The flowers vary in colour, but they are always pretty. In the search for its garden varieties the simple beauty of the wild species must not be overlooked. Tufts of it in the rock or wall garden are always interesting.

$D$. chinensis is the famous Chinese Pink, a native of Asia, and introduced from China-the Manchurian coast-nearly two hundred years ago. The species is about eighteen inches high, of branching growth, and the reddish flowers scent the winds of summer with their sweet fragrance. It has given rise to a race of showy border plants, which show a wonderful diversity of flower colour and form. Probably the best known is the Japanese variety, $D$. Heddewigii, a strain of dwarf compact plants, and there is also a section with more deeply cut petals. A. c., var. dentosus (the Amur Pink), is very distinct and pretty, the violet-shaded flowers, each an inch across, with toothed margins and dark spots near the base of the petals, giving the flower the appearance of having a dark eye. The varieties are very numerous, and include single and double forms, the colours varying from the white of albus to the crimson of fulgens. Their culture is simple, and they may be regarded as annual or biennial flowers. When to be grown as annuals sow the seed in March in pots 
filled with a well drained soil composed of loam and leaf-mould mixed with some sharp silver sand. Sow thinly, and cover the seed lightly. Transfer to pots, or shallow boxes will answer the same purpose, and place in a warm frame or house in which there is gentle warmth, and when the seedlings are an inch and a half high prick them out into other boxes, but still keeping them in a frame. Air must be given, however, on all favourable occasions to promote a strong, or what the gardener calls a stocky, growth, and in the first days of June they may go to the places they are to beautify during the summer months. A sowing may also be made in the open garden in June, but this is not always satisfactory; it is better to treat the Chinese Pink as a tender annual, and to sow in the way suggested. When a sowing is made in July, flowers are not forthcoming before the following year. Choose an open spot, and sow in drills of fine soil about six inches apart, and cover the seed very lightly. While germination is proceeding shade a little, but remove this when the seedlings appear. Transplant to the borders in August. It is a common mistake to leave annuals crowded in the seed beds, for plants treated in this way are rarely a success. When it is found impossible to prepare a permanent place for them, it is better to prick them out again, giving each seedling ample space to develop, until the positions they are to flower in are ready for their reception. The seed may also be sown in late August, the seedlings wintered under glass and planted out in spring. This means a display of flowers before 
the spring sown are even in bud. The most beautiful of the Heddewigii form is Diadematus fl. pl., but there are many selections in the lists of the leading nurserymen.

D. ciliatus.-This is a shrubby Pink from Italy, tufted in growth, and with white almost beardless flowers.

D. deltoides. - A charming little flower, better known as the "Maiden Pink," and a native of the British Isles in dry and gravelly pastures. The wilding is of straggling growth, with short bluntpointed leaves on the barren stems and longer and narrower ones on those which bear the flowers. I think none of the wild Pinks grow with greater vigour than this; it seems happy everywhere, on dry wall or in rock garden, and may be grown easily in the mixed border, and the abundance of its bright pink prettily spotted flowers gives a touch of decided colouring wherever a colony of it is established. D. d., variety glauca, is found on Arthur's Seat, Edinburgh, and has white flowers with a pink centre. The Maiden Pink is found over Europe except the northern part.

D. fragrans.-This wild Pink, like so many of its family, has an untidy growth which is not commendable. It sprawls over the rock or stone against which it is placed, and is impossible in the mixed border. In spite of this it has a certain prettiness which cannot be overlooked, and its sprawling stems are not so apparent when the plant is in the wall with other things near to it. The stems are from nine inches to twelve inches high, generally bearing 
only one flower, but sometimes a second one appears on a short axillary peduncle; the flowers are pure white with finely toothed petals, and appear in July. The double variety we noticed one summer in the interesting collection of Pinks in the nursery of $\mathrm{Mr}$. Charles Turner of Slough. It is more compact than the type, and its white flowers are perfect little rosettes. D. fragrans comes from the Caucasus.

D. Freynii.-A Pink that reminds one of D. glacialis (the Glacier Pink), and so closely allied is it that some authorities regard it as only a variety. It is one of the smallest and most compact of the wild species, and has pale grey leaves and purple flowers three-quarters of an inch across on very short stems. These is also a variety with paler coloured flowers. It is a native of Hungary and Bosnia, and was introduced in 1892 .

D. glacialis (the Glacier Pink).-This is a very small and rare tufted plant with grassy leaves, and comes from the high granitic mountains of Central Europe. The scentless flowers have dentate petals, and their colouring is reddish-purple, while they are on stems only one inch to three inches high. Fortunately it has frequently a very long life under cultivation, its chief enemy being the slug, which relishes the juicy foliage, and against this pest the plant must be carefully protected. The soil it delights in most is sandy peat to which a proportion of granite chippings have been added. D.g., var. gelidus, from the Transylvanian Alps, is now given specific rank in Williams' monograph. 
D. leptopetalus.-This Pink is more curious than beautiful, and is remarkable for its long and narrow white petals. The flowers appear in July in twos and in threes on slender stems, which are sometimes often a foot in length. It is a native of the Caucasus, and was introduced in $\mathrm{I} 8 \mathrm{I} 4$.

D. longicaulis.-A tufted Pink from Mount Amaro in Italy. Its rose-coloured flowers are solitary, on slender stems nine inches to twelve inches high, and expand in summer.

D. masmenxus. - This is named after one of its habitats, Masmeneu-dagh, in Kurdistan, and is also found in the alpine regions of the mountains of Cappadocia. It is a pretty Pink, of somewhat sprawling growth, and the flowers are usually in loose cymes on short peduncles; the dentate petals are rose-coloured above and of a yellowish shade on the under side.

D. microlepis.-A distinct little alpine, very dwarf and tufted in growth, with small rose-coloured flowers, each on a stem one inch to two inches high ; these open in August. It is a native of Eastern Europe, on the high alpine rocks in Transylvania and Macedonia. There is also a white-flowered variety in gardens.

$D$. neglectus.-One of the most beautiful wild Pinks in cultivation. It is referred to $\mathrm{D}$. glacialis by some authorities, and is made a variety of it by Williams in his monograph. It is, however, much taller, the stems six inches high, with tufts of narrower and more pointed leaves, which are more of a glaucous colour than those of the Glacier Pink ; the deep rose-coloured 
flowers are frequently borne two on each stem. A native of the high alpine regions of the Swiss and Italian Alps, and introduced in I869. No rock-garden should be without this lovely Pink, and it succeeds well in an open place in stony soil or in a crevice.

$D$. nitidus. - Another pretty Pink, with leaves somewhat similar to those of D. alpinus, but with generally more acute points. The stems spring from tufts of grass-like leaves, and have from two to three flowers. It is a native of the calcareous Alps in Hungary, growing in alpine pastures and opening its rose-coloured dentate petals in August and September. As it suffers greatly from damp, choose a dry position for it, wedged between stones.

D. neanus.-A very distinct summer-flowering species from Rumelia and Servia, with tufts of fine rigid foliage. It is exceptionally free-flowering, and the slender stems are from 6 inches to 9 inches high, branching at the top into two to three divisions, each terminating with a small solitary white flower, the petals of which are incised. A Pink of free growth in any sunny position, but the soil must be a gritty loam.

D. petræus.-This is the Rock Pink. It was introduced from Eastern Europe in 1804 , and is not unlike D. nœanus, but the leaves are broader and less rigid, and the rose-coloured beardless flowers are on slender stems, which branch at the top into three or four. Summer flowering.

D. pinifolius.-An interesting species, tufted and woody at the base, the branching stems being clothed 


\section{I24 CARNATIONS AND PINKS}

with many long very fine leaves. The flowering stems are quite slender, I foot to 18 inches high, and the wildings only have one or two blooms on each, but under cultivation this number is doubled. It is a curious plant, and grows in stony places on the mountains of Greece. June flowering.

$D$. pubescens.-This is a biennial summer-flowering species, and a native of Greece. It is covered with a fine "down" or pubescence, and the flowering stems are very branching, each terminating in a single red flower, but the effect at a distance is of a little cluster.

D. pungens.-A Spanish Pink, grows on rocks and mountain pastures in Asturia. It is dwarf, tufted, and has either solitary or a few flowered slender stems. The colour is pink.

$D$. siculus.-A tufted plant, with long grassy leaves and tall branching stems 12 inches to 18 inches high, and solitary red flowers, of which the petals are incised.

D. strictus. - This is a small white Pink which quickly forms large tufts of glaucous leaves, and apart from its flowers it is useful for covering the rougher parts of the rock-garden. It is found on rocks in Eastern Europe. D. s., variety bebius, has broader leaves and larger flowers.

D. subacaulis.-A very dwarf tufted plant, with one flower to each of the short stems. It comes from the Dauphiny.

D. sylvestris.-The Wood Pink, and found abundantly in rock and stony places on Mount Jura and the neighbouring Alps. It was once thought by some 
authorities to have given rise to the garden Carnation, but it has no fragrance. It is one of the prettiest and most easily grown of the rock Pinks, and grows into a tuft of slender grassy leaves, which are almost hidden with the mantle of pink flowers on rather weakly stems. It has a creeping root or underground stem, and is best in loose stony soil on a sunny ledge, where the roots can penetrate into the moisture below. Introduced in $18 \mathrm{I} 4$.

D. tener.-A Pink from the Piedmont, the stems slender, one-flowered, and the pink flowers beardless and cut into narrow irregularly-shaped lobes.

D. viscidus. - The not ungraceful flower clusters of this Pink, which comes from the mountains of Greece and Macedonia, are reminiscent of those of D. deltoides; they are larger and deeper in colour.

D. zonatus. - A native of the arid mountains in various parts of Asia Minor, and suggesting the Wood Pink, with rose-coloured bearded flowers and purple zone.

D. - D. arenarius. - This Pink is easily recognised by the deeply fringed petals, which are cut to below the middle, and each has a faint green mark, covered with short, dark purple hairs. The plant is slightly woody at the base, and divides into many branches, which are terminated with tufts of linear leaves. From the centre of each tuft springs a stem bearing one or two white flowers. It is very hardy, grows in almost any position, and delights in a sandy soil, being found on the shores of the Baltic, from whence it was introduced into this country in 1804. Summer is its 


\section{I26 CARNATIONS AND PINKS}

season for flowering. Those who have a wall garden should plant this Pink, as it will root into the crevices and make drifts of soft colouring at all times.

D. gallicus.-A Pink of straggling growth and with beardless pink flowers, of which the petals are deeply cut; it blooms in May. A native of South-Western Europe, it is found near Biarritz in sand-hills under the pines.

D. monspessulanus. - This is also known as D. alpestris, and is one of the prettiest of the family; it is very free in all ways, in its wealth of flowers and easy culture. It succeeds in any open place, and forms tufts of grassy leaves from which spring many branching stems in summer; the flowers are red in colour, and not bearded. The plant grows from 6 inches to 12 inches high, and is found in high thickets and mountain pastures of the Alps of South and Eastern Europe. Introduced in 1764 .

D. plumarius (the wild Pink).-This differs from the wild Carnation in having a much smaller flower, and the petals are deeply cut or fringed. It is also much hardier, and is seldom grown in pots. One of the most luxuriant in growth of all the wild Pinks, and quickly covers a large space; it also seeds freely and crosses readily. The leaves are glaucous in colour, and the stems bear from two to five deeply-fringed and sweet-scented flowers, which vary in colour from white to purple. It is wild in Middle and Eastern Europe. Many beautiful garden varieties have been derived from this species.

D. Requienii. - A dwarf tufted Pink from the 
Pyrenees, the slender stems 6 inches to 9 inches high, and each has one small rose-coloured flower.

D. squarrosus.-This has flowers similar to those of D. plumarius, but the calyx segments are longer, the leaves short, stiff, and recurved, and the plant is not more than 6 inches high. It came from South Russia in $18 \mathrm{I} 7$.

D. Sternbergi.-Similar to D. monspessulanus in growth and appearance, but smaller, and the flowers are rose in colour, with the petals deeply cut. It is wild on the mountains of South Tyrol and Carinthia.

$D$. superbus.-This beautiful Pink is known by the fringe-like petals, delicious scent, and the long slender tube of the calyx; the colour of the flowers varies from white to purple, and the flowering season begins in August, continuing far into the autumn. A shortlived plant, but seeds ripen freely. It has been in gardens for over three hundred years, and is widely distributed, extending over Europe and Northern Asia to China, varying greatly in size and growth. The larger forms come from China, a plant in the Royal Gardens, Kew, raised from seed collected in China, reaching three feet in height, the flowers appearing in branching panicles.

D. Waldsteinii.-A native of the Eastern Alps of Europe, and like a small D. monspessulanus.

\section{Growing the Alpine Pinks}

The wild Pinks are for the most part quite easy to grow, requiring only a little care during their 


\section{I28 CARNATIONS AND PINKS}

early growth. A few of the rarer species, the Alpine and Glacier Pinks as examples, are more difficult to manage, and must have more than ordinary attention if they are to grow into healthy tufts and flower freely. Some of the smaller Pinks suffer from winter damp, and it is not unusual for large plants which have taken years to develop to die from this cause. Seed is the easiest way to increase the plants, but unfortunately the seedlings cannot be depended upon to come true to the right colouring unless the various kinds are kept quite apart. The reason is that Pinks hybridise with great freedom. Cuttings taken just after the plants have finished flowering root readily in small pots filled with a mixture of loam to which plenty of sand has been added. The pots should be plunged in a shady frame and kept close until the cuttings are rooted, when they may be potted off singly.

The smaller tufted species may be divided in spring. The larger species, such as D. Carthusianorum, $D$. Caryophyllus, D.cruentus, D. giganteus, and D. liburnicus, which may be regarded as border plants, are easily raised from seed sown in gentle heat in spring. When large enough to handle the seedlings should be pricked out in boxes in a compost of half fibrous loam, one part sand, and the same of leaf-mould. When well rooted they may be planted out in their permanent places ready for flowering the following spring. This early treatment is also suitable for $D$. plumarius, $D$. cresius, $D$. arenarius, and others of similar growth, but lime rubbish may be added with 
advantage to the soil in which they are grown. $D$. alpinus, D. callizonus, D. glacialis, D. monspessulanus, $D$. sylvestris, and others from the higher altitudes may also be raised in the same way, but they require more care afterwards. Instead of being pricked out in boxes they should be potted off singly in small pots, which should be plunged in a cool, shady frame until the seedlings are of sufficient size for planting out; the compost should be loam and leaf soil, with plenty of grit and lime rubble. This mixture is suitable for almost all the alpine species, with the exception of $D$. glacialis, which is a graniteloving plant, and to the soil in which it is potted and planted out granite chippings may be added with advantage in place of lime. When planting out in the rock-garden a sunny, well-drained position should be chosen for nearly all the alpine species, though there are some exceptions, such as D. callizonus and $D$. sylvestris, which require a certain amount of shade. They should be planted where they receive the direct rays of the sun for a brief period only. Established tufts of the smaller alpine species require top-dressing once or twice during the season with a mixture of sand and leaf soil. This should be worked well amongst the young growths, but the growing points must not be covered up. The autumn dressing should contain more sand, so as to absorb the excessive moisture surrounding the plant in winter. 


\section{CHAPTER XIII}

\section{THE PINKS OF THE ALPS}

\section{By Henry CoRrevon}

$\mathrm{U}^{\mathrm{P}}$

PON mountain rocks, in dry, poor - soiled pastures, and on arid, sun-scorched slopes, everywhere, are to be seen, shining out like twinkling stars, the rosy, blood-red, crimson and purple flowers of the wild Pinks, some scentless, some fragrant. It is a summer-long fairyland, whose bright and pretty blossoms are a joy to see.

Hidden in woodland are the exquisite flowers of Dianthus superbus and its numerous following, while shining in the high rocks, brilliant in the sunlight, are the fiery corollas of D.cxsius, Carthusianorum, sylvestris, Seguieri, and others; and in the pastures, some hiding in the grass, some rising above it, are D. glacialis, alpinus, neglectus, \&c.

With the months of June and July the brilliant show begins, with Dianthus Carthusianorum and $D$. cresius, the earliest to flower; presently it is increased by other species; and there soon follows a whole scale of colour-tone and perfume, that rises from the soil to delight and gratify the imagination. 


\section{THE PINKS OF THE ALPS I3I}

In the valleys of the Waldenses (Cottian Alps), a small Protestant country hidden in the midst of surrounding Catholic Italy, some of the most attractive of the wild Pinks may be seen in bloom throughout the summer. The scene is a striking one, for the plants are in profusion as well as in many different types and varieties. This abundance is no doubt owing to the nature of the soil and to the full, free light of the mountain heights.

The Dianthus group contains flowers whose colouring is some of the most intensely brilliant that may be found in Nature, so that they are all the more welcome to eyes that enjoy bright and warm colourings.

The Dianthus are plants belonging exclusively to the Old World. Many of them have been grown in gardens for centuries, and have given us some of our most ornamental plants, such as Carnations, Picotees, Pinks, Sweet Williams, \&c.

As a general rule they love the sun, and, above all, full open light. Many are sweetly perfumed, and a large number are of brilliant colouring. Those of the Alps and other mountains of Europe are especially beautiful because of their dwarf, tufted habit and large flowers, but the best of all come from the mountainous regions of Eastern Europe.

In the plant catalogue of our gardens of Floraire we have classified the genus Dianthus in two categories ; firstly, the alpine species, the dwarf, tufted kinds, which spread over the soil and form carpets of flowers; and secondly, those with upright stems and an erect and branching habit. 
I propose to follow this order, although it is not strictly scientific.

In the first division we will treat of those species, proper to rock and mountain, that we call Saxatile. It comprises some of the most interesting and brilliantly coloured, though we shall only name those that are the most suitable for use in garden and rockery.

Dianthus alpinus (L.).-A beautiful small plant, low-growing, and flattened upon the soil, where it forms bright green tufts of shining foliage, covered with large, nearly sessile flowers. In any case the flower-stem is short. The corolla is of a bright rosy-carmine colour, with spotted centre and throat set with closely packed hairs. Leaf channelled and widely linear. April and May is the flowering time; July in the mountains, where the plant is entirely covered with flowers. Eastern Alps, from the Tyrol to Transylvania. It is in error that Williams ${ }^{1}$ ascribes it to Switzerland and arctic Russia. A white variety has been known, but, I believe, is not now in cultivation. It has been considered easy to grow Dianthus alpinus, but it is by no means so in such a dry and hot climate as that of Geneva. It is easier in England, where in gardens in hilly or mountainous places, especially on calcareous soil, it does very well. In some gardens in the Vaudois Jura it has become so freely naturalised that it has spread selfsown beyond the gardens' limits.

It requires stony, calcareous soil, half - sun in 1 F. N. Williams, "The Pinks of Central Europe," p. 40. 
continental climates, full sun in north and middle England. It is well to divide the tufts every two or three years; without this care they are easily lost.

$D$. arenarius (L.). - Near D. plumarius. A strongly cæspitose species, forming dwarf, spreading tufts with widely stoloniferous stems. Foliage bluishgreen. Flowers carried on erect, slender, unbranched stems three to four inches high, sweetly scented; petals of moderate size, deeply cut into numerous straps. From northern and eastern Europe, extending from Finland to Dalmatia and to the centre of Germany. It likes light, sandy soils, and flowers from May to August and September.

D. brachyanthus (Boiss.).-Much tufted and freerambling. Leaves narrow and bluish, flowers small, solitary, carried on stalks eight to ten inches high. Petals rose-coloured, not incised. June to August. Mountains of Spain in full sun.

D. brevicaulis (Fenzl.).-A small species with very dense bluish foliage. Flowers solitary on very short stalks, of moderate size and violet-carmine colour, centres hairy, edges toothed. June and July.

$D$. crsius (L.).-A small species, extremely cæspitose, forming large tufts of bluish foliage, spreading on the soil, and covered, in May and June, with large flowers of rosy flesh-colour, sweet-scented, petals irregularly toothed. Mountains of western Europe, from Somerset to Germany and from Dauphiny to Silesia. There are a number of 


\section{I34 CARNATIONS AND PINKS}

varieties and of hybrids, resulting from crossings both intentional and spontaneous.

It is a plant of firm texture, easily grown in gardens, where it is sometimes used as an edging. In its rocky homes it forms wide tufts, in halfsunny rather than wholly exposed places.

D. callizonus (Schott \& Kotschy). - The brightest of all the mountain Pinks, and one of the most sought for in gardens. Cæspitose, with linearlanceolate, pointed leaves, wide in the middle and of bluish colour, which at once distinguishes it from $D$. alpinus. The stalks are one-flowered, from six to nine inches high; the large flowers are of a tender rosy-carmine colour, with a band of bright red-purple in the centre. The edge of the petals is toothed, and the base thickly set with hairs. It blooms from May to July. We have a variety without the inner belt, but the type is the better flower. Mountains of Transylvania and Wallachia. It is rather difficult to grow. In our hot and dry summer climate we do well with it in the open ground, well drained, composed of one-third sand, one-third leaf-mould, and one-third loam, in a position sheltered from the sun during the greatest heat of the day.

In the Botanical Garden of La Linnæa, at an altitude of 4000 feet, it grows grandly and flowers abundantly, while at Geneva we have only two or three flowers on the two-year-old tufts. The variety Brandzae, of Pancic, has taller and more slender stems, and untoothed petals. 


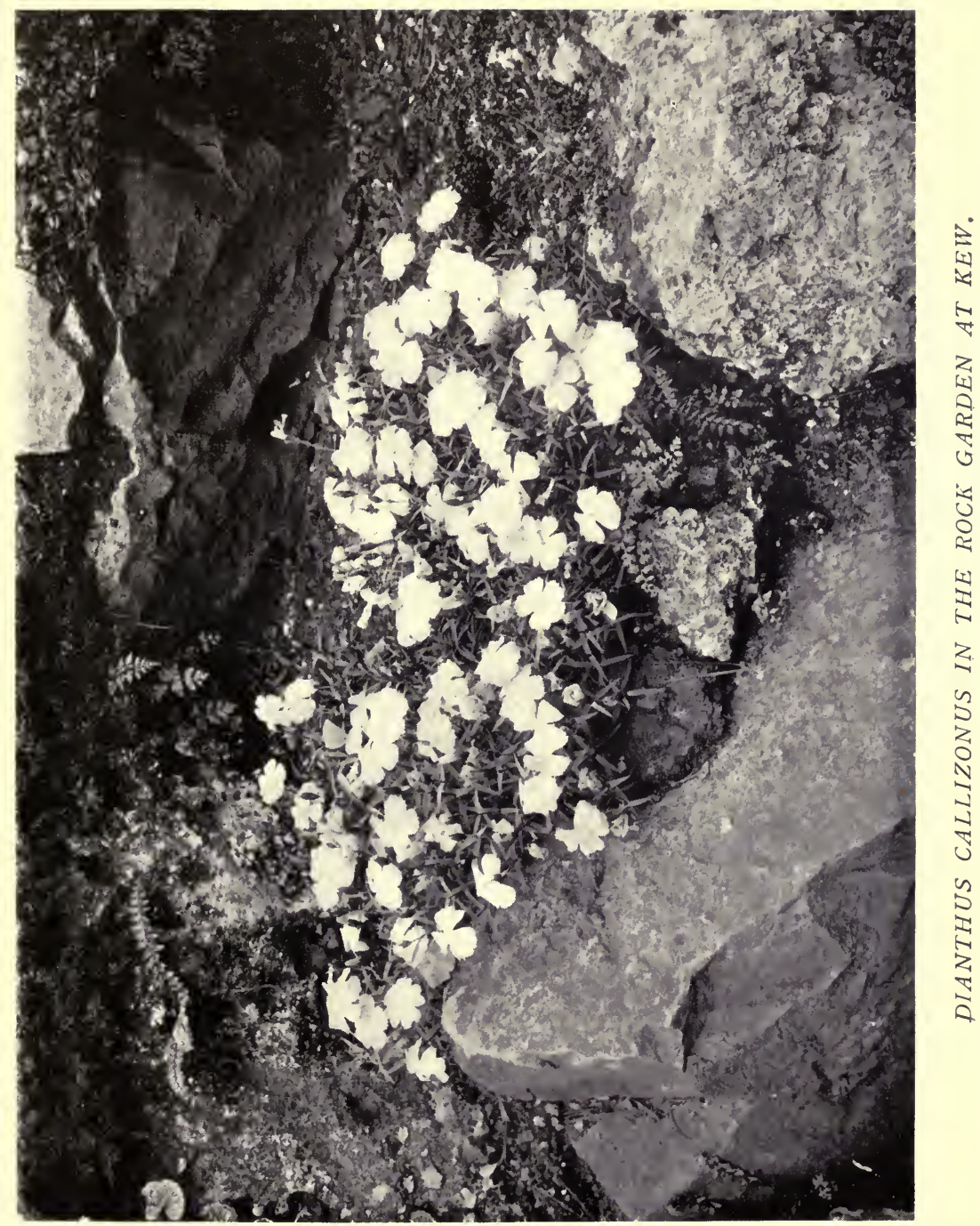




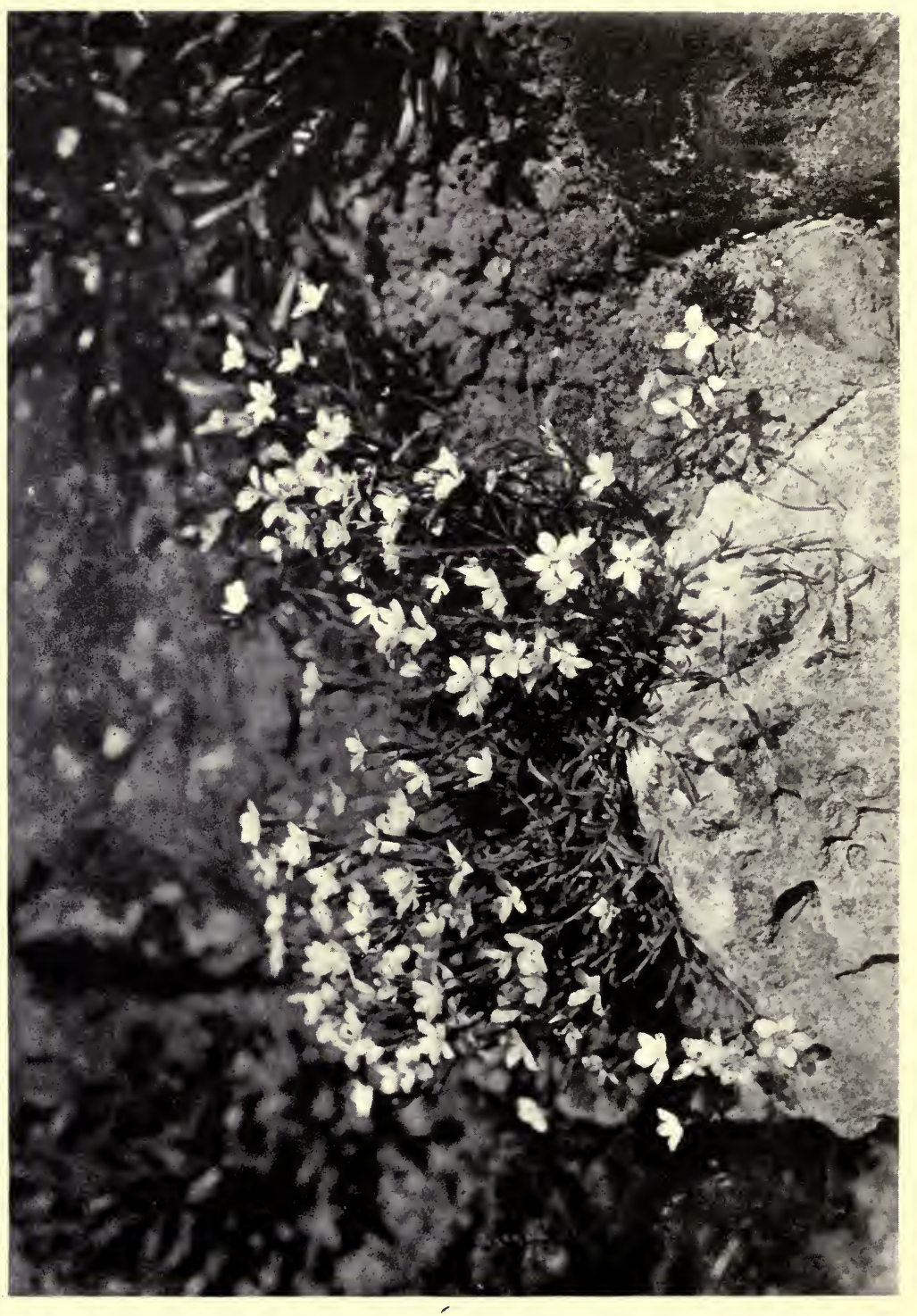

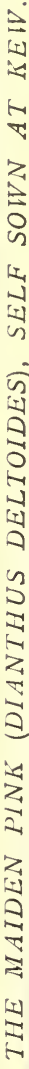




\section{THE PINKS OF THE ALPS I35}

D. deltoides (L.). - A many-stemmed, extremely turfy plant, forming large tuits of bright, shining foliage that in itself is ornamental. The flowers of moderate or rather small size, and of a bright rosy-carmine colour, are on branched stems from 4 to Io inches high; they are extremely numerous, and appear from June to late autumn. At the throat they have dark purple spots of delta form, hence the specific name. There is a variety with white flowers in which the spots are of a very dark colour, and another with bluish, glaucous leaves.

It is very easy to grow. Whether in sun or in half-shade it succeeds nearly everywhere, flowering with remarkable abundance. It can not only be used as an edging and in ornamental rock-work, but actually as a turf, and it is an admirable plant for clothing dry and arid slopes. It is found wild throughout a large part of Europe and temperate Asia.

D. Falconeri (Edgew.). - A small plant with extremely glaucous foliage, almost blue, with rambling shoots and small yellowish-white flowers that appear in May and June. We have had the seed from Mr. Duthie, Director of the Saharanpur Botanical Garden, marked provisionally as "Dianthus sp. Hazara." It was identified for us by Dr. F. N. Williams, but it does not quite correspond with Edgeworth's description, ${ }^{1}$ and Dr. Williams thinks that it is a new species not yet described.

D. fragrans (Bieb.). - A Caucasian plant, very rare 1 Hook, "Fl. Brit. Ind.," i. p. 214. 


\section{I36 CARNATIONS AND PINKS}

in cultivation, for under this name we generally have $D$. plumarius and its variety fragrans. The true $D$. fragrans is a tufted plant of a fine green colour, with stems 12 to 14 inches high, and pink flowers recurved at the edges, spotted with purple, and highly scented. May to June. Full sun.

D. Freynii (Vandas.). - A small species of the Transylvanian Alps, with narrow keeled leaves. Flower-stem short, two to three inches, bearing a solitary flower of a light rose-carmine colour, with yellowish reverse. May and June. Culture the same as for callizonus. I have seen lately, in the Botanic Gardens of Giessen (Germany), a white variety of it.

D. frigidus (Kit.). - Carpathians. A very small form of $D$. sylvestris; dwarf and few-flowered. I have never grown it, and only know it by description.

D. gallicus (Pers.).-Plant entirely sarmentose, with long branches spreading over the earth; leaves thick, dark green with bluish metallic shading. Flowers purplish crimson, of medium size, highly scented; petals laciniate. It flowers from June to October, forming pretty tufts, and likes sandy soil in full sun. It is a sea-coast plant, growing on the coasts of France and Portugal; abundant in the neighbourhood of Biarritz.

D. gelidus (Schott).-A small tufted plant; leaves narrow, one-veined, recurved at the edges; flowers large, of a fine crimson colour, spotted in the centre. May and June. This species is very near to glacialis, from which it is chiefly distinguished by the one- 
veined leaf (three-veined in glacialis), its larger, spotted flowers, and non-contiguous petals; also by its pointed calyx, with membranaceous acuminate teeth, which in glacialis are triangular-obtuse and scarious. It is a native of the Alps of Transylvania and the alpine zone of Wallachia, and likes a welldrained soil rich in vegetable humus, and a halfsunny exposure.

D. glacialis (Haenk.).-A pretty little species with long grass-like leaves, from the centre of which rise the flowers, half hidden by the foliage, which overtops them by a good third of their length. Corolla scentless, of a fine crimson colour. April and May. Eastern Alps, from the Canton of Grisons to the Carpathians and Balkans, in high alpine and granitic regions. It requires a half-sunny exposure and a non-calcareous soil, well drained. It is well suited with a compost of one-third each of peat, leaf-mould, and loam.

D. slutinosus (Boiss.).-A viscous-glutinous plant; leaves narrow, acute, incurved; flowers small, bright rose-coloured above, yellowish underneath, numerous, carried on stems from 12 to 16 inches high. May to July. Mountains of Macedonia and Asia Minor. Of easy culture.

D. gracilis (Sibth.).-Leaves bluish, linear, pointed, erect. Stems 9 to $\mathbf{I} 2$ inches, slender, bearing two or three flowers with deep crimson anthers. June and July. Balkans. Of easy culture.

D. graniticus (Jord.).-A small species with narrow, pointed leaves. Flowers usually solitary, carried on 
stems 4 to 6 inches high; calyx red; corolla rather large, bright flesh-pink, paler underneath; anthers bluish. June and July. In rocks in full sun. A native of the Pyrenees, extending through southwestern France from the department of Gironde as far as Gard.

D. hungaricus (Reich.).-A white-flowered variety of D. plumarius.

D. integer (Vis.). - A spreading plant from the mountains of Dalmatia. Stems prostrate; leaves linear-lanceolate; flowers small, reddish-violet, solitary, on short stalks 4 to 5 inches long. June and July. Situation dry and sunny.

D. microlepis (Boiss.).-A very small species, resembling a miniature $D$. glacialis; leaves short, flat, keeled, one-nerved; flowers small, solitary, stalk very short; corolla light rose-colour. It flowers in May and June, and we grow it in sunny rock-work. Native of the high mountains of Thrace, between 7000 and 8000 feet.

D. monspessulanus (L.). - Close tufts of bluish foliage, forming turfy, spreading masses, from which rise numerous erect stems 4 to 12 inches high, bearing large handsome, very sweet-scented flowers of a rose-lilac colour; petals beautifully fringed. June to August. A sunny position in rocky soil rich in humus, calcareous if possible. It grows in nearly all the mountainous regions of Europe. There is a variety, alpestris (D. alpestris) (Hoppe \& Sternb.), with short stems and solitary flowers; also a variety, erubescens (Tier.), with pink petals. 


\section{THE PINKS OF THE ALPS I39}

D. neglectus (Lois.). - This species, which many botanists consider to be only a variety of glacialis, is really quite distinct. I have pleasure in stating here that the Index Kewensis, whose tendency is to reduce the number of species, maintains it, while Williams erroneously holds that it is identical with glacialis, the two plants belonging to absolutely distinct groups. Dianthus neglectus not only has entirely different foliage (leaves linear-oblong, acute, glaucous, ending in a point and three-nerved, thus differing from its congener), but also its habit, manner of growth, stem, and inflorescence-all are different. $D$. neglectus grows in more or less dense, sometimes very wide, carpet-like masses, with the foliage dwarf and glaucous. From this rise the flowers, usually solitary, but sometimes several together, on stalks 4 to 6 inches high. The flower is large, of a fine bright crimson colour above, but greenish-yellow below, with bluish shades, thus accounting for the local name, the Blue Pink, by which it is known to the mountain folk of Dauphiny. With us it flowers from May to July (July to August in the mountains). It is one of the handsomest plants of our rock and alpine gardens. It requires a place in full light, and not too heavy a soil. It is easy to grow, and very floriferous.

It is to be regretted that this plant should be so little known, and that a plant that has nothing to do with the true neglectus should be generally sold under its name. Its home is in that group of eastern Alps between Turin, Grenoble, and Grasse; also in 


\section{I40 CARNATIONS AND PINKS}

the Pyrenees. It abounds at the Col du Lautaret, and especially in the Cottian Alps and the Piedmontese valleys of the Waldenses. It has been indicated in the Tyrol, but I think in error, the species being essentially occidental. It is so well acclimatised at the garden of La Linnæa that we find it in all sorts of corners where it has sowed itself spontaneously.

D. nitidus (Waldst. \& Kit.).-Close tufts of intense green foliage; stems slender and prostrate, bearing two to three handsome, sweet-scented pink flowers spotted with purple. June and July. Full sun. Carpathians and mountains of Macedonia. Rare in cultivation.

D. Nö̈anus (Boiss.).-A rather pretty, tufted plant, with fringed white flowers, three to five on stiff stalks. June and July. Mountains of Rumelia. Of easy culture.

D. petræus (Waldst. E Kit.).-Shoots spreading over the soil and forming tufts of foliage, leaves linearlanceolate, rigid. Flowers sweet-scented, pink, fringed. May to July. Balkans and Banat Mountains. Of easy culture.

$D$. plumarius (L.).-This species is the commonest and the strongest of the tufted group of Pinks; it is, besides, extremely variable. The type is handsome, and sweet-scented. The plant is tufted, leaves bluish-green, with numerous branches extended on the ground; flowers relatively large, extremely fragrant, the petals fringed and of a lilac-pink colour. May to October. From Hungary and southern Russia. It can be grown anywhere, except 


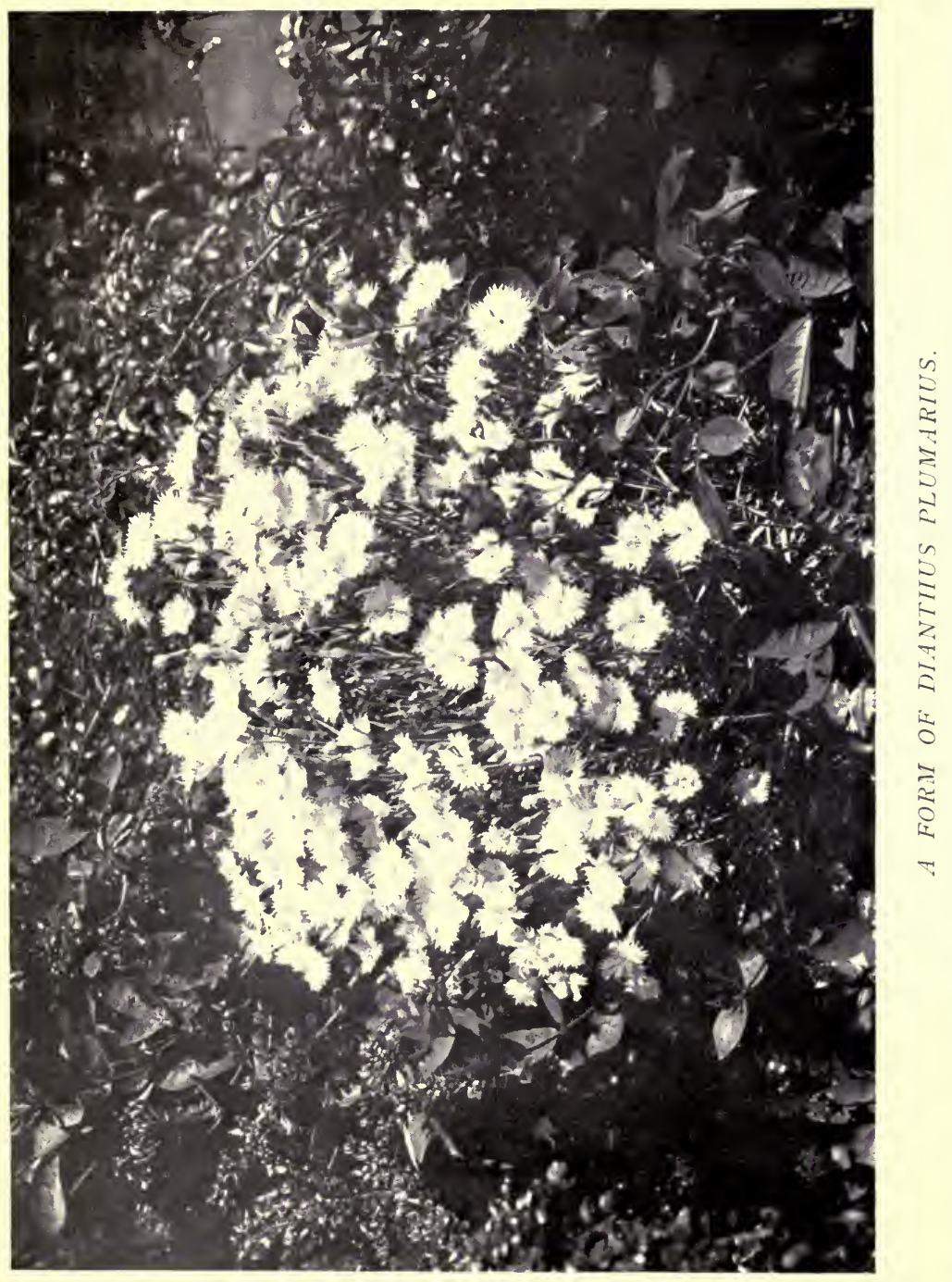





\section{THE PINKS OF THE ALPS I4I}

in shade. We have it at Floraire as edgings in a dry and arid place; these edgings are remarkably beautiful, and are much admired by our visitors in the spring. It sows itself in the poorest gravels. It is an excellent plant to sow in dry and sterile places, where it will grow to perfection.

The garden varieties of $D$. plumarius are well known, and under the name of Pinks are widely distributed in our English gardens. These are hybrids of-

\section{D. plumarius $\times$ cresius. \\ plumarius $\times$ Seguieri: \\ plumarius $\times$ Caryophyllus, \&c.}

At the great horticultural exhibition at Turin, Dr. Ragioneri, of Florence, showed a whole series of varieties and hybrids of $D$. plumarius, which had a fine effect and aroused lively interest.

D. polycladus (Boiss.).--Plant slightly hairy-tomentose, forming pretty spreading tufts, from which rise a quantity of flowers, not very large, but of a light rosy-carmine colour, making a considerable effect from their great number. May and June, with sometimes a second bloom in autumn.

We have had from the Lebanon, under the name $D$. polycladus diffusus, an extremely floriferous variety of this handsome species, with bright crimson flowers, and have thought it better than the type. In a burntup gravelly corner at Floraire we have had it full of flower from May to July. D. polycladus is an oriental plant, growing in the Anti-Lebanon and on the hills of northern Syria. It must have full sun. 
D. pungens (Gren. \& Godr.).-A spreading, glaucous plant, with suffruticose (rather shrubby) base and thickened rhizome; stems from 8 to ro inches high, bearing from one to three small, rose-coloured, insignificant flowers. July and August. Full sun. From the south of France.

D. sabuletorum (Wilk.).-A plant of little decorative value, rather erect than tufted in habit; stem 4 to 8 inches high; flowers small, and without scent. June to August. Mountains of Spain.

D. serotinus (Waldst. \& Kit.). - Rather near plumarius; leaves glaucous; stems spreading; flowers rather large, white, very fragrant, and deeply fringed. June and July. Eastern Europe.

D. spinosus (Desf.).-A Persian plant, which has no right to the name Dianthus, its real name being Acanthophyllum Fontanesii (Boiss.).

D. squarrosus (Bieb.). - A tufted plant, with the branches spreading on the ground, stems slender, few-flowered; leaves linear-acute, recurved; flower pink, of moderate size; petals bearded and deeply cut. June and July. Southern Russia. Full sun.

D. Sternbergii (Sieber.). - Glaucous and cæspitose, near monspessulanus, with two-flowered stems 8 to ro inches high; flowers pink, petals bearded and fringed. It differs chiefly from monspessulanus by its lesser height and by the petals being spotted and noncontiguous. May to July. Half shade, a soil rich in humus and, if possible, calcareous. Mountains of southern Europe.

D. suavis (Wild.) is a form of cxsius. 
D. subacaulis (Vill.).-A very small species, with glaucous foliage forming small rosettes. These gathered together in quantity form wide, flat tufts. They are covered with small rose-coloured flowers borne on stems 2 to 3 inches high in June and July. Sun and rocky soil. Native of rocks in the alps of Dauphiny and the mountains of Spain.

D. tener (Balbis.).-A plant with a slender rootstock throwing out a number of sterile shoots bearing narrow linear leaves, striated beneath and furrowed at the edges. Flowers small, rose-coloured; stems simple, tetragonal, 3 to 6 inches high. June and July. Dry place in sun. Pyrenees, mountains of Spain, and Maritime Alps.

D. viscidus (Bor. \& Chaub.). - A tufted, viscous, and pubescent plant; leaves flat, acuminate; stems slender, simple, from 6 to 8 inches high, bearing fasciculate clusters of from five to six flowers that are small, deep carmine-red and spotted with purple. June to August. Of easy culture. From the Balkans.

\section{SECOND GROUP}

In the second division, the one comprising the slimmer, upright-growing species, the plants are not those of the rocks and alpine pastures and other mountainous places, but of lower regions, such as meadows, woods, and valley slopes. The following species are in cultivation:-

D. acaulis (Hort.).-A very pretty form of D.sylvestris, with large, scentless flowers of a bright pink colour, 


\section{44 CARNATIONS AND PINKS}

bluish towards the base of the petals, which are slightly fringed and carried on stems $\frac{3}{4}$ to 2 inches high. The wealth of flowers makes the tufts very ornamental. May and June. Sun, and preferably in rockwork. This form sows itself in our Jardin alpin d'acclimatation at Floraire.

D. ambiguus (Panc.).-Stems I6 to 20 inches high, quadrangular; leaves flat. Flowers in close heads, their petals violet-red. June and July. Servia and Bulgaria.

$D$. arboreus (L.).-A tall plant, attaining a height of 39 inches; root-stock woody, crooked; stems woody at the base, bearing many-flowered corymbs of handsome, rose-coloured, fragrant flowers, whose petals are spotted with deep purple. July and August. Greece and Macedonia. Rare in cultivation; with us it suffers from the winter's frost, and has to be housed in the orangery.

D. aridus (Janka).-A handsome species, with wide leaves of a bright green colour; stems simple, 4 to 8 inches high. Fine flowers of a bright canary-yellow ; petals slightly toothed, two to four together on very leafy stems. June to August. This beautiful species grows in sterile regions in Bulgaria and Servia. It stands the winter well with us if it is given a dry, rocky place in full sun.

D. Armeria (L.).-A biennial species, forming dark, slightly downy tufts. Stems 8 to 16 inches high; leaves flat; flowers small, numerous, bright crimson, set together in forked terminal bunches. May to August. In woody regions of all Europe, and a plant 


\section{THE PINKS OF THE ALPS I 45}

of the easiest culture. It should be seen in half shade.

D. atrorubens (All.).-An Alpine form of D. Carthusianorum, distinguished from the latter by its taller stem of from I9 to 28 inches, its numerous flowers clustered in large heads, and its longer and narrower petals of a very deep red colour. June and July. Eastern and southern Alps.

D. attenuatus $(S m$.).-A glaucous plant, with suffruticose base; stems I9 inches high, diffuse, tortuous; flowers in pairs, small, in lax panicles, pink, inodorous. May and June. Pyrenees, mountains of Spain, and the Atlas.

D. Balbisii (Ser. non Schur.) is a variety of D. Carthusianorum, with glaucous leaves.

D. banaticus (Heuff.).-A glaucous plant. Stems Io to 12 inches high, simple; leaves outspread, with recurved edges; flowers bright rose, rather small, in close heads of from ten to twelve blooms. June and July. Balkans and Banat Mountains.

D. bicolor (Bieb.).-A pretty species, with upright stems ro to 12 inches high, furnished with broad leaves, and of a rather bluish-green colour, and surmounted by one to five flowers, bright rose above and greenish-yellow below, as in $D$. neglectus. June to September. Caucasus.

D. blandus (Reich.).-This is a variety of D. plumarius, with handsome rose-coloured flowers.

D. Boissieri (Willk.).-A stout plant, with bluish leaves; stems I 2 to 16 inches high, erect, one or two flowered; leaves thick and narrow; flowers large, 


\section{I46 CARNATIONS AND PINKS}

rose-coloured, unevenly toothed, with yellow anthers. July and August. Mountains of Spain and Portugal. With us it requires a dry, hot position, and a soil rich in humus.

D. calocephalus (Boiss.).-A glaucous plant, with stiff, simple stems 27 to $3 \mathrm{I}$ inches high. Flowers small, five to seven together in a head or dense corymb. Corolla bright rose spotted with purple. June and July. Balkans and mountains of Asia Minor.

D. campestris (Bieb.).-A tufted plant, with many leafy stems $\mathrm{I} 2$ to $\mathrm{I} 6$ inches high, bearing numerous paniculate flowers of moderate size that are bright rose above and yellowish underneath. June to August. Caucasus.

D. capitatus (Balb.).-An upright, glaucous plant, with simple, four-sided stems 8 to I6 inches high, bearing heads of from six to eight bright crimson Howers spotted with dark purple. June to August. Mountains of the Levant.

D. Carthusianorum (L.).-A polymorphous plant with pale green leaves, rarely bluish; stems unbranched, four-sided, 8 to I6 inches high; flowers small, brilliant carmine. May to August. Mountainous regions of Europe. One of the easiest plants to cultivate, and one that succeeds best in dry and arid places, also among grass, as well as in the open ground. A number of varieties are in cultivation, of which the most distinct are: pumilum (Schur.), from Transylvania; Pontederx (Kern), from the Italian Tyrol; Sabuletorum (Heuff.), from the mountains of Austria.

D. ciliatus (Guss.).-A beautiful southern species, 


\section{THE PINKS OF THE ALPS}

near $D$. sylvestris, from which it is chiefly distinguished by its ciliated calyx, and also by its larger and sweetscented flowers. Corolla of a fine rose colour; sometimes pure white. July and August. Sicily, Egypt, \&c. Scarcely hardy in our climate, where it must have a dry, hot exposure.

D. cinnabarinus (Sprun.).-A many-stemmed plant, shrubby at the base, with radiating roots. Stems unbranched, four-sided, 4 to 6 inches high; leaves flat, stiff, pointed; heads few-flowered. Flowers cinnabar-red, yellowish on the under sides of the petals. June. Greece, in the rocks of Mount Parnassus and of Mount Malevo in Laconia.

This very curious plant, the only one of its colour in the genus Dianthus, is probably lost to cultivation. Though formerly abundant in gardens it is no longer to be found. The firm Haage \& Schmit sent us seed in 1894 ; we subsequently distributed plants, and had some in flower in our Swiss National Exhibition in 1896. Since then we have lost it, and have been unable to obtain it again. Should any reader have it, or be able to tell me where to obtain it, I should be grateful for the information. Everything that we have received of late years, both of plants and seeds, under its name have been wrongly named, and have had nothing whatever to do with the true Dianthus cinnabarinus.

It grew very well in poor, deep, sandy soil, in full sun. It dislikes damp.

D. cinnamomeus (Sibth. \& Smith).-A plant ro to I2 inches high; stems paniculate-corymbose, set 


\section{I48 CARNATIONS AND PINKS}

with blunt, flat, bluish-green leaves; flowers bright rose, greenish-purple below, petals irregularly toothed. June to August. Caucasus and Asia Minor.

$D$. Courtoisii (Reich.) is a variety of $D$. superbus.

D. cruentus (Gris.).-A stout plant, 20 to $3 \mathrm{I}$ inches high ; stems upright, bearing close, globular heads of eighteen to twenty-five scentless flowers of a brilliant crimson colour with blue anthers. May to July. Greece, the Balkans, and Herzegovina.

D. fimbriatus (Bieb.).-A many-branched plant, with half shrubby base, stem slender, simple, I2 to I6 inches high; leaves short, straight, linear, rough at the edges; flowers rose-coloured, fringed. May to July. Caucasus. There are many forms and varieties.

D. Frizualdskyanus (Boiss.).-A glaucous plant; stems angular at the base; leaves triquetrous, also linear-acute; flowers pink, two or three on stems 8 to ro inches high. May and June. Mountains of Thrace. The plant somewhat resembles Saxifraga iuniperina. Rocks, in full sun.

D. giganteiformis (Borb.).-A much taller and altogether larger variety of $D$. Carthusianorum; found in mountainous regions of eastern Europe.

$D$. giganteus (Urv.).-A plant with bluish foliage, 24 to 28 inches high; flowers of medium size; ten to twelve in a close head on unbranched upright stems; bright crimson, with blue anthers. June and July. Balkans.

D. Heptaneurus (Gris.).-A plant 24 to 26 inches high; leaves linear-oblong, with seven veins; flowers 


\section{THE PINKS OF THE ALPS I49}

crimson, rather small, fasciculate. June and July. Hungary.

D. hispanicus (Asso.).-Glaucous, with half-shrubby base, stems 8 to ro inches high, three-nerved; flowers rose-coloured, with violet anthers. May to June. Mountains of Spain.

D. Knappi (Asch.).-A D. Carthusianorum, with yellow flowers and blue anthers, forming one of the most beautiful of species. The flowers are borne in heads more or less compact; the under sides of the petals are of a reddish-yellow, while the upper surface is a sulphur yellow. June and July. Banat Mountains, Herzegovina, Apulia, \&c. With us it requires a place in full sun, in well-drained, porous soil.

D. Libanotis (Labill.).- This is another beautiful and curious species, rarely found in gardens. A plant with few shoots, bearing a small number of thick leaves of the size and shape of those of Malmaison Carnations, extremely glaucous, very stiff, and deeply channelled. The shoots are drooping or sinuous, very thick, and terminated by large flowers powerfully scented; petals large and white, fringed like $D$. superbus, and spotted with brown and yellow; the anthers are golden-yellow. June and July. Lebanon.

Two years ago we received seed from the Lebanon, and have done fairly well with it in dry, rocky soil in full sun. The plant, however, always looks somewhat out of health, and it is possible that the soil we have given it is not the most suitable for its wellbeing, though it has flowered well in spite of its want of vigour. 


\section{I50 CARNATIONS AND PINKS}

D. Liburnicus (Barth.).--Stems simple, erect, ro to 20 inches high; four to six flowers in a head. June and July. Southern Europe.

D.Mrsiacus (Panc.).-A variety of D.Carthusianorum, with rough leaves and loose heads of the same crimson flowers.

D. pallens (Sibth.). - Foliage glaucous, stems upright, reddish ; leaves flat, rough at the edges; flowers small, fasciculate, milk-white inside, and greenishbrown or bronze beneath. July and August. Mountains of the Levant. Rock, in full sun.

D. papillosus (Vis.). - A rare plant. I received it from Servia in 1894 , but have lost it since r9oo. I am unaware whether it is elsewhere in cultivation. Stem four-sided ; leaves thick; flowers crimson, large, spotted ; anthers blue. It is near D. sylvestris. May to July. Balkans. Rock, in full sun and in well-drained soil.

D. pinifolius (Sibth. \& Smith).-Leaves extremely narrow and stiff, dark greyish-green. Flowers small, scentless, dark violet-rose, in close heads, borne on slender, drooping stems i6 to 20 inches long. July and August. Balkans, Greece. Rock in full sun.

D. pubescens (Sibth. E Smith).-A glandular-pubescent, hispid plant, 8 to 12 inches high; leaves flat, three-nerved; flowers one, sometimes two, scentless, borne on long peduncles; corolla rather large, rosecolour, spotted above, yellowish-green below. June and July. Caucasus, Balkans, \&c.

D. Requienii (Gren. E Godr.).-Close, compact tufts of glaucous foliage, stems quadrangular, bifurcate, ro 


\section{THE PINKS OF THE ALPS I5I}

to 12 inches high; leaves narrow, pointed, erect; flowers bright crimson, in terminal bunches. May to August. Pyrenees. Rock, in half sun.

D. rupicola (Jord.) is a variety of $D$. sylvestris.

D. rupicola (Bivon), syn. D. Bisignani (Ten.).-A pretty Sicilian species, tender in our climate; flowers 3 to 5 inches, in wide fasciculate cymes, large and handsome; corolla rose-coloured, with reddish anthers, on erect stems I 2 to I4 inches high. June to August. Sicily and Tunis. Too tender for us; we have to winter it in the orangery.

$D$. sanguineus ( $V i$ s.). - I can see no difference between this variety of $D$. Carthusianorum and $D$. cruentus, if I may judge by the many parcels of seeds I have received from various gardens.

D. saxicola (Jord.) is a large-flowered variety of D. sylvestris.

D. Seguieri (Chaix.).-A plant with erect shoots forming a little bush 30 inches high; leaves widely linear, flat, stiff and pointed, bright green; flowers of medium size inclining to large, very bright crimson, toothed at the edges, and spotted with purple at the throat. June to August, and even to September. Southern Europe.

D. speciosus (Reich.).-A variety of $D$. superbus.

D. strictus (Sibth. \& Smith).-A small species with stiff, upright stems 8 to ro inches high; leaves linearlanceolate ; flowers small, scentless, and rather inconspicuous. June and July. Levant.

$D$. superbus (L.).-A beautiful plant, well known in gardens, where it is valued from its graceful habit, its 


\section{I52 CARNATIONS AND PINKS}

paniculate stems sometimes over 3 feet in height, and its deliciously fragrant flowers, which are of a pale lilac colour with greenish spots at the base, and have their edges delicately cut and fringed. It is a plant of wood and thicket, blooming from June until autumn. It should be treated rather as a biennial than as a perennial. There are a great many forms and varieties, of which the best is D. speciosus, an alpine form, with dwarf habit and very large flowers. There are also $D$. nanus, $D$. Wimmeri, \&c., both very floriferous, and best of all, the beautiful $D$. Hoeltzeri, which blooms early, May and June, and produces a fine effect.

D. sylvestris (Wulf.).-A polymorphous species, well known in gardens, where it is a brilliant and effective ornament. It is a dwarf, closely-tufted plant, with slightly bluish foliage; leaves narrow, grass-like, arched; the pink flowers large, elegant, bluish-spotted at the base of the petals, with blue-lilac anthers; petals more or less toothed. The plant is stout and strong, extremely floriferous, blooming from June to September in rock-work in full sun. It is a native of central and southern Europe, and is found in a considerable number of varieties. I have found one near Bourg St. Pierre with pure white flowers.

D. tenuifolius (Schur.).-A variety of D. Carthusianorum, with very slender leaves.

D. tergestinus (Reich.).-A variety of D. sylvestris, with a long stem and small flowers.

$D$. vaginatus (Vill.).-A variety of $D$. Carthusianorum.

D. versicolor (Fisch.). - A tufted plant, , o to 14 inches 


\section{THE PINKS OF THE ALPS 153}

high, stems erect, paniculate, branching, set with flat widely linear leaves. The radical leaves are recurved, the stem leaves incurved. Flowers rather large, bright crimson, spotted, greenish on the under side; anthers blue. June to August. Siberia.

D. virgineus (Gren. \& Gort.). - A glaucous plant, 8 to 1o inches high, stems simple or very slightly branched, flowers solitary, fragrant, rose-coloured with violet anthers; petals toothed. May to July. Western and southern France and Mediterranean region. Not quite hardy with us.

D. Wimmeri (Wich.).-An earlier variety of $D$. superbus, with smaller flowers of a pale lilac colour.

As the greater number of the species in this section can be grown as ordinary herbaceous plants without any unusual care or preparation of soil, I have in many cases given no special cultural directions.

All the Dianthus can be easily raised from seed, which germinates quickly. Some of the alpine species produce very little seed; in this case they can be increased by cuttings, which root freely. 



\section{N D E X}

Agrostemma, 4

America, Carnation growing in, 75; Carnation Society, the, 77

Anemone Pulsatilla, 4

Armeria alba, 5 ; A. rubra, 5

Atkinson, Mr., and the Pink, 106

Acanthophyllum Fontanesii, 142

Area coronalis, 3

BACTERIOSIS and the Carnation, 92

Balfour, Lady Eleanor, 24

"Book of the Carnation," Brotherston's, 45

Bordeaux mixture, preparation, 92

Bradley, Professor, and the Carnation, 2

Calathus, the, 6

Cantabrica, 3, 6, 7

Cariophillon, 2

Carnation, Alegatiere strain, French varieties of the, 75 ; and bacteriosis, 92 ; and Cranefly, 90 ; and Daddy-long-legs, 90 ; and Gout, 93 ; and Greenfly, 84 ; and Red Spider, 90 ; and Spittle-fly, 84; and Sparrows, 93 ; and Thrips, 90 ; and the history of hybridisation, 4 ; and wireworm, 88 ; Adonis 80; Agnes Sorrel, 29; Alba, 53; Admiral Curzon, 29; Arline, 30 ; Alisemond, 30 ; America, 52; Ann Boleyn, 29 ; Apollo, 53 ; Ascot Yellow, 34 ; Benbow, 29 ; Cecilia, 29 ; Banner, 29 ; Bookham Clove, 29 ; Boreas, 29; Border, varieties of the, I4; C. F. Thurston, 30 ; Comet, 29 ; Copperhead, 29 ; Belladonna, I2, I5; Burn Pink, 29; Countess of Paris, I4 ; derivation of the word, 3 ; Chas. Henwood, 30 ; disease of the, 8I ; Dorothy Whitney, 53; Dr. Hogg, 29; Duchess of Fife, I 5 ; Dundee Scarlet, 67 ; Earl Stamford, 30 ; early history of, I ; Edward Adams, 29; Enchantress, 53, 80; English v. American, 76; Ethel Crocker, 80; exhibition, layering, 60; Fiancée, 80 ; Flambeau, 30 ; Flamingo, 80 ; Floriana, 80; Fred Phillips, 30 ; flowers, their use in chaplets, 3; Francis Wellesley, 67 ; fungoid diseases of, 9I ; Garvel Gem, I5 ; 
George, 29; General Maceo, 8o; George Maquay, I4, 67 ; George Melville, 30 ; Germania, 14; Gil Polo, 29; Harmony, 30 ; Gloire de Nancy, 67 ; Gordon Lewis, 30 ; Governor Bliss, 53 ; Governor Roosevelt, 80 ; Great Double, 3 ; growing, in America, 52, 53, 75 ; picturesque, object of, 9 ; Guardsman, 30; Henry Fenn, 80 ; Herbert J. Cutbush, 29 ; hares and rabbits among, 93 ; Hogg on the, 33 ; Harlowarden, 80 ; importance of equable climate for, 9 ; in the garden, 8; James Douglas, 30 ; J. S. Hedderley, 30 ; John Keet, 30 ; John Wormald, 30 ; Ketton Rose, 29 ; Lady Bountiful, 80 ; Lady Hermione, 29 ; Lady Hindlip, 29 ; Lilian Bond, 8o; Lady Mary Currie, 30 ; layered (illus.), 21 ; Maceo, 76 ; Master Fred, 30 ; Matador, 30 ; Melba, 80 ; Melody, 30; Mephisto, 12, 29 ; Midas, I 2, 29 ; Miss Alley, 14; Miss Audrey Campbell, I2; 29, 67 ; Miss Shiffner, 29 ; Mrs. Sydney Diver, 29; Mrs. Eric Hambro, 29 ; Mrs. Keen, 30 ; Mrs. Reynolds Hole, I2 ; Mrs. Tom Lord, 30 ; Mrs. T. W. Lawson, 52, 76, 80 ; Nautilus, 4 r

Malmaison Albion, 39, 40, 41 ; Calypso, 41 ; Horace Hutchinson, 4I; Iolanthe, 41 ; King Oscar, 4I ; Lady Grim- ston, 40 ; Lord Rosebery, 40 ; Maggie Hodgson, $4 \mathrm{I}$; Mary Measures, 4I ; Monk, 4I ; Mrs. Everard Hambro, 40 ; Mrs. Martin Smith, 4 I ; Mrs. Trelawny, 4I ; Nell Gwynne, 40 ; origin of the, 45 ; Prime Minister, 40, 41 ; Princess May, 40 ; propagation of, 42 ; Sir Charles Freemantle, 40 ; Sir Evelyn Wood, 40; The Churchwarden, 40; Thora, 4 I ; Trumpeter, 40 ; varieties of the, 40 ; maggot, 85

Mrs. Theodore Roosevelt, 53 ; Norway, 80 ; Prince of Orange, 34; Robert Houlgrave, 30 ; Squire Whitbourne, 30 ; Society, American, the, 77 ; Old Clove, the, 67 ; old abbey and monastic ruins, 3 ; Painted Ladies, 6 ; Pandelli Ralli, 14 ; Pandora, 30 ; Paul Engleheart, 67 ; Phœbe, 30 ; Quentin Durward, 67 ; Raby Castle, I 5, 67 ; Robert Lord, 30 ; Royalty, 8o ; Sarah Payne, 30 ; Seymour Corkran, 29; spot on the, 92 ; Sportsman, 30 ; Squire Penson, 30 ; Stella, 53; Tenella, I 5 ; Thaddeus, 30; Thalia, 30 ; the President, 80 ; the Queen, 76

Tree, 47 ; America, 52; Countess of Warwick, 52 ; Duchess of Devonshire, 52 ; from seed, 51 ; General French, 52 ; Lady Carlisle, 52 ; Lizzie McGowan, 52 ; Lord Roberts, 52 ; Mlle. Therese Franco, 52 ; 
so-called for autumn flower beds, Io; potting the, 50 ; Sir Redvers Buller, 52 ; varieties of the, 52; Tree or Perpetual, propagation of the, 48 ; William Robinson, 52

Triton, 29; Trojan, 29; Uriah Pike, I 5, 67 ; versus Eelworm, 86 ; where to plant the, 10 ; White Lawson, 80; White Star, 67 ; wild, the, 117 ; William Skirving, 30; writers of antiquity on, I

Carnations and the Earwig, 86; Bizarresand flakes, 29; border, 24 ; Continental plan of growing, 8; description of, 32 ; disbudding, 23; drying off, $8 \mathrm{r}$; Fancy, 29; for exhibition, 54; from cuttings, 2 I ; from seed, I 8 ; hares and rabbits among, 8 ; Hayes' Scarlet, I 5 ; hybridising in the open, $15,16,17$; importance of spring planting, 64 ; in Fifeshire, 25 ; in summer time, 22; in Spain, 8; in tubs and window boxes, 69 ; in town gardens, 63 ; propagation of, 67 ; summer treatment of, $65,66,67$; varieties of, 67 ; layering, 19 ; Malmaison, failure out of doors, IO; Marguerite, 7I ; planting, 27 ; Ruby Pink, II ; Trojan, II ; Old Clove, II, I 5 ; staking, 22 ; varieties of, I I, 28; varieties of, at the end of the sixteenth century, 3

Caryophyllus Carthusianorum, 5 ; maximus multiplex, 3; sylvestris, 7
Castore Durante's Herbarium, 6

Catling, Edward, 32

Chaucer, 2

Clou de Girofle, 2

Clove, the, 2 ; Old, in a town garden, 63 ; Pink, the, I 17

Cloves by the sea, Io

Coquelourde, 4

Coronaria, 4

Coronation, 3

"Century Book of Gardening," 87

Cranefly, the, and the Carnation, 89

DADDY-LONG-LEGS and the Carnation, 89

Dean, R., Mr., I03

Des Armoiries, 5

Dianthus acaulis, 143; Alice Lee, I05 ; alpinus, II6, I30, I 32 ; ambiguus, 144 ; arboreus, IIO, III, I44 ; arenarius, 125, I33; aridus, I44; Armeria, 113, 144 ; Atkinsoni, I06 ; atrorubens, I I I, I I 2, I45 ; attenuatus, I45; Balbisii, I 45 ; banaticus, I45; barbatus, 5, IIO, I14 ; b. latifolius, I1 15 ; b. magnificus, I 16 ; bicolour, I45 ; Bisignani, I I I ; blandus, I 45 ; Boissieri, I45 ; brachyanthus, 133; brevicaulis, I16, I33; cæsius, 108, I 17, I30, I 33 ; callizonus, I29, I34 ; calocephalus, I 46 ; campestris, I 46; capitatus, I 12, I46; Carthusianorum, I 1 2, I 28, I 30, 145, I46; varieties: pumilum, Pontederæ, Sabuletorum, I46; Caryophyllus, I, I17, I28; on 
Rochester Castle, 3 I ; chinensis, 71, 72, 73, I 18 ; var. dentosus, I I 8 ; ciliatus, $120, \mathrm{I}_{46}$; cinnabarinus, I I 2 , I 47 ; cinnamomeus, I47 ; Courtoisii, I48; cruentus, II 2, I28, I48; Cyclops, I08; deltoides, ro8, I10, I20, I35; glauca, I 20; derivation of the word, 4 ; Diadematus fl. pl., I20; Falconeri, I35; fimbriatus, I48; fragrans, I20, I36; double variety in Mr. Turner's nursery, I2I ; Freynii, I21, I36 ; frigidus, I 36 ; Friwaldskyanus, I48; gallicus, 126, I 36 ; giganteiformis, 148; giganteus, I 12 , I 13, I28, I48; gelidus, I36; glacialis, I2 I, I29, I 30, I 37 ; glacialis gelidus, I 2 I ; glutinosus, 137 ; gracilis, I 37 ; graniticus, I37 ; Grievei, I06; Heddewigii, II8; Heptaneurus, I48; hispanicus, I 49 ; hungaricus, 138 ; integer, 138 ; intermedius, I I3; Knappii, I13, I49; Lady Dixon, I06; leptopetalus, 122; Libanotis, I49; Liburnicus, I 13, I28, I 50 ; longicaulis, I22; Mœsiacus, I 50 ; masmenæus, I 22 ; Marie Paré, I06; microlepis, 122, 138 ; monspessulanus, I26, 129, I38; monspessulanus alpestris, 138 ; monspessulanus erubescens, 138 ; nœanus, I23, I40; Napoleon III., 99, IO2 ; neglectus, I 22, I30, I39; nitidus, I23, I40; petræus, I23; pallens, I50 ; papillosus, I 50 ; petræus, I40 ; pinifolius, I23, I 50 ; plumarius, 5, 126, 138, 140; plumarius $\times$ cæsius, $14 \mathrm{I}$; plumarius $\times$ Caryophyllus, I4I ; plumarius $\times$ Seguierii, I4I; polycladus, I4I ; diffusus, I4I ; pubescens, 124,150 ; pungens, I24, I42; Requienii, I26, I50; rupicolor, III, I 5 I ; sabuletorum, I42; sanguineus, $15 \mathrm{I}$; saxicola, I51; Seguieri, I 16, I 5 I ; siculus, I24; serotinus, I42; speciosus, I 5 I, I52; Spencer Bickham, I08; spinosus, 142; squarrosus, 127, I42; Sternbergi, 127, I42 ; strictus, I24, I 5 I ; s. bebius, I24; suavis, I42; subacaulis, I24, I43; superbus, I08, I IO, I27, I 30, I5I ; and varieties: nanus, Wimmeri, Hoeltzeri, I 52 ; sylvestris, I24, I27, I30, I 43, I52; tener, I25, I43 ; tenuifolius, I52; tergestinus, I 52 ; vaginatus, 152 ; versicolor, I52 ; virgineus, I53; viscidus, 125, I43; Waldsteinii, I27; Warley, I08; Wimmeri, I 53 ; zonatus, 125

Dianthuses from seed, I 53

Diseases, fungoid, of the Carnation, 9I

Dodoens' Imagines Stirpium, 2 Dormer, Frederick, Mr., 53

Douglas, James, Mr., 82

EARWIGS and the Carnations, 86

Eelworms and the Carnations, 86 ; Stem, the, 87

Empress Josephine, 33, 39 
Exhibition, Carnations for-a year's work, 54 ; Carnations, layering, 60

\section{FAIRCHILD, Mr., 4, 99}

Fifeshire, Carnations in, 25

Finch, Frederick, 32

Fisher, Peter, Mr., 53

Fitch, Adam, 32

"Floricultural Cabinet," 32

Forficula auricularia, 86

Fungoid diseases of the Carnations, 9 I

GARDEN, Carnation, the, in the, 8,102

Gardens, Town, Carnations in, 63 ; Carnations in, propagation of, 67; Carnations in, summer treatment of, 65 ; the Old Clove in, 63 ; varieties of Carnations for, 67

Gariophlus, 2

Garyophillata siluestre, 7

Gelower, english wylde, 7

Gerarde, 2, 3I; and the "Pinkes," 7

Gillyflowers and Shakespeare, I ; and "Winter's Tale," I

Godfrey, W. J., Mr., 83

Gout and the Carnation, 93

Green-fly and the Carnation, 84

Grieve, James, Mr., and the Pink, Io6

Gyrofflees, 7

HARES and Rabbits and the Carnation, 93

Headly, Richard, 32

Helminthosporium echinulatum, 9I
Herba Tunica, 6

Hogg on the Carnation, 33; and the Pink, 95

Honesties, small, and their use in physicke, 7

"Horseflesh," 3

Hybridising Carnations in the open, 16,17

Hylemyia nigrescens, 85

"Index Kewensis," the, I39

"JARDIN ALPINE D'ACCLIMATATION," I 44

"Jove's flower," 4

Jullyflower, 2

July-flower, 2

Keynes, John, Mr., the late, 94

LADHAMS, Mr., 99

Leete, Master Nicholas, 3 I

Lychnis monachorum hortensis, 5

MAJOR, Mr., IO4

"Malmaisons, Martin Smith's," $4 \mathrm{I}$

Matthiolus, 2

Nelson, Captain, the late, and the Pink, Io6

Nyman and the European Pinks, I Io

OCELluS, 2, 5

Eillet, 2, 5

Oeilletz, 7

PARKINSON and the Sweet William, 5 
Pasque-flower, 4

Perkins, Mr., 34

Picotee, Abbot, 35 ; Acme, 30, 35 ; Alcinous, 35 ; Aldeboran, 35; Alladin, 35 ; Alpine Glow, 80; Amphion, 35 ; Amy Robsart, 30 ; Argosy, 35 ; Astarte, 35; Borderer, 35 ; Brunette, 30 ; Calypso, 30 ; Caracci, 35 ; Childe Harold, 34,35 ; culture of the, 36 , 37 ; Dalkeith, 35; Daniel Defoe, 35 ; Dr. Epps, 30; Duchess of York, 30 ; Empress Eugenie, 35 ; Ethel, 30 ; Etna, 30 ; Evelyn, 35; Fanny Tett, 30 ; Fortrose, 30 ; Ganymede, 30 ; Gertrude, 35; Glee Maiden, 35 ; Grace Darling, 30; Grace Ward, 30 ; Hesperia, 35 ; John Smith, 30 ; Kate Coventry, 35 ; Lady Avebury, 35; Lady Bristol, 35 ; Lavinia, 30; Lady Sophie, 35; Lady St. Oswald, 35; Lauzan, 35 ; Liddington's Favourite, 3o; Little Phil, 30 ; Lord Napier, 35 ; Mazarin, 35 ; Merry Duchess, 35 ; Mohican, 35 ; Miss Lee, 30; Mrs. A. R. Brown, 30 ; Mrs. Beswick, 30; Mrs. Bowen, 30 ; Mrs. Durrant, 35 ; Mrs. Fox-Pitt, 35 ; Mrs. Gorton, 30 ; Mrs. Lovatt, 30 ; Mrs. Openshaw, 30 ; Mrs. Walter Heriot, 35; Mrs. Rudd, 30 ; Mrs. Tremayne, 35 ; Mrs. William Barron, 30; Muriel, 30; Onda, 35 ; Othello, 35 ; origin of, $3 \mathrm{I}$;
Pamela, 35 ; Rabelais, 35 ; St. Just, 35 ; Somerhill, 30 ; Thomas William, 30 ; W. H. Johnson, 30 ; Pilgrim, 35 ; Pride of Leyton, 30; Professor, 35 ; the white and yellow ground, 3I ; Verlina, 30 ; Violet Douglas, 30 ; Voltaire, 35; Wanderer, 35 ; Xerxes, 36 ; white ground, $3 \mathrm{I}$; introduction of the, 34

Picotees, Mr. Martin Smith's, I2; show, 33 ; "spot" or " rust" on, 36 ; varieties of, 33 ; white ground, selection of, 30

Pink, Albino, ro5; Alpine, the, I16, I28; growing, the, I27; Amur, the, II 8 ; Ascot, IOI ; general treatment of, 97 ; Glacier, the, I2 I, I28; Indian, the, $7 \mathrm{I}$; introduction of the, 7 ; Mrs. Welsh, I05; perpetual, Ethel, I00 ; Florence, I00 ; Mrs. Monland, IOO ; propagation of, 97 ; Samuel Barlow, I03; Society, Natural, the, 96 ; sowing seed of the, 96 ; the, 94 ; Blue, the, I 39 ; Cheddar, the, II 7 ; Chinese, the, II8; Clove, the, II7; Deptford, the, II3; Her Majesty, I05; Japanese, the, I13. Laced : Amy, I03; Boiard, I03; Brackleen, IO3 ; Capo di Monti, I03; Chantilly, I03; Clara, I03; Device, I03; Duke of York, IO3; Empress of India, I03; Eurydice, I03; Excellent, I03; Godfrey, I03 ; Harry Hooper, 
IO3; Jeannette, IO3; John Ball, I03, I04; Lady Stoverdale, I04; Lupra, Io3; Maggie, I03 ; Minerva, I03; Modesty, IO3, IO4; Mrs. Darke, IO3, I04; Mrs. Lakin, I03; Mrs. Pomeroy, I03; Mrs. Welsh, I03; Morna, I03; Rainbow, I03; Reliance, I03; The Rector, I03; Retiro, I03; Mrs. Waites, I03; Old Chelsea, ro3; Pheasant's Eye, ro3; Wedgwood, I03; Zurich, I03. Maiden, the, I20; Marion, 100 ; Mrs. Sinkins, I05; the old fringed white, I05; Rock, the, 123; Mule, the, 99; the, 5 ; early names of, 5 ; the, and Thomas Hogg, 95; the old black and white, ror ; Snowflake, I05; wild, the, 126 ; Wood, the, 124

Pinks, European, Nyman and the, IIo; florists', Ior ; garden, choosing, I00; garden hybrid, I Io ; laced, selection of, I03; Mule a hybrid, I05; perpetual, 99

Pinks, the, of the Alps, 130 ; the white and other, 105; wild, the, 109

Pinkes, 7

"Pinkes" and Gerarde, 7

Pliny, 6

RABBITS and Hares and the Carnation, 93

Red Spider and the Carnation, 90

Richard Bradley's “New Improvements of Planting and
Gardening, both Philosophical and Practical," 4 ; "Ten Practical Discourses concerning Earth and Water, Fire and Air, as they relate to the Growth of Plants," 4

Ruellius and the Carnation, 3

Rust, 9r

Saunders, G. S., Mr., 87

Seed, Carnations from, I 8

Smith, Martin, Mr., 40

Spot on the Carnation, 92

Sulphide of potassium, preparation of, 92

Sweet William and Parkinson, 5

Simonite, B., Mr., 34

Smith, Martin, Mr., 34 ; Richard, Mr., 34

Society, National Carnation, 84 ; Pink, the National, 96 ; Royal Horticultural, 84

Sparrows and the Carnation, 93

Spittle-fly and the Carnation, 84

Standish, Mr., 34

Stock Gilloflowers, 2

Summer work amongst the Carnations, 22

"Superba," 7

Sweet William, the, 4, 5; the, and forms, 114 ; introduction of, 5 ; and Tournefort, 5

Sweete Iohns, 5

TETRANYCHUS TELLARIUS, 90 'Thrips and the Carnation, 90 Thyne, Paton, Messrs., I07 
Tournefort and the Sweet Vetonica, 2 ; altilis, 2 William, 5

Vetonicæ secundum genus, 5

Tubs and window boxes, Carnations in, 69

Tulip, the Triumph of Europe, 5 Turner, Charles, Mr., the late, 39, 94

Turner's "Names of Herbes," 7

Twitchett, James, 32

Tylenchius devastatrix, 87

UREDO DIANTHI, 92

Violettes herbues, 7

WARD, C. W., Mr., 92

Widnal, Samuel, 32

Williams, F. N., Dr., I09

Window boxes and tubs, Carnations in, 69

Wireworm and the Carnation, 88

Wylder negleblorum, 7 





\section{DAY USE \\ RETURN TO DESK FROM WHICH BORROWED \\ LOAN DEPT.}

This book is due on the last date stamped below, or on the date to which renewed.

Renewed books are subject to immediate recall.

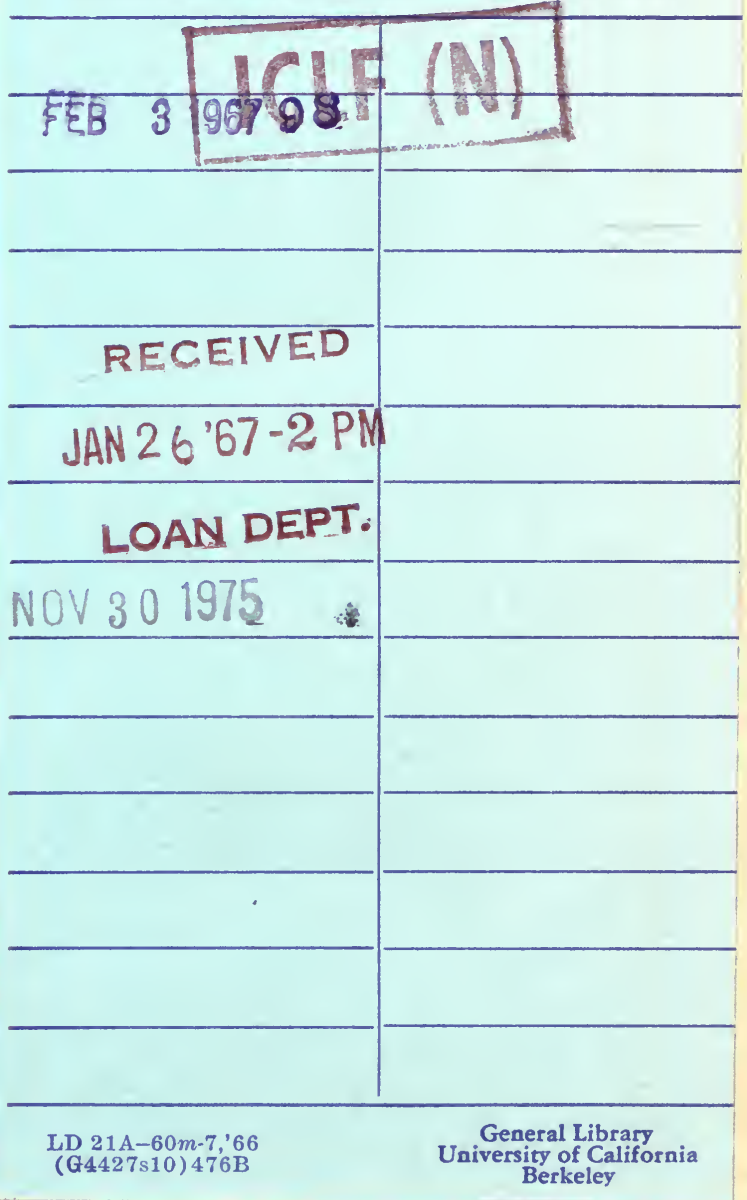


YC 63745 
